\title{
Antóceros e Hepáticas dos Estados de Alagoas, Bahia, Pernambuco e Sergipe, Brasil, depositados no Herbário SP
}

\author{
Olga Yano ${ }^{1}$, Denilson Fernandes Peralta ${ }^{1,2}$ e Juçara Bordin ${ }^{1}$
}

Recebido: 18.02.2010; aceito: 8.09.2011

\begin{abstract}
Hornworts and Liverworts of Alagoas, Bahia, Pernambuco and Sergipe States, Brazil, deposited in SP herbarium). During the study of the hornworts and liverworts deposited in the Maria Eneyda P. Kauffmann Fidalgo herbarium (SP), 197 taxa of Anthocerotophyta and Marchantiophyta were identified for the Brazilian States of Alagoas, Bahia, Pernambuco and Sergipe. The taxa are distributed into 61 genera and 23 families. Out of these, 69 are new records for at least one of the States. Plagiochila fordiana Steph. is a new record for Brazil.

Key words: Anthocerotophyta, Marchantiophyta, new records
\end{abstract}

RESUMO - (Antóceros e hepáticas dos Estados de Alagoas, Bahia, Pernambuco e Sergipe, Brasil, depositados no herbário SP). Durante o estudo de antóceros e hepáticas depositados no herbário Maria Eneyda P. Kauffmann Fidalgo (SP) foram identificados 197 táxons de Anthocerotophyta e Marchantiophyta para os Estados de Alagoas, Bahia, Pernambuco e Sergipe. Os táxons estão distribuídos em 61 gêneros e 23 famílias. Destes, 69 táxons são novas citações para pelo menos um dos Estados. Plagiochila fordiana Steph. é uma nova referência para o Brasil.

Palavras-chave: Anthocerotophyta, Marchantiophyta, novas ocorrências

\section{Introdução}

Os Estados de Alagoas, Bahia, Pernambuco e Sergipe localizam-se na Região Nordeste do Brasil, ocupando uma área de 712.682,29 $\mathrm{km}^{2}$. A região Nordeste foi historicamente pouco coletada e estudada em relação às briófitas.

Desde a década de 1980, houve um grande avanço nos estudos de hepáticas nos Estados da Bahia e Pernambuco. Os principais trabalhos foram: Pôrto \& Yano (1985), Yano \& Andrade-Lima (1987), Yano et al. (1987), Pôrto \& Grolle (1987), Pôrto (1990), Yano \& Costa (1992), Pôrto et al. (1993, 1994, 1999, 2000), Almeida Sá \& Pôrto (1996), Germano \& Pôrto (1996, 1998, 2004, 2005), Pôrto \& Bezerra (1996), Bastos et al. (1998a, b, 2000), Vilas Bôas-Bastos \& Bastos (1998), Gradstein \& Costa (2003), Bastos (2004), Bastos \& Gradstein (2006), Bastos \& Yano (2002, 2003, 2006a, b, 2008, 2009), Bastos \& Vilas-Bôas Bastos (2000a, b, c), Valente \& Pôrto (2006a, b, c), Vilas Bôas-Bastos et al. (2006), Yano (1994, 2004),
Yano \& Peralta (2006a, b), Alvarenga et al. (2008) e Costa (2008).

A vegetação predominante nestes Estados é a Caatinga no interior e Floresta Atlântica próximo ao litoral (Fiaschi \& Pirani 2010), apresentando áreas de transição entre estas vegetações que formam manchas de cerrado na Bahia.

O Herbário Científico do Estado "Maria Eneyda P. Kauffmann Fidalgo" (SP) é o maior herbário em número de amostras de briófitas do Brasil (Costa \& Pôrto 2003), possui amostras de todos os Estados e biomas brasileiros. O herbário atualmente conta com cerca de 85 mil exsicatas, sendo que Costa \& Pôrto (2003) listam o segundo maior herbário o Museu Goeldi (MG) com 14 mil exsicatas.

O objetivo principal do trabalho foi identificar e listar todas as amostras dos Estados acima referidos que estão depositados no herbário SP e não foram citadas em trabalhos anteriores, contribuindo assim para o conhecimento da distribuição geográfica de cada espécie nos Estados e no Brasil.

1. Instituto de Botânica, Caixa Postal 68041, 04045-972 São Paulo, SP, Brasil

2. Autor para correspondência: denilsonfp@yahoo.com.br 


\section{Material e métodos}

Foram utilizadas as amostras de diversos coletores, provenientes dos Estados de Alagoas, Bahia, Pernambuco e Sergipe que estão depositadas no Herbário Científico do Estado "Maria Eneyda P. Kauffmann Fidalgo", do Instituto de Botânica (SP), coletados por D.M. Vital, O. Yano, A. Schäfer-Verwimp, D. Andrade-Lima, K.C. Pôrto, W.R. Buck e M.R. Pietrobom-Silva.

Foram encontradas depositadas no herbário SP, 852 exsicatas de antóceros e hepáticas provenientes dos Estados acima citados. Foram excluídas as amostras depositadas no Herbário SP que já foram citadas em trabalhos anteriormente publicados: Bastos (2004), Costa (1999, 2008), Pôrto et al. (1999), Yano (1994), Yano \& Peralta (2006a, b), Yano et al. (1987), Jovet-Ast (1991) e Vital et al. (1991).

As espécies foram identificadas utilizando-se os trabalhos citados como referência para a ilustração, abaixo do cabeçalho taxonômico. O sistema de classificação adotado foi Crandall-Stotler \& Stotler (2000) para Marchantiophyta e Stotler \& Crandall-Stotler (2005) para Anthocerotophyta.

Os táxons estão listados em ordem alfabética de família, gênero e espécies, dentro das divisões, sendo apresentada para cada um a distribuição geográfica no Brasil, baseada nos catálogos de Yano (1984, $1989,1995,2006,2008,2010)$ e trabalhos publicados recentemente, como de: Bordin \& Yano (2009), Ilkiu-Borges et al. (2009a, b), Imbassahy et al. (2009), Oliveira \& Bastos (2009), Silva \& Pôrto (2009), Tonini et al. (2005) e Yano et al. (2009a, b).

\section{Resultados e Discussão}

Foram identificados 197 táxons de Anthocerotophyta e Marchantiophyta distribuídos em 61 gêneros e 23 famílias. Os asteriscos (*) indicam ocorrência nova para pelo menos um dos Estados, totalizando 69 referências novas de antóceros e hepáticas, o que corresponde a cerca de $35 \%$ do total de espécies identificadas, sendo 54 para Pernambuco (16\% de contribuição), dez para Bahia ( $2 \%$ de contribuição), nove para Alagoas (12\% de contribuição) e dois para Sergipe (4\% de contribuição). Quando comparados aos 609 táxons ocorrentes na região Nordeste brasileira citados por Forzza et al. (2010), são tratados $32 \%$ ou seja um terço de todas as espécies conhecidas para esta região foram identificadas para este trabalho.

\section{Anthocerotophyta}

\section{ANTHOCEROTACEAE}

* Anthoceros punctatus L., Sp. Pl. 2: 1139. 1753. Ilustração: Hässel de Menéndez (1962), Hell (1969) e Gradstein \& Costa (2003).

Material examinado: BRASIL. BAHIA: Cruz das Almas, mata ciliar, 24-VI-2004, D.F. Peralta et al. 2459 (SP368940). Pernambuco: Recife, Mata de Dois Irmãos, perto da sede do reservatório, 3-VIII-1998, O. Yano et al. 25417 (SP322272); idem, Campus da Universidade Federal de Pernambuco, junto às sementerias, 10-IX-1984, O. Yano \& K.C. Pôrto 9067 (SP191690); idem, em frente o prédio da Biblioteca, entre as gramíneas na sombra da mangueira, 7-VIII-1986, O. Yano \& M.G.V. Marinho 10345 (SP207019); idem, 7-VIII-1986, O. Yano \& M.G.V. Marinho 10346 (SP207020); idem, 3-VIII-1994, O. Yano \& K.C. Pôrto 23058 (SP281480); Taquaritinga do Norte, Morro Cafundó, perto das pedras no morro da microonda, 24-VIII-1980, O. Yano \& D. Andrade-Lima 2609 (SP191171); São Lourenço da Mata perto do Engenho São Bento, Mata de Tapacurá, plantação de cana, 6-VIII-1986, O. Yano et al. 10313 (SP206988); Bonito, Cachoeira do Oriente, ca. $19 \mathrm{~km}$ da cidade, ca. $500 \mathrm{~m}$ alt., perto da cachoeira, 6-VIII-1998, O. Yano et al. 25496 (SP322342); Brejo da Madre de Deus, Reserva Bituri Grande, ca. $950 \mathrm{~m}$ alt., perto da reserva, 10-VIII-1998, O. Yano et al. 25503 (SP322347).

Distribuição no Brasil: AM, BA, CE, ES, RJ, RS, SC, SP.

Ocorre em solo ou húmus, associada a Notothylas orbicularis (Schwein.) Sull.

\section{NOTOTHYLADACEAE}

Notothylas breutelii (Gottsche) Gottsche, Bot. Zeitung (Berlin)15:21.1858 $\equiv$ Anthoceros breutelii Gottsche, Syn. Hepat.: 583. 1846

Ilustração: Schuster (1992) e Gradstein \&Costa (2003).

Material examinado: BRASIL. Pernambuco: Salgueiro, $8^{\circ} 04^{\prime} \mathrm{S}, 39^{\circ} 10^{\prime} \mathrm{W}$, a sparse caatinga vegetation, 25-V-1978, D.M. Vital 8192 (SP133072).

Distribuição no Brasil: AM, BA, FN, PE. 
Ocorre em solo úmido, associada a Archidium microthecium Dixon \& P. de la Varde. A espécie tem esporos marrons ou pretos, com superfície distal tuberculada e os pseudo-elatérios pequenos e com reforço na parede.

* Notothylas orbicularis (Schwein.) Sull., Musci Allegh.: 69. 1846 三 Targionia orbicularis Schwein., Spec. Fl. Amer. Crypt.: 23. 1821.

Ilustração: Schuster (1992) e Yano \& Peralta (2008).

Material examinado: BRASIL. BAHIA: Ilhéus, Centro de Pesquisas do Cacau, km 22 on BR-415, between Ilhéus and Itabuna, 1450'S, 39 $13^{\circ} \mathrm{W}$, 15-VII-1991, D.M. Vital \& W.R. Buck 20168 (NY, SP353867); Cruz das Almas, mata ciliar, 24-VI-2004, D.F. Peralta et al. 2459 p.p. (SP368940); idem, 24-VI-2004, D.F. Peralta et al. 2466 (SP368947).

Distribuição no Brasil: AM, CE, FN, PE.

Ocorre em solo, associada a Anthoceros punctatus L. A espécie tem esporos amarelados e possuem pseudo-elatérios semelhantes a esporos com reforço na parede.

* Notothylas vitalii Udar \& Singh, Misc. Bryol. Lichénol. 8(9): 173. 1980.

Ilustração: Udar \& Singh (1980) e Gradstein \& Costa (2003).

Material examinado: BRASIL. BAHIA: Feira de Santana, perto da praça Matriz, quintal do Museu, 23-X-1990, O. Yano et al. 15058 (SP231178); idem, Campus da Universidade Estadual de Feira de Santana, 29-VI-2009, D.F. Peralta \& L.T.P. Silva 8524 (SP413957); Ilhéus, Centro de Pesquisas do Cacau, $\mathrm{km} 22$ on BR-415 between Ilhéus and Itabuna, $50 \mathrm{~m}$ alt., $14^{\circ} 50^{\prime}$ 'S, $39^{\circ} 13^{\prime} \mathrm{W}$, Parque Zoobotânico, 15-VII-1991, D.M. Vital \& W.R. Buck 20167 (NY, SP353866). Pernambuco: Recife, campus da Universidade Federal de Pernambuco, 4-IX-1984, O. Yano \& K.C. Pôrto 9036 (SP191660); idem, 16-V-1997, O. Yano \& K.C. Pôrto 24808 (SP284954); idem, 5-VIII-1998, O. Yano et al. 25422 (SP322277); idem, Mata de Dois Irmãos perto da sede do reservatório, 3-VIII-1998, O. Yano et al. 25418 (SP322273); Cabo, Estação Gurjau, 14-IX-1984, O. Yano \& K.C. Pôrto 9145 (SP191767); idem, 14-IX-1984, O. Yano \& K.C. Pôrto 9193 (SP191815).

Distribuição no Brasil: AC, FN, GO, MA, MS, PE, SP.
Ocorre em solo e barranco, associada a Riccia membranacea Gottsche e $R$. subdepilata Jovet-Ast. A espécie tem esporos amarelado-translúcidos e não apresenta pseudo-elatérios.

Phaeoceros laevis (L.) Prosk., Bull. Torrey Bot. Club 78(4): 346. 1951 Anthoceros laevis L., Sp. Pl. 2: 1139. 1753.

Ilustração: Müller (1954), Hässel de Menéndez (1962), Gradstein \& Costa (2003) e Yano \& Peralta (2008).

Material examinado: BRASIL. Pernambuco: Cabo, Engenho Pantorra, estrada perto da plantação de cana de açúcar, 23-VIII-1980, O. Yano \& D. Andrade-Lima 2559 (SP191133); Altinho, Fazenda Taboca, entre a plantação de banana, base do morro, 29-VIII-1980, O. Yano \& D. Andrade-Lima 2801 (SP191329); idem, entre a plantação de banana, 29-VIII-1980, O. Yano \& D. Andrade-Lima 2803 (SP191331); Triunfo, margem do riacho perto da estrada para o Engenho, 7-IX-1980, O. Yano \& D. Andrade-Lima 2993 (SP191492); idem, Cachoeira do Pinga, 7-IX-1980, O. Yano \& D. Andrade-Lima 2997 (SP191495); Cabo, Estação de Gurjau, próx. plantação de Zea sp., 14-IX-1984, O. Yano \& K.C. Pôrto 9194 (SP191816); idem, estrada para estação, 14-IX-1984, O. Yano \& K.C. Pôrto 9146 (SP191768); idem, 14-IX-1984, O. Yano \& K.C. Pôrto 9147 (SP1919769); Caruaru, Brejo dos Cavalos, \pm 780 m alt., sopé do morro, 11-VIII-1998, O. Yano et al. 25533 (SP322376).

Distribuição no Brasil: AM, BA, DF, ES, GO, MG, MS, PE, RJ, RS, SC, SP, TO.

Ocorre em solo e rocha, associada a Philonotis hastata (Duby) Wijk \& Margad.

\section{Marchantiophyta}

\section{ANEURACEAE}

Riccardia chamedryfolia (With.) Grolle, Trans. Brit. Bryol. Soc. 5: $772.1969 \equiv$ Jungermannia chamedryfolia With., Bot. Arr. Veg. Gr. Brit. 2: 699. 1776.

Ilustração: Hell (1969, como R. sinuata), Gradstein $\&$ Costa (2003) e Yano \& Peralta (2008).

Material examinado: BRASIL. BAHIA: Uruçuca, $6,2 \mathrm{~km} \mathrm{~N}$ of town of Serra Grande, ca. $40 \mathrm{~km} \mathrm{~N}$ of Ilhéus along coast, $14^{\circ} 26^{\prime} \mathrm{S}, 3^{\circ} 9^{\circ} 03^{\prime} \mathrm{W}$, ca. 200 m, wet tropical forest, 17-VII-1991, D.M. Vital \& 
W.R. Buck 20318 (NY, SP353949); Ilhéus, 5 km S of Ilhéus on road to Olivença, $14^{\circ} 52^{\prime} \mathrm{S}, 39^{\circ} 02^{\prime} \mathrm{W}$, restinga, 14-VII-1991, D.M. Vital \& W.R. Buck 20090 (NY, SP353832); idem, Centro de Pesquisas do Cacau, km 22 da rod. Ilhéus-Itabuna, 19-XII-1991, A.C. Messias \& S.L. Oliveira 198 (CEPEC51606, SP280855).

Distribuição no Brasil: AC, AM, BA, DF, ES, GO, MG, MT, RJ, SC, SP.

Ocorre sobre tronco em decomposição.

* Riccardia digitiloba (Spruce) Pagán, Bryologist 42(1): 6. 1939 三 Aneura digitiloba Spruce, Hedwigia 27: 276. 1888.

Ilustração: Hell (1969), Gradstein \& Costa (2003) e Yano \& Peralta (2008).

Material examinado: BRASIL. BAHIA: Ilhéus, $5 \mathrm{~km} \mathrm{~S}$ of Ilhéus on road to Olivença, $14^{\circ} 52^{\prime} \mathrm{S}, 39^{\circ} 02^{\prime} \mathrm{W}$, restinga, 14-VII-1991, D.M. Vital \& W.R. Buck 20088 (NY, SP353830). Pernambuco: Caruaru, Fazenda Caruaru, Brejo dos Cavalos, 29-II-1980, O. Yano \& D. Andrade-Lima 2764 (SP191305); Rio Formoso, Estação Experimental de Saltinho, 11-IX-1984, O. Yano et al. 9119 (SP191742); Quipapá, Engenho Brejinho, km 31 da BR-423, perto da cachoeira, 2-IX-1980, O. Yano \& J.Z. Brito 2878 (SP191394). SergiPe: Itabaiana, Serra de Itabaiana, 13-IX-1981, D. Andrade-Lima 81-6823 (SP174014).

Distribuição no Brasil: AC, BA, CE, DF, ES, MG, MS, MT, PE, RJ, SC e SP.

Ocorre em solo e tronco em decomposição.

Riccardia regnellii (Ångstr.) K.G. Hell, Bol. Bot. Univ. São Paulo 335, Bot. 25: $110.1969 \equiv$ Pseudoneura regnellii Ångstr., Öfvers. Kongl. Vetensk.-Akad. Förh. 33(7): 89. 1876.

Ilustração: Hell (1969), Yano et al. (2003) e Gradstein $\&$ Costa (2003).

Material examinado: BRASIL. Pernambuco: Rio Formoso, Córrego da Juçara, próximo do córrego, 11-IX-1984, O. Yano et al. 9074 (SP191697); idem, 11-IX-1984, O. Yano et al. 9085 (SP191708); Gurjaú, Mata do Jafé, 18-IX-1995, P.S.A. Sá \& S.R. Germano s.n. (UFP11324, SP284153).

Distribuição no Brasil: ES, MG, MT, PE, RJ, RS, $\mathrm{SC}$ e SP.

Ocorre em rocha e tronco em decomposição.

\section{CALYPOGEIACEAE}

* Calypogeia laxa Gottsche \& Lindenb. in Gottsche et al., Syn Hepat.: 713: 1847.

Ilustração: Bischler (1962), Fulford (1968) e Gradstein \& Costa (2003).

Material examinado: BRASIL. Alagoas: Quebrangulo, Fazenda Pedra Talhada, 28-X-1980, D. Andrade-Lima 80-6646 (SP191531). PeRnAMBUCO: Rio Formoso, Córrego da Juçara, 11-IX-1984, O. Yano et al. 9084 (SP191707); idem, 11-IX-1984, O. Yano et al. 9086 (SP191709); idem, Estação Experimental de Saltinho, próx. lagoa, 11-IX-1984, O. Yano et al. 9118 (SP191741); Cabo, Estação de Gurjaú, junto da lagoa, 14-IX-1984, O. Yano \& K.C. Pôrto 9154 (SP191776).

Distribuição no Brasil: CE, DF, ES, MG, PE, RJ, SC e SP.

Ocorre em solo, associada a Fissidens hornschuchii Mont. e F. pellucidus Hornsch.

Calypogeia miquelii Mont. in Gottsche et al., Syn. Hepat.: 200. 1845.

Ilustração: Bischler (1962) e Gradstein et al. (2001).

Material examinado: BRASIL. Pernambuco: Bonito, estrada para Cachoeira do Oriente, ca. $700 \mathrm{~m}$ alt., 6-VIII-1998, O. Yano et al. 25474 (SP322326); Brejo da Madre de Deus, Reserva Bituri Grande, ca. $950 \mathrm{~m}$ alt., 10-VIII-1998, O. Yano et al. 25514 (SP322358).

Distribuição no Brasil: AM, BA, CE, DF, MG, PA, PE e RJ.

Ocorre em solo.

\section{CEPHALOZIACEAE}

Odontoschisma falcifolium Steph., Bull. Herb. Boissier. ser. 2, 8: 585. 1908.

Ilustração: Fulford (1968) e Griffin III (1979).

Material examinado: BRASIL. BAHIA: Serra da Água de Rega, ca. $23 \mathrm{~km} \mathrm{~N}$ of Seabra, road to Água de Rega, cerrado, ca. 100 m alt., 24-II-1971, H.S. Irwin et al. 30951 (NY, SP133700); Lençóis, vicinity of Lençóis, trail to Barro Branco, ca. 5 $\mathrm{km}$ on N of Lençóis, 13-VI-1981, B.M. Boom \& S.A. Mori 1188 (SP379193).

Distribuição no Brasil: AM, BA, ES, GO, MG, MT, RJ e SP.

Ocorre em solo. 


\section{CEPHALOZIELLACEAE}

* Cephaloziella granatensis (J.B. Jack) Fulford, Mem. New York Bot. Gard. 11(4): 411. $1976 \equiv$ Cephalozia granatensis J.B. Jack in Stephani, Sp. Hepat. 3: 330. 1908.

Ilustração: Fulford (1976), Gradstein et al. (2001) e Gradstein \& Costa (2003).

Material examinado: BRASIL. Pernambuco: Taquaritinga do Norte, mata ao lado da microonda, 24-VIII-1980, O. Yano \& D. Andrade-Lima 2642 (SP191200); Formoso, estação Experimental de Saltinho, junto da lagoa, 11-IX-1984, O. Yano et al. 9134 (SP191756); Cabo, Estação de Gurjaú, estrada para a estação, 14-IX-1984, O. Yano \& K.C. Pôrto 9151 (SP191773).

Distribuição no Brasil: MG e RJ.

Ocorre em solo e sobre tronco em decomposição. A espécie tem o filídio mais ou menos transversalmente disposto no caulídio; o filídio tem o ápice bífido; os segmentos são agudos e as células conspicuamente alongadas, provavelmente é uma espécie pouco amostrada e deve ocorrer em outras áreas de Floresta Atlântica.

\section{CORSINIACEAE}

Cronisia fimbriata (Nees) Whittemore \& Bischl., Cryptog. Bryol. Lichénol. 22: 170. $2001 \equiv$ Riccia fimbriata Nees in Martius, F1. Bras. Enum. Pl. 1(1): 301. 1833.

Ilustração: Gradstein \& Costa (2003) e Bischler-Causse et al. (2005).

Material examinado: BRASIL. BAHIA: Brumado, $\mathrm{km} 121$ on BA-262 between Vitória da Conquista and Brumado, $15 \mathrm{~km}$ SE of Brumado, $445 \mathrm{~m}, 1^{\circ} 16^{\prime} \mathrm{S}$, $41^{\circ} 15^{\prime} \mathrm{W}$, scruby caatinga vegetation, 18-VII-1991, D.M. Vital \& W.R. Buck 20366 (NY, SP353970). Pernambuco: Salgueiros, along the BR-116, km 596, 24-I-1972, D.M. Vital 1980 (SP87726).

Distribuição no Brasil: BA, CE, MG, MS, PB, PE e PI.

Ocorre em solo e rocha.

Cronisia weddellii (Mont.) Grolle, J. Bryol. 9: 532. $1977 \equiv$ Boschia weddellii Mont., Ann. Sci. Nat., Bot. sér. 4, 5: 352. 1856.

Ilustração: Gradstein et al. (2001), Bischler-Causse et al. (2005) e Yano \& Peralta (2008).
Material examinado: BRASIL. AlagoAs: Junqueiro, along road BR-101, km 145, 18-I-1972, D.M. Vital 1963 (SP87717). BAHIA: ca. 35 km Sw de Maracás, clareira na caatinga, 26-I-1980, D.M. Vital 8719 (SP133376). Pernambuco: Salgueiro, $8^{\circ} 04^{\prime} \mathrm{S}, 39^{\circ} 10^{\prime} \mathrm{W}$, sparse caatinga vegetation, 25-V-1978, D.M. Vital 8188 (SP133070).

Distribuição no Brasil: AL, BA, CE, ES, GO, MT, PB, PE e PI.

Ocorre em solo úmido.

\section{CYATHODIACEAE}

Cyathodium cavernarum Kuntze, Nov. Stirp. Pug. 6: 18.1834.

Ilustração: Yano \& Costa (1992, como C. africanum), Gradstein et al. (2001) e Bischler-Causse et al. (2005).

Material examinado: BRASIL. Pernambuco: Triunfo, Cachoeira do Pinga, sobre parede úmida da cachoeira, 7-IX-1980, O. Yano \& D. Andrade-Lima 2994 (SP191493).

Distribuição no Brasil: $\mathrm{BA}, \mathrm{CE}, \mathrm{GO}, \mathrm{MG}, \mathrm{MS}$, MT e PE.

Ocorre em solo úmido ou paredões perto de cachoeira.

\section{FOSSOMBRONIACEAE}

Fossombronia porphyrorhiza (Nees) Prosk., Bryologist 58(3): 197. 1955 三 Jungermannia porphyrorhiza Nees in Martius, Fl. Bras. Enum. Pl. 1(1): 343. 1833.

Ilustração: Gradstein \& Costa (2003) e Yano \& Peralta (2008).

Material examinado: BRASIL. BAHIA: Cruz das Almas, mata ciliar, 24-VI-2004, D.F. Peralta et al. 2464 (SP368945). Pernambuco: Rio Formoso, Estação Experimental de Saltinho, próx. lagoa, 11-IX-1984, O. Yano et al. 9121 (SP191744); idem, 11-IX-1984, O. Yano et al. 9122 (SP191745); Cabo, Estação de Gurjaú, estrada para estação, 14-IX-1984, O. Yano \& K.C. Pôrto 9148 (SP191770).

Distribuição no Brasil: BA, CE, DF, ES, GO, MG, MS, MT, PE, RJ, SP e TO.

Ocorre em solo. 


\section{GEOCALYCACEAE}

Lophocolea bidentata (L.) Dumort., Recueil Observ. Jungerm.: $17.1835 \equiv$ Jungermannia bidentata L., Sp. Pl. ed. 1, 2: 1132. 1753.

Ilustração: Fulford (1976, como L. coadunata) e Gradstein \& Costa (2003).

Material examinado: BRASIL. Pernambuco: Caruaru, Brejo dos Cavalos, ca. $940 \mathrm{~m}$ alt., interior da mata, 3-XII-2001, M.R. Pietrobom et al. 5246 p.p. (SP403043); Quipapá, Engenho Brejinho, km 31 da BR-423, perto da cachoeira, 2-IX-1980, O. Yano \& J.Z. Brito 2880 (SP191396); São Lourenço da Mata, Tapacurá, 4-II-1988, O. Yano \& G. Mariz 11264 (SP222208); idem, Engenho São Bento, Estação Ecológica de Tapacurá, Mata Toró-Cuieira, 26-VIII-1980, O. Yano \& D. Andrade-Lima 2674 (SP191228).

Distribuição no Brasil: AC, AM, CE, DF, ES, GO, MG, MS, MT, PE, PR, RJ, RR, RS, SC e SP.

Ocorre em rocha e tronco em decomposição, associada a Dumortiera hirsuta (Sw.) Nees e Lopholejeunea nigricans (Lindenb.) Schiffn.

Lophocolea martiana Nees in Gottsche et al., Syn. Hepat.: 152. 1845.

Ilustração: Fulford (1976), Lemos-Michel (2001) e Yano \& Peralta (2008).

Material examinado: BRASIL. Pernambuco: Altinho, Fazenda Taboca, 29-VIII-1980, O. Yano \& D. Andrade-Lima 2798 (SP191326).

Distribuição no Brasil: AL, AM, AP, BA, CE, ES, GO, MG, MT, PA, PE, PR, RJ, RS, SC, SE e SP.

Ocorre sobre tronco em decomposição.

* Lophocolea platensis C. Massal., Atti Accad. Sci. Med. Nat. Ferrara 80(3-4): 12. 1906.

Figura 1

Ilustração adicional: Gradstein \& Costa (2003).

Material examinado: BRASIL. Pernambuco: Inajá, Serra Negra, mata da serra, 6-IX-1980, O. Yano \& D. Andrade-Lima 2933 (SP191442).

Distribuição no Brasil: BA, ES, GO, MG, MT, RS, SC e SP.

Ocorre sobre tronco em decomposição.

\section{FRULLANIACEAE}

* Frullania arecae (Spreng.) Spruce, Trans. \& Proc. Bot. Soc. Edinburgh 15: 20. 1884 (1885)三 Jungermannia arecae Spreng., Neue Entdek. Pflanzenk. 2: 99. 1821.

Ilustração: Lemos-Michel (2001), Gradstein \& Costa (2003) e Yano \& Peralta (2008).

Material examinado: BRASIL. Pernambuco: Taquaritinga do Norte, Morro Cafundó, sombra da Lauraceae, 24-VIII-1980, O. Yano \& D. Andrade-Lima 2615 (SP191176).

Distribuição no Brasil: AC, BA, DF, ES, GO, MG, MT, PR, RJ, RR, RS, SE e SP.

Ocorre em rocha, associada a Groutiella tomentosa (Hornsch.) Wijk \& Margad.

Frullania atrata (Sw.) Dumort., Recueil Observ. Jungerm.: 13. 1835 三 Jungermannia atrata Sw., Prodr. (Swartz): 144. 1788.

Ilustração: Clark \& Svihla (1945) e Gradstein \& Costa (2003).
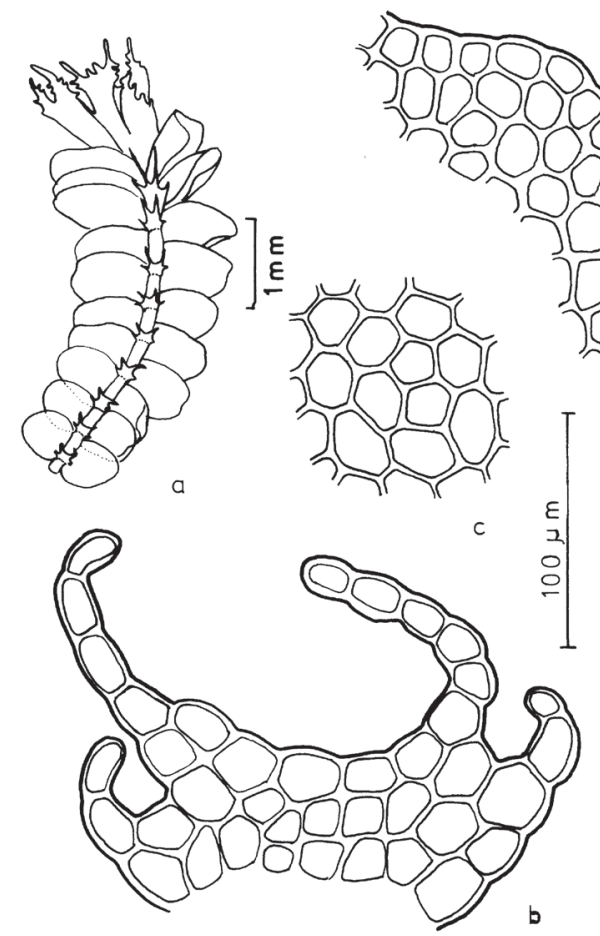

Figura 1. Lophocolea platensis. a. Aspecto geral do gametófito. b. Anfigastro. c. Células da região mediana do filídio. d. Células da margem do filídio.

Figure 1. Lophocolea platensis. a. General aspect of the gametophyte. b. Underleaf. c. leaf cells. d. Marginal cells of the leaf. 
Material examinado: BRASIL. BAHIA: Serra do Tombador, summit of Morro do Chapéu, ca. $7 \mathrm{~km} \mathrm{~S}$ of town of Morro do Chapéu, elev. ca. 1,150 m, 16-III-1971, H.S. Irwin et al. 32321 (NY, SP133687). PERnAMBUCO: Caruaru, Brejo dos Cavalos, folhedo, 5-III-1998 K.C. Pôrto s.n. (SP322631).

Distribuição no Brasil: AM, BA, MG, PA, PE, PR, RJ, RS, SC e SP.

Ocorre sobre tronco e ramos de árvore.

Frullania beyrichiana (Lehm. \& Lindenb.) Lehm. \& Lindenb. in Gottsche et al., Syn. Hepat.: 460. $1845 \equiv$ Jungermannia beyrichiana Lehm. \& Lindenb., Nov. Stirp. Pug. 5: 25. 1833.

Ilustração: Lemos-Michel (2001), Gradstein \& Costa (2003) e Yano \& Peralta (2008).

Material examinado: BRASIL. BAHIA: Jacobina, Distrito de Itaitu, Cachoeira do Véu de Noiva, $11^{\circ} 19^{\prime} 58^{\prime}$ 'S, 3040'8'W, $600 \mathrm{~m}$ alt., junto à cachoeira, 4-VIII-2001, F.R. Nonato et al. 940 (HUEFS55685, SP362493).

Distribuição no Brasil: AC, BA, ES, GO, MG, MT, PA, PE, RJ, RS e SP.

\section{Ocorre em rocha.}

Frullania brasiliensis Raddi, Mem. Mat. Fis. Soc. Ital. Sci. Modena 19: 36. 1822.

Ilustração: Stotler (1970), Gradstein \& Costa (2003) e Yano \& Peralta (2008).

Material examinado: BRASIL. BAHIA: Santa Teresinha, Serra da Jibóia, próx. Torre da Embratel, $\pm 500 \mathrm{~m}$ alt., 6-IX-1994, C.W.N. Moura s.n. (SP283933); Lençóis, planalto, IX-1995, A.M. Giulietti s.n. (SP283955); Itabuna, plantações de cacau da CEPLAC, sobre cacaueiro, 14-I-1980, D.M. Vital 685 (SP133358); idem, 14-I-1980, D.M. Vital 8692 (SP133361); idem, 25-I-1980, O. Yano 2311 (SP133491); idem, $50 \mathrm{~m}$ alt., sobre cacaueiro, 24-I-1980, D.M. Vital 8711 (SP133374); Ilhéus, Centro de Pesquisas do Cacau, km 22 on BR-415 between Ilhéus and Itabuna, $14^{\circ} 50^{\prime} \mathrm{S}, 39^{\circ} 13^{\prime} \mathrm{W}$, mata higrófila sul baiana, Parque Zoobotânico, 15-VII-1991, D.M. Vital \& W.R. Buck 20158(NY, SP353857); idem, km 22 da rod. Ilhéus-Itabuna, sobre sobreiro, 17-IX-1991, A.C. Messias \& S.L. Oliveira 141 (CEPEC51622, SP280843); Pico das Almas, Capão da Mata, $1.400 \mathrm{~m}$ alt., 21-II-1987, R.M. Harley et al. 24563 (SPF, K, SP230715). Pernambuco: Timbaúba, Complexo da Serra do Mascarenhas, Usina Cruangi, Engenho Água Azul, área do poço caudaloso, $7^{\circ} 37^{\prime} 7,3^{\prime}$ S, $35^{\circ} 23$ ' 43, '”W, ca. 304-451 m alt., margem da trilha na encosta, 15-XII-2001, M.R. Pietrobom 5462 (SP403059); Bezerros, Serra Negra, Sítio Frexeiras, Morro da Caverna de Serra Negra, 31-VIII-1999, M.R. Pietrobom-Silva et al. 4611 (SP352776).

Distribuição no Brasil: BA, ES, GO, MG, PE, RJ, RS, SC e SP.

Ocorre sobre tronco, associada a Ceratolejeunea cornuta (Lindenb.) Schiffn.

* Frullania breuteliana Gottsche in Gottsche et al., Syn. Hepat.: 461. 1845.

Ilustração: Stotler (1970) e Lemos-Michel (1980).

Material examinado: BRASIL. BAHIA: Morro do

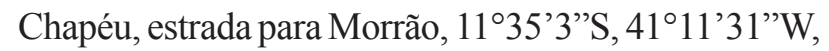
$1.144 \mathrm{~m}$ alt., 5-VIII-2001, F.R. Nonato et al. 985 (HUEFS55730, SP362492).

Distribuição no Brasil: PE, RJ, RS e SP.

Ocorre em rocha.

Frullania caulisequa (Nees) Nees in Gottsche et al., Syn. Hepat.: 448. 1845 三 Jungermannia caulisequa Nees in Martius, F1. Bras. Enum. P1. 1(1): 373. 1833.

Ilustração: Yuzawa (1988), Gradstein \& Costa (2003) e Yano \& Peralta (2008).

Material examinado: BRASIL. AlAGOAS: Boca da Mata, Alto da Serra da Nacéia, 29-X-1980, D. Andrade-Lima 80-664 (SP191541). BAHIA: Ilhéus, $5 \mathrm{~km} \mathrm{~S}$ of Ilhéus on road to Olivença, $14^{\circ} 52^{\prime} \mathrm{S}, 39^{\circ} 02^{\prime} \mathrm{W}$, restinga, 14-VII-1991, D.M. Vital \& W.R. Buck 20085 (NY, SP353827). Pernambuco: Altinho, Fazenda Taboca, 29-VIII-1980, O. Yano \& D. Andrade-Lima 2793 (SP191322); Inajá, Serra Negra, sobre Pisonia sp., 6-IX-1980, O. Yano \& D. Andrade-Lima 2921 (SP191433); Rio Formoso, Estação Experimental de Saltinho, 11-IX-1984, O. Yano et al. 9124 (SP191747); São Lourenço da Mata, Tapacurá, 4-II-1988, O. Yano \& G. Mariz 11250 (SP222194); Recife, Mata de Dois Irmãos, perto da sede do reservatório, 3-VIII-1998, O. Yano et al. 25409 (SP322265); Bonito, Reserva Municipal, ca. $8 \mathrm{~km}$ da cidade, ca. $720 \mathrm{~m}$ alt., 6-VIII-1998, O. Yano et al. 25426 (SP322281).

Distribuição no Brasil: AC, AL, BA, CE, DF, ES, MG, MT, PA, PE, RJ, RR, RS, SC, SE e SP. 
Ocorre sobre tronco, associada a Cheilolejeunea xanthocarpa (Lehm. \& Lindenb.) Malombe, Lejeunea elliottii Spruce, L. maxonii (A. Evans) X.-L. He, Microlejeunea epiphylla Bischler e Omphalanthus filiformes (Sw.) Nees.

* Frullania dilatata (L.) Dumort., Recueil Observ. Jungerm.: 13. 1835 三 Jungermannia dilatata L., Sp. Pl. ed. 1, 2: 1133. 1753.

Ilustração: Smith (1996), Oliveira e Silva \& Yano (2000) e Yano \& Peralta (2008).

Material examinado: BRASIL. Pernambuco: Inajá, Serra Negra, sobre Terminalia sp., transição caatinga-mata, 6-IX-1980, O. Yano \& D. Andrade-Lima 2920 (SP191432).

Distribuição no Brasil: BA, CE, ES, GO, MG, MS, MT, RJ e SP.

Ocorre sobre tronco. A espécie tem o lóbulo do filídio em forma de capacete, estilete na base com quatro células de largura e ápice alongado; anfigastro no ápice bífido e dois dentes menores laterais; perianto com pequenas projeções. É semelhante a $F$. glomerata (Lehm. \& Lindenb.) Nees \& Mont.

Frullania dusenii Steph. in Dusén, Arch. Mus. Nac.

Rio de Janeiro 13: 115. 1905.

Ilustração: Lemos-Michel (1980), Yuzawa (1991) e Gradstein \& Costa (2003).

Material examinado: BRASIL. Pernambuco: Cabo, Estação de Gurjau, mata ao redor da lagoa, 14-IX-1984, O. Yano \& K.C. Pôrto 9164 (SP191786).

Distribuição no Brasil: AL, ES, GO, MG, PE, RJ, RR, RS, SC, SE e SP.

Ocorre sobre tronco.

Frullania ecklonii (Spreng.) Spreng. in Gottsche et al., Syn. Hepat.: 413. 1845 三 Jungermannia ecklonii Spreng., Syst. Veg. 4(2): 324. 1827. Ilustração: Yuzawa et al. (1987) e Yuzawa (1991).

Material examinado: BRASIL. SERgIPE: Itabaiana, along a temporary river Tábora, 29-I-1974, D.M. Vital 2870 (SP88376).

Distribuição no Brasil: AC, DF, MG, RJ, RR, SE e SP.

Ocorre sobre tronco, associada a Frullanoides corticalis (Lehm. \& Lindenb.) van Slageren.
Frullania ericoides (Nees) Mont., Ann. Sci. Nat., Bot. sér. 2, 12: 51. 1839 三 Jungermannia ericoides Nees in Martius, Fl. Bras. Enum. Pl. 1(1): 346. 1833. Ilustração: Yano \& Mello (1999); Lemos-Michel (2001) e Yano \& Peralta (2008).

Materia examinado: BRASIL. BAHIA: Porto Seguro, praça Arraial da Juda, 15-I-1979, M.F. Silva s.n. (SP133242); idem, ca. $4 \mathrm{~km} \mathrm{~N}$ de Jequié, sobre Umbuzeiro, caatinga arbustiva, 26-I-1980, D.M. Vital 8650 (SP133347); Itabuna, plantações de cacau da CEPLAC, sobre cacaueiro, 24-I-1980, D.M. Vital 8684 (SP133357); Salvador, sobre Flamboayan no jardim da Universidade Federal da Bahia, 25-I-1980, R.G. Silva s.n. (SP133501); ca. 25 km SW de Maracás, encosta de um morro, caatinga arbórea, 26-I-1980, D.M. Vital 8726 (SP133378); Iraquara, Fazenda Pratinga, margin of Rio Santo Antonio, ca. $16 \mathrm{~km}$ SSE of Iraquara, on bark, $600 \mathrm{~m}$ alt., 14-VI-1981, B.M. Boom et al. 1200 (SP379196); Santa Bárbara, ca. $45 \mathrm{~km}$ de Feira de Santana na BR-116, 23-X-1990, O. Yano \& J.O. Pereira 15096 (SP231195); idem, caatinga, 23-X-1990, O. Yano \& J.O. Pereira 15105 (SP231201); Ilhéus, Centro de Pesquisas do Cacau, km 22 da rod. Ilhéus-Itabuna, sobre sombreiro, 17-IX-1991, A.C. Messias \& S.L. Oliveira 142 (CEPEC51638, SP280844); Feira de Santana, pátio do Colégio Gastão Guimarães, sobre jaqueira, 23-X-1990, O. Yano et al. 15065 (SP231181); Tremedal, km 72 on BA-262 between Vitória da Conquista and Brumado, 21,5 km WNW

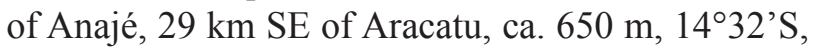
$41^{\circ} 05^{\prime} \mathrm{W}$, caatinga, 19-VII-1991, D.M. Vital \& W.R. Buck 20377 (NY, SP353974). Pernambuco: Triunfo, Engenho Júlio Ramos, 7-IX-1980, O. Yano \& D. Andrade-Lima 2990 (SP191489); São Lourenço da Mata perto do Engenho São Bento, Mata de Tapacurá, 6-VIII-1986, O. Yano et al. 10327 (SP207001); idem, Tapacurá, 4-II-1988, O. Yano \& G. Mariz 11271 (SP222215); Inajá, Serra Negra, sobre Phyllostylon brasiliense na mata da serra, 6-IX-1980, O. Yano \& D. Andrade-Lima 2941 (SP191448); Triunfo, Engenho Júlio Ramos, 7-IX-1980, O. Yano \& D. Andrade-Lima 2986 (SP191485); Fernando de Noronha: Ponta da Sapata, 20-XI-1989, O. Yano \& D.P. Costa 13621 (SP228512); idem, 20-XI-1989, O. Yano \& D.P. Costa 13622 (SP228513); idem, 20-XI-1989, O. Yano \& D.P. Costa 13633 (SP228524); idem, sobre Erythrina na mata, 20-IX-1989, O. Yano \& D.P. Costa 13634 (SP228525); idem, 20-IX-1989, O. Yano \& D.P. Costa 13638 (SP228528); idem, 
20-XI-1989, D.P. Costa \& O. Yano 1041 (SP228612); idem, 20-XI-1989, D.P. Costa \& O. Yano 1042 (SP228613); idem, 20-XI-1989, D.P. Costa \& O. Yano 1044 (SP228615); idem, 20-XI-1989, D.P. Costa \& O. Yano 1043 (SP228614); idem, sobre Tabebuia na mata, 20-XI-1989, D.P. Costa \& O. Yano 1045 (SP228616); idem, Morro do Francês, morro, 21-XI-1989, O. Yano \& D.P. Costa 13644 (SP228531); idem, 21-XI-1989, O. Yano \& D.P. Costa 13645 (SP228532); idem, 21-XI-1989, O. Yano \& D.P. Costa 13646 (SP228533); idem, morro, 21-XI-1989, D.P. Costa \& O. Yano 1057 (SP228628); idem, 21-XI-1989, D.P. Costa \& O. Yano 1058 (SP228629); idem, Morro do Pico, ca. $321 \mathrm{~m}$ alt., chão da mata do pico, 22-XI-1989, O. Yano \& D.P. Costa 13651 (SP228538); idem, 22-XI-1989, O. Yano \& D.P. Costa 13655 (SP228539); idem, base do tronco de Ficus sp. na mata do pico, 22-XI-1989, O. Yano \& D.P. Costa 13661 (SP228542); idem, pico, 25-XI-1989, O. Yano \& D.P. Costa 13668 (SP228543).

Distribuição no Brasil: AC, AM, BA, CE, DF, ES, FN, GO, MG, MS, MT, PB, PE, PR, RJ, RS, SC, SE e SP.

Ocorre sobre tronco, rocha e no solo perto de árvore.

Frullania gibbosa Nees in Montagne, Ann. Sci. Nat., Bot. sér. 2, 14: 333. 1840.

Ilustração: Yuzawa (1984) e Yano \& Peralta (2008).

Material examinado: BRASIL. BAHIA: cidade de Ilhéus, sobre tronco de Cocos nucifera, ao longo da praia do Sul, 22-I-1980, D.M. Vital 8640 (SP133342); Ilhéus, ca. $3 \mathrm{~km} \mathrm{~W}$ of Ilhéus, on road to Itabuna, $14^{\circ} 50^{\prime} \mathrm{S}, 39^{\circ} 04^{\prime} \mathrm{W}$, mangrove swamp of Laguncularia racemosa and Acrostichum, 16-VII-1991, D.M. Vital \& W.R. Buck 20199 (NY, SP353892). Pernambuco: Recife, Horto Zoo-Botânico da Mata de Dois Irmãos, sobre tronco de Palmae, junto da mata, 6-IX-1984, O. Yano \& K.C. Pôrto 9042 (SP191666); idem, 6-IX-1984, O. Yano \& K.C. Pôrto 9062 (SP191686).

Distribuição no Brasil: AC, AM, AP, BA, DF, ES, GO, MG, MS, MT, PA, PB, PE, PR, RJ, RR, SC e SP.

Ocorre em tronco.

* Frullania glomerata (Lehm. \& Lindenb.) Nees \& Mont., Ann. Sci. Nat., Bot. sér. 2, 9: 46. $1838 \equiv$ Jungermannia glomerata Lehm. \& Lindenb., Nov. Stirp. Pug. 5: 21. 1833.

Ilustração: Yano \& Mello(1999)e Yano \& Peralta(2008).
Material examinado: BRASIL. BAHIA: Ilhéus, Praça perto do Forum Epaminondas Berbert de Castro, sobre pinácea em frente o fórum, 26-I-1980, O. Yano 2339 (SP133500); idem, sobre laranjeiras no jardim do convento, 27-I-1980, D.M. Vital 8739 (SP133382); idem, Morro de Pernambuco, small peninsula projecting into the ocean, $14^{\circ} 50^{\prime} \mathrm{S}, 39^{\circ} 02^{\prime} \mathrm{W}$, rocky hillsides with Cocos nucifera, 13-VII-1991, D.M. Vital \& W.R. Buck 20063 (NY, SP353811); Porto Seguro, sobre mangueira, 28-I-1980, D.M. Vital 8743 (SP133386); Ilhéus, sobre palmeira, longo da praia do Sul, 22-I-1980, D.M. Vital 8643 (SP133343); Feira de Santana, Pátio do Colégio Gastão Guimarães, sobre mangueira, 23-X-1990, O. Yano et al. 15068 (SP231184). Pernambuco: Inajá, Serra Negra, sobre Terminalia sp., mata da Serra, 6-IX-1980, O. Yano \& D. Andrade-Lima 2958 p.p. (SP191459).

Distribuição no Brasil: BA, CE, DF, ES, GO, MG, MS, MT, PR, RJ, RS e SP.

Ocorre sobre tronco. A espécie é muito parecida com $F$. dilatata, mas o lóbulo do filídio é cilíndrico; estilete na base com duas células de largura, anfigastro bífido sem dentes laterais.

Frullania gymnotis Nees \& Mont., Ann. Sci. Nat., Bot. sér. 2, 19: 257. 1843.

Ilustração: Yuzawa \& Koike (1989), Lemos-Michel (2001) e Yano \& Peralta (2008).

Material examinado: BRASIL. Pernambuco: Caruaru, Brejo dos Cavalos, ca. $780 \mathrm{~m}$ alt., 11-VIII-1998, O. Yano et al. 25530 (SP322373); Taquaritinga do Norte, Morro Cafundó, sobre Inga sp. na mata da serra Cafundó, 24-VIII-1980, O. Yano \& D. Andrade-Lima 2598 (SP191165); idem, 24-VIII-1980, O. Yano \& D. Andrade-Lima 2599 (SP191166).

Distribuição no Brasil: BA, CE, ES, GO, PA, PE, RJ, RR, RS, SE e SP.

Ocorre sobre tronco. A espécie é semelhante a $F$. neesii, mas o lóbulo é clavado e forma um ângulo com o caulídio e o anfigastro ovalado.

Frullania neesii Lindenb. in Gottsche et al., Syn. Hepat.: 450. 1845.

Ilustração: Stotler (1970), Lemos-Michel (2001) e Yano \& Peralta (2008).

Material examinado: BRASIL. BAHIA: Litoral, Ilhéus, Mangrovenvegetation an der Straße nach Olivença, 
Rhizophora mangle, 19-VII-1987, Schäfer-Verwimp \& Verwimp 8762 (hb. Schäfer-Verwimp, SP388361); Andaraí, trilha para Cachoeira do Ramalho, Serra do Sincorá, 1246'59”'S, 4120'58”W, $461 \mathrm{~m}$ alt., 6-VIII-2001, F.R. Nonato et al. 1018 (HUEFS55763, SP362495); Santa Bárbara, ca. 35 km de Feira de Santana na BR-116, caatinga, 23-X-1990, O. Yano \& J.O. Pereira 15100 (SP231197); Ilhéus, Centro de Pesquisas do Cacau, km 22 da rod.Ilhéus-Itabuna, sobre sombreiro, 17-IX-1991, A.C. Messias \& S.L. Oliveira 143 (CEPEC51623, SP280845). Pernambuco: Recife, Mata de Dois Irmãos, perto da sede do reservatório, 3-VIII-1998, O. Yano et al. 25410 (SP322265); Brejo da Madre de Deus, Reserva Bituri Grande, ca. $950 \mathrm{~m}$ alt., base do arbusto, 10-VIII-1998, O. Yano et al. 25521 (SP322364); Caruaru, Fazenda Caruaru, Brejo dos Cavalos, 29-VIII-1980, O. Yano \& D. Andrade-Lima 2766 (SP191307); idem, Brejo dos Cavalos, ca. 780 m alt., 11-VIII-1998, O. Yano et al. 25545 (SP322388); Recife, Sítio Pitiguari, sobre mangueira, 30-VIII-1980, O. Yano \& D. Andrade-Lima 2824 (SP191350); idem, Mata de Dois Irmãos, 25-X-1980, D. Andrade-Lima 80-6631 (SP191521); idem, Horto Zoo-Botânico da Mata de Dois Irmãos, sobre Ficus sp., 6-IX-1984, O. Yano \& K.C. Pôrto 9053 (SP191677); Inajá, Serra Negra, mata da serra, 6-IX-1980, O. Yano \& D. Andrade-Lima 2972 (SP191473); Taquaritinga do Norte, Morro Cafundó, sobre Clusia sp., entre as pedras no morro, 24-VIII-1980, O. Yano \& D. Andrade-Lima 2620 (SP191180); São Caetano, Serra Pelada, sobre urtiga nas pedras da serra perto da microonda, 29-VIII-1980, O. Yano \& D. Andrade-Lima 2813 (SP191342). Sergipe: Itabaiana-Areia Branca, Estação Ecológica da Serra de Itabaiana, base de arbusto na restinga, $100 \mathrm{~m}$ alt., 24-I-1992, M.P. Marcelli et al. 16503 (SP240784).

Distribuição no Brasil: AC, AM, BA, CE, DF, ES, GO, MG, MT, PB, PE, PR, RJ, RR, RS, SE e SP.

Ocorre em rocha, tronco e tronco em decomposição, associada a Cheilolejeunea acutangula (Nees) Grolle e C. trifaria (Reinw. et al.) Mizut.

Frullania nodulosa (Reinw., Nees \& Blume) Nees in Gottsche et al., Syn. Hepat.: 433. 1845 三 Jungermannia nodulosa Reinw., Nees \& Blume, Nova Acta Phys.-Med. Acad. Caes. Leop.-Carol. Nat. Cur. 12: 217. 1825.

Ilustração: Griffin III (1979), Gradstein et al. (2001) e Gradstein \& Costa (2003).
Material examinado: BRASIL. Pernambuco: São Lourenço da Mata, Engenho São Bento, Estação Ecológica de Tapacurá, Mata Toró-Cuieira, perto do riacho, 26-VIII-1980, O. Yano \& D. Andrade-Lima 2684 (SP191236).

Distribuição no Brasil: AC, AM, BA, PA, PE, RR e SE.

Ocorre sobre tronco.

Frullania riojaneirensis (Raddi) Ångstr., Öfvers. Kongl. Vetensk.-Akad. Förh. 33(7): 88. $1876 \equiv$ Frullanoides riojaneirensis Raddi, Mem. Mat. Fis. Soc. Ital. Sci. Modena 19: 37. 1822.

Ilustração: Yuzawa (1991); Gradstein \& Costa (2003) e Yano \& Peralta (2008).

Material examinado: BRASIL. BAHIA: Itabuna, plantações de cacau da CEPLAC, sobre cacaueiro, 24-I-1980, D.M. Vital 8701 (SP133368); idem, 25-I-1980, O. Yano 2304 (SP133488); Ilhéus, sobre Sapotaceae no jardim do convento, 27-I-1980, D.M. Vital 8736 (SP133381); Porto Seguro, sobre laranjeiras, 28-I-1980, D.M. Vital 8742 (SP133385); Santa Bárbara, ca. 45 km de Feira de Santana na BR-116, 23-X-1990, O. Yano \& J.O. Pereira 15077 (SP231187); idem, 23-X-1990, O. Yano \& J.O. Pereira 15088 (SP231193); Ilhéus, Centro de Pesquisas do Cacau, km 22 da rod. Ilhéus-Itabuna, sobre Hibiscus, 16-IX-1991, A.C. Messias \& S.L. Oliveira 140 (CEPEC51583, SP280880). Pernambuco: Taquaritinga do Norte, sobre Citrus perto da cidade, 24-VIII-1980, O. Yano \& D. Andrade-Lima 2594 (SP191161); Inajá, Serra Negra, 6-IX-1980, O. Yano \& D. Andrade-Lima 2922 (SP191434); Rio Formoso, Córrego da Juçara, 11-IX-1984, O. Yano et al. 9079 (SP191702); Bonito, Cachoeira do Oriente, ca. $19 \mathrm{~km}$ da cidade, ca. $500 \mathrm{~m}$ alt., 6-VIII-1998, O. Yano et al. 25490 (SP322336); Caruaru, Brejo dos Cavalos, ca. $780 \mathrm{~m}$ alt., 11-VIII-1998, O. Yano et al. 25531 (SP322374).

Distribuição no Brasil: BA, CE, DF, ES, GO, MG, MS, MT, PA, PB, PE, PR, RJ, RS, SC, SE e SP.

Ocorre sobre tronco.

* Frullania vitalii Yuzawa \& S. Hatt., J. Jap. Bot. 63(1): 30-32. 1988.

Ilustração: Yuzawa \& Hattori (1988) e Gradstein \& Costa (2003).

Material examinado: BRASIL. Pernambuco: Recife, Parque do Curado, mata do parque, 21-XII-1984, O. Yano et al. 9326 (SP191945). 
Distribuição no Brasil: BA, RJ, SC e SP.

Ocorre sobre tronco, associada a Cheilolejeunea rigidula (Mont.) R.M. Schust.

\section{HERBERTACEAE}

* Herbertus angustevittatus (Steph.) Fulford, Mem. New York Bot. Gard. 11(1): 102. 1963 ESchisma angustivittata Steph., Sp. Hepat. 4: 12. 1909.

Ilustração: Fulford (1963) e Gradstein \& Costa (2003).

Material examinado: BRASIL. PeRnAmBuco: Jaqueira, Serra do Urubu, Mata do Quengo, 8०42'37'S, 35 50 ' 1 ' W, ca. 500-750 m alt., encosta, 31-V-2001, M.R. Pietrobom \& M.S. Lopes 5290 (SP403026).

Distribuição no Brasil: AM, ES, MG, PR, RJ, RR, RS e SP.

Ocorre sobre tronco.

Herbertus juniperoideus (Sw.) Grolle, Rev. Bryol. Lichénol. 30: 80. 1961 Jungermannia juniperoides Sw., Prodr. (Swartz): 144. 1788.

Ilustração: Fulford (1963) e Gradstein \& Costa (2003).

Material examinado: BRASIL. BAHIA: Palmeiras, Pai Inácio, BR-242 W of Lençóis at km 232, 12-VI-1981, B.M. Boom \& S.A. Mori 1176 (SP379186).

Distribuição no Brasil: BA, CE, ES, PE e RJ.

Ocorre em rocha.

* Herbertus subdentatus (Steph.) Fulford, Mem. New York Bot. Gard. 11(1): 104. 1963 三 Schisma subdentatum Steph., Trans. Linn. Soc. London, Bot. ser. 2, 6: 99. 1901.

Figura 2

Ilustração adicional: Fulford (1963).

Material examinado: BRASIL. BAHIA: Rio de Contas, Topo do Pico das Almas, 13 31'19"S, 41 ${ }^{\circ} 57^{\prime} 44^{\prime \prime} \mathrm{W}, 1.870 \mathrm{~m}$ alt., 27-X-1994, S.R. Visnadi \& D.M. Vital 2613 (SP399106).

Distribuição no Brasil: RR.

Ocorre em rocha. A distribuição disjunta pode ser falta de coleta ou ter uma relação com a vegetação. Existem hipóteses de que antigamente a mata amazônica chegava até o sul da Bahia e Norte do Espírito Santo, provavelmente por isso em briófitas existem espécies amazônicas que ocorrem nos dois Estados.

\section{JUNGERMANNIACEAE}

Jamesoniella rubricaulis (Nees) Grolle, Bryologist 71(4): 355. 1968 三 Jungermannia rubricaulis Nees in Martius, Fl. Bras. Enum. Pl. 1(1): 344. 1833. Ilustração: Grolle (1971) e Gradstein \& Costa (2003).

Material examinado: BRASIL. BAHIA: Palmeiras, Pai Inácio BR-242 of Lençóis at km 232, 12-VI-1981, B.M. Boom \& S.A. Mori 1175 (SP379185).

Distribuição no Brasil: BA, MG, RJ, SC e SP.

Ocorre em rocha.

\section{LEJEUNEACEAE}

Acrolejeunea emergens (Mitt.) Steph. in Engler, Pflanzenw. Ost-Afrikas C: 65. 1895 $\equiv$ Phragmicoma emergens Mitt., Philos. Trans. 168: 397. 1879.

Ilustração: Bastos (2004) e Yano \& Peralta (2008).

Material examinado: BRASIL. BAHIA: Morro do Chapéu, BR-052, 4-6 km E of Morro do Chapéu, ca. $1.000 \mathrm{~m}$ alt., 18-VI-1981, B.M. Boom \& S.A. Mori 1283 (SP379212); Lençóis, along BR-242, ca. $15 \mathrm{~km} \mathrm{NW}$ of Lençóis at km 225, ca. $900 \mathrm{~m}$ alt., 10-VI-1981, B.M. Boom \& S.A. Mori 1091 (SP379175).

Distribuição no Brasil: AC, AM, BA, CE, DF, ES, GO, MA, MG, MS, MT, PA, RJ, RO, RR e SP.

Ocorre em rocha.

Anoplolejeunea conferta (C.F.W. Meissn. ex Spreng.) A. Evans, Bull. Torrey Bot. Club 35: 175-176. $1908 \equiv$ Jungermannia conferta C.F.W. Meissn. ex Spreng. in L., Syst. Veg. ed. 16, 4(2): 325. 1827. Ilustração: Costa (1992), Lemos-Michel (2001) e Gradstein \& Costa (2003).

Material examinado: BRASIL. Pernambuco: Inajá, Serra Negra, sobre Caesalpinia leucostachia na mata da serra, 6-IX-1980, O. Yano \& D. Andrade-Lima 2970 (SP191471).

Distribuição no Brasil: AL, BA, ES, MG, PA, PE, PR, RJ, RS, SC e SP.

Ocorre sobre tronco, associada a Drepanolejeunea anoplantha (Spruce) Steph.

Archilejeunea auberiana (Mont.) A. Evans, Bull. Torrey Bot. Club 35: 168. 1908 ELejeunea auberiana Mont. in Sagra, Hist. Phys. Cuba, Bot., Pl. Cell.: 483. 1842.

Ilustração: Ilkiu-Borges (2000), Gradstein \& Costa (2003) e Bastos (2004). 


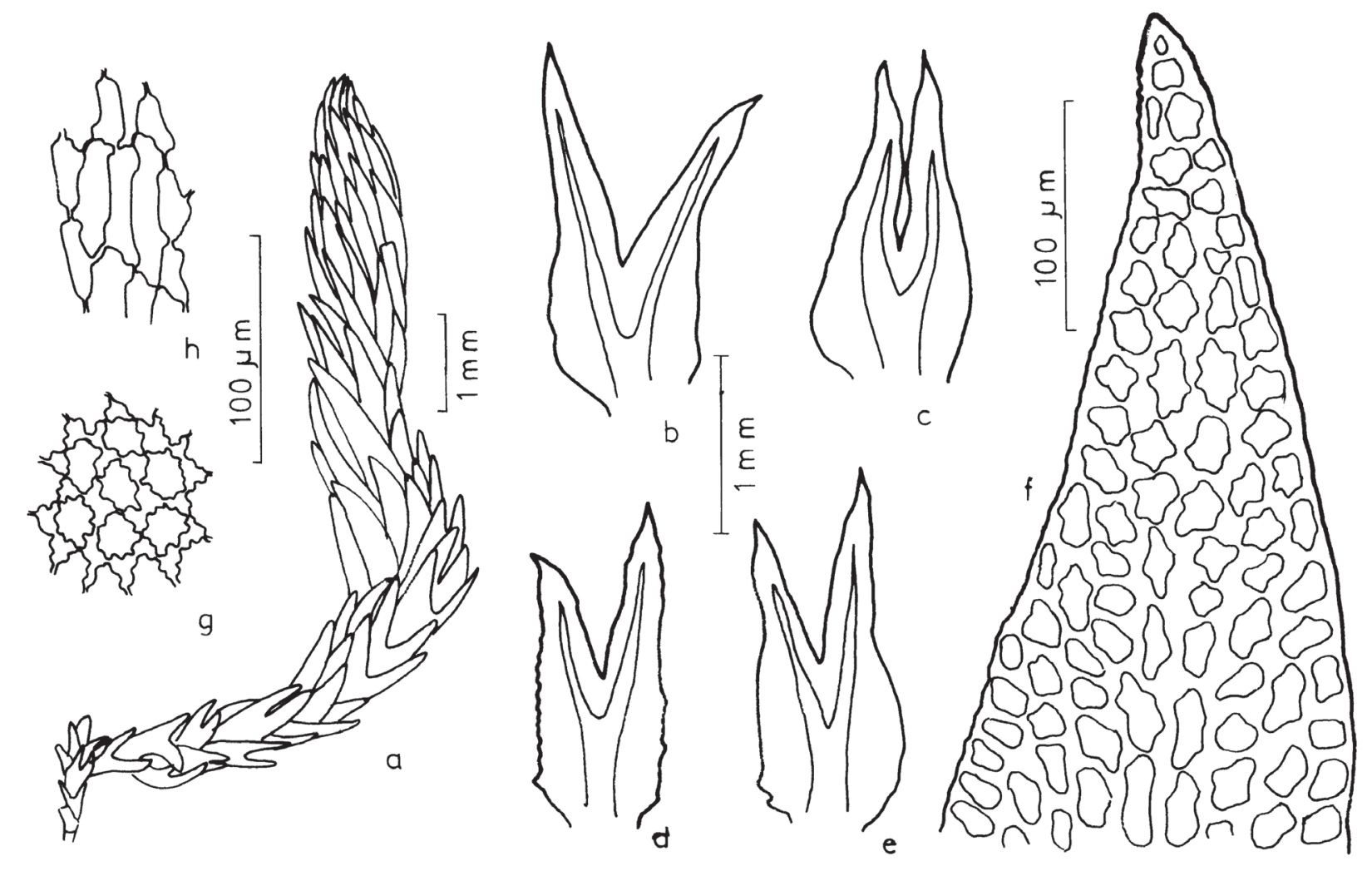

Figura 2. Herbertus subdentatus. a. Aspecto geral do gametófito. b-c. Filídios. d-e. Anfigastros. f. Células do ápice do filídio. g. Células da região mediana do filídio. h. Células da vita.

Figure 2. Herbertus subdentatus. a. General aspect of the gametophyte. b-c. Leaves. d-e. Underleafs. f. Apical cells of the leaf. g. Leaf cells. h. Vitta cells.

Material examinado: BRASIL. BAHIA: Ilhéus, Centro de Pesquisas do Cacau, km 22 on BR-415 between Ilhéus and Itabuna, $14^{\circ} 50^{\prime} \mathrm{S}, 39^{\circ} 13^{\prime} \mathrm{W}$, Parque Zoobotânico, cacau plantation, 15-VII-1991, D.M. Vital \& W.R. Buck 20166 (NY, SP353865).

Distribuição no Brasil: AC, AM, AP, BA, ES, MS, MT, PA, PE, PR, RJ, RO, RR, RS e SP.

\section{Ocorre sobre tronco.}

Archilejeunea fuscescens (Hampe ex Lehm.) Fulford, Bryologist 45(6): 174. $1942 \equiv$ Lejeunea fuscescens Hampe ex Lehm., Nov. Stirp. Pug. 7: 16. 1838. Ilustração: Gradstein \& Costa (2003), Bastos (2004) e Zartman \& Ilkiu-Borges (2007).

Material examinado: BRASIL. Bahia: Monte Pascoal zwischen Porto Seguro und Itamaraju, $17^{\circ} 53^{\prime} \mathrm{S}, 39^{\circ} 24^{\prime} \mathrm{W}$, mata atlântica am Weg zum Gipfel, 350 m alt., 21-VII-1987, Schäfer-Verwimp \&
Verwimp 8791 (hb. Schäfer-Verwimp, SP388364); Uruçuca, $6.2 \mathrm{~km} \mathrm{~N}$ of town of Serra Grande, ca. $40 \mathrm{~km}$ of Ilhéus along coast, ca. $200 \mathrm{~m}$ alt., $14^{\circ} 26^{\prime} \mathrm{S}, 3^{\circ} 03^{\prime} \mathrm{W}$, wet tropical forest, 17-VII-1991, D.M. Vital \& W.R. Buck 20317 (NY, SP353948); idem, 17-VII-1991, D.M. Vital \& W.R. Buck 20276 (NY, SP353923). Pernambuco: Inajá, Serra Negra, sobre Terminalia sp., topo da Serra, 6-IX-1980, O. Yano \& D. Andrade-Lima 2927 (SP191436); idem, 6-IX-1980, O. Yano \& D. Andrade-Lima 2950 (SP191453); Cabo, Estação de Gurjaú, 14-IX-1984, O. Yano \& K.C. Pôrto 9167 (SP191789); idem, mata próx. lagoa, 14-IX-1984, O. Yano \& K.C. Pôrto 9197 (SP191819); São Lourenço da Mata, Tapacurá, 4-II-1988, O. Yano \& G. Mariz 11258 (SP222202).

Distribuição no Brasil: AC, AM, BA, ES, PA, PE, RJ, RR e SP.

Ocorre sobre tronco, associada a Lejeunea tapajosensis Spruce. 
Archilejeunea parviflora (Nees) Schiffn., Sp. Hepat. 4: 716. 1911 三 Jungermannia parviflora Nees in Martius, Fl. Bras. Enum. Pl. 1(1): 353. 1833. Ilustração: Gradstein (1994), Gradstein \& Costa (2003) e Zartman \& Ilkiu-Borges (2007).

Material examinado: BRASIL. BAHIA: Uruçuca, $6.2 \mathrm{~km} \mathrm{~N}$ of town of Serra Grande, ca. $40 \mathrm{~km} \mathrm{~N}$ of Ilhéus along coast, $14^{\circ} 26^{\prime} \mathrm{S}, 39^{\circ} 03^{\prime} \mathrm{W}$, ca. $200 \mathrm{~m}$ alt., wet tropical forest, 17-VII-1991, D.M. Vital \& W.R. Buck 20319 (NY, SP353950).

Distribuição no Brasil: AC, AL, AM, AP, BA, ES, MS, MT, PA, PE, RJ, RO, RR, SC e SP.

Ocorre sobre tronco.

Bryopteris diffusa (Sw.) Nees in Gottsche et al., Syn. Hepat.: 286. 1845 三 Jungermannia diffusa Sw., Prodr. (Swartz): 144. 1788.

Ilustração: Lemos-Michel \& Yano (1998) e Gradstein $\&$ Costa (2003).

Material examinado: BRASIL. Alagoas: Boca da Mata, Alto da Serra de Nacéia, 29-X-1980, D. Andrade-Lima 80-6656 (SP173610). BAHiA: Santa Terezinha, Serra da Jibóia, próx. torre da Embratel, \pm 500 m alt., 6-IX-1994, C.W.N. Moura s.n. (SP283928); Ilhéus, 5-6 km de Olivença na estrada Olivença-Povoado do Maruim, restinga, 29-VII-1993, S.L. Oliveira 332 (CEPEC55885, SP280894); idem, ca. $6 \mathrm{~km}$ Sw of Olivença on road to Maruim, $15^{\circ} \mathrm{S}$, 3904'W, ca. $100 \mathrm{~m}$ alt., restinga, 16-VII-1991, D.M. Vital \& W.R. Buck 20226 (NY, SP353902); idem, Centro de Pesquisas do Cacau, km 22 da BR-415, between Ilhéus and Itabuna, $14^{\circ} 50^{\prime} \mathrm{S}, 39^{\circ} 13^{\prime} \mathrm{W}$, Parque Zoobotânico, 15-VII-1991, D.M. Vital \& W.R. Buck 20157 (NY, SP353856). PernamBuco: Brejo da Madre de Deus, propriedade Bituri Grande, Mata da Pontaria, 20-II-1981, D. Andrade-Lima 81-6687 (SP173611); Jaqueira, Serra do Urubu, Mata do Grengo, 842'50,4'S, 3550'25,8”'W, ca. 713 m alt., 6-XII-2001, M.R. Pietrobom 5248 (SP403050); idem, encosta, interior da mata, 31-V-2001, M.R. Pietrobom \& M.S. Lopes 5289 (SP403025); idem, 31-V-2001, M.R. Pietrobom \& M.S. Lopes 5292a (SP403018); idem, Córrego da Guariba, epífita de dossel, 29-V-2003, M.R. Pietrobom 5590 (SP403077); São Lourenço da Mata, perto do Engenho São Bento, Mata de Tapacurá, perto do riacho na mata, 6-VIII-1986, O. Yano et al. 10341 (SP207015).
Distribuição no Brasil: AC, AL, AM, BA, CE, ES, MG, MT, PA, PE, PR, RJ, RS, SC, SE e SP.

Ocorre sobre tronco, associada a Squamidium leucotrichum (Taylor) Broth. e Omphalanthus filiformes (Sw.) Nees.

Bryopteris filicina (Sw.) Nees in Gottsche et al., Syn. Hepat.: 284. 1845 三 Jungermannia filicina Sw., Prodr. (Swartz): 145. 1788.

Ilustração: Gradstein (1994), Lemos-Michel (2001) e Gradstein \& Costa (2003).

Material examinado: BRASIL. BAHIA: Aurelino Leal, $10-11 \mathrm{~km} \mathrm{~W}$ of BR-101 on road from Aurelino Leal to Lage do Banco, $1^{\circ} 20^{\prime}$ S, 39²3'W, 16-II-1994, J. Kallunk et al. 566 (NY, SP352788). Pernambuco: Caruaru, Brejo dos Cavalos, ca. 780 m alt., 11-VIII-1998, O. Yano et al. 25543 (SP322386); São Vicente Ferrer, Complexo da Serra do Mascarenhas, Mata do Estado, 7³5'S, 35 30'W, ca. 600-650 m alt., junto de regato, 22-II-1999, M.R. Pietrobom-Silva 4533 (SP352772).

Distribuição no Brasil: AC, AM, BA, DF, GO, MG, MS, MT, PA, PE, PR, RJ, RR, RS, SC e SP.

Ocorre sobre rocha, tronco e tronco em decomposição.

* Bryopteris trinitensis (Lehm. \& Lindenb.) Lehm. \& Lindenb. in Gottsche et al., Syn. Hepat.: 285. $1846 \equiv$ Jungermannia trinitensis Lehm. \& Lindenb., Nov. Stirp. Pug. 5: 12. 1833.

Ilustração: Lemos-Michel \& Yano (1998) e Yano \& Peralta (2008).

Material examinado: BRASIL. BAHIA: Santa Teresinha, Serra da Jibóia, 1251'17'S, 39²8'30'W, 15-V-1999, G. Britto et al. 991 (HUEFS37964, SP326899).

Distribuição no Brasil: AM, CE, DF, ES, GO, MG, MT, PR, RJ, RS, SC e SP.

Ocorre sobre tronco. A espécie é semelhante a B. filicina, mas tem o padrão de ramificação, o ápice do anfigastro e o lóbulo do filídio são diferentes, assim preferimos adotar esta classificação.

Caudalejeunea lehmanniana (Gottsche) A. Evans, Bull. Torrey Bot. Club 34: 544. 1845 三 Lejeunea lehmanniana Gottsche in Gottsche et al., Syn. Hepat.: 325. 1845.

Ilustração: Gradstein (1994), Gradstein \& Costa (2003) e Bastos (2004). 
Material examinado: BRASIL. Pernambuco: São Lourenço da Mata, Estação Ecológica de Tapacurá, Mato Toró-Cuieira, 15-VIII-1980, D. Andrade-Lima 80-6625 (SP191507); idem, Mata de Tapacurá, mata úmida, 6-VIII-1986, O. Yano et al. 10320 (SP206994); idem, perto do riacho, 6-VIII-1986, O. Yano et al. 10325 (SP206999); idem, 4-II-1988, O. Yano \& G. Mariz 11263 (SP222207).

Distribuição no Brasil: AL, AM, AP, BA, CE, ES, GO, MT, PA, PE, PR, RJ, RO, RR, RS, SC, SE e SP.

Ocorre sobre tronco.

* Ceratolejeunea coarina (Gottsche) Schiffn. in Engler \& Prantl, Nat. Pflanzenfam. 1(3): 125.1893 三 Lejeunea coarina Gottsche in Gottsche et al., Syn. Hepat.: 395. 1845.

Ilustração: Dauphin-López (2003), Bastos (2004) e Zartman \& Ilkiu-Borges (2007).

Material examinado: BRASIL. Pernambuco: Rio Formoso, Córrego da Juçara, 11-IX-1984, O. Yano et al. 9082 (SP191705); idem, sobre coco da baia, margem do rio, 11-IX-1984, O. Yano et al. 9130 (SP191752).

Distribuição no Brasil: AC, AL, AM, AP, BA, MA, PA, SE e SP.

Ocorre sobre rocha e tronco, associada a Ceratolejeunea cornuta (Lindenb.) Steph.

Ceratolejeunea confusa R.M. Schust., J. Elisha Mitchell Sci. Soc. 72: 313. 1956.

Ilustração: Schuster (1956), Dauphin-López (2003) e Bastos (2004).

Material examinado: BRASIL. BAHIA: Ilhéus, Centro de Pesquisas do Cacau, km 22 on BR-415 between Ilhéus and Itabuna, $14^{\circ} 50^{\prime} \mathrm{S}, 39^{\circ} 13^{\prime} \mathrm{W}$, Parque Zoobotânico, cacau plantation, 15-VII-1991, D.M. Vital \& W.R. Buck 20131 (NY, SP353844); idem, 15-VII-1991, D.M. Vital \& W.R. Buck 20170 (NY, SP353869); idem, ca. $6 \mathrm{~km} \mathrm{SW}$ of Olivença on road to Maruim, $15^{\circ} \mathrm{S}, 39^{\circ} 04^{\prime} \mathrm{W}$, restinga, 16 -VII-1991, D.M. Vital \& W.R. Buck 20249 (NY, SP353907); idem, 16-VII-1991, D.M. Vital \& W.R. Buck 20256 (NY, SP353910). Pernambuco: Recife, Parque do Curado, 21-XII-1984, O. Yano et al. 9325 p.p. (SP191944).

Distribuição no Brasil: AL, AM, BA, PE e SP.

Ocorre sobre tronco, associada a Cheilolejeunea rigidula (Mont.) R.M. Schust., Lopholejeunea subfusca
(Nees) Schiffn. e Pycnolejeunea porrectilobula C. Bastos \& O. Yano.

Ceratolejeunea cornuta (Lindenb.) Steph. in Engler, Pflanzenw. Ost-Afrikas C: 65. 1895 三Jungermannia cornuta Lindenb., NovaActa Phys.-Med.Acad. Caes. Leop.-Carol. Nat. Cur. 14(suppl.): 23. 1829.

Ilustração: Dauphin-López (2003), Gradstein \& Costa (2003) e Yano \& Peralta (2008).

Material examinado: BRASIL. BAHIA: Ilhéus, Centro de Pesquisas do Cacau, km 22 on BR-415 between Ilhéus and Itabuna, $14^{\circ} 50^{\prime} \mathrm{S}, 39^{\circ} 13^{\prime} \mathrm{W}$, Parque Zoobotânico, cacau plantation, 15-VII-1991, D.M. Vital \& W.R. Buck 20156 (NY, SP353855). Pernambuco: Recife, Mata de Dois Irmãos, perto da sede do reservatório, 3-VIII-1998, O. Yano et al. 25397 (SP322253); idem, 3-VIII-1998, O. Yano et al. 25407 (SP322262); Bonito, Reserva Municipal, ca. 8 km da cidade, ca. 720 m alt., 6-VIII-1998, O. Yano et al. 25429 (SP322284); idem, 6-VIII-1998, O. Yano et al. 25431 (SP322286); idem, 6-VIII-1998, O. Yano et al. 25460 (SP322313); Caruaru, Brejo dos Cavalos, Mata de Galileu, ca. 800-900 m alt., 11-VIII-1998, O. Yano et al. 25550 (SP322393); Escada, Engenho Massauaçu, perto do rio Pirapama, 23-VIII-1980, O. Yano \& D. Andrade-Lima 2577 (SP191146); Quipapá, Engenho Brejinho, km 31 da BR-423, sobre Musaceae, perto do rio, 2-IX-1980, O. Yano \& J.Z. Brito 2839 (SP191364); idem, 2-IX-1980, O. Yano \& J.Z. Brito 2840 (SP191365); idem, perto da cachoeira, 2-IX-1980, O. Yano \& J.Z. Brito 2870 (SP191387); idem, perto da cachoeira, 2-IX-1980, O. Yano \& J.Z. Brito 2882 (SP191398); Inajá, Serra Negra, 6-IX-1980, O. Yano \& D. Andrade-Lima 2934 (SP191443); Rio Formoso, Córrego da Juçara, sobre Melastomataceae, 11-IX-1984, O. Yano et al. 9077 (SP191700).

Distribuição no Brasil: AC, AL, AM, AP, BA, CE, GO, MG, PA, PE, PR, RJ, RO, RR, SC, SE e SP.

Ocorre sobre rocha, tronco, tronco em decomposição e folha, associada a Ceratolejeunea confusa R.M. Schust., Cheilolejeunea trifaria (Reinw. et al.) Mizut., Frullania brasiliensis Raddi e Microlejeunea epiphylla Bischler.

* Ceratolejeunea cubensis (Mont.) Schiffn. in Engler \& Prantl, Nat. Pflanzenfam. 1(3): 125. $1893 \equiv$ Lejeunea cubensis Mont. in Sagra, Hist. Phys. Cuba, Bot., Pl. Cell.: 481. 1842.

Ilustração: Schuster (1956, 1980), Dauphin-López (2003) e Zartman \& Ilkiu-Borges (2007). 
Material examinado: BRASIL. Alagohs: Boca da Mata, Alto da Serra de Nacéia, 29-X-1980, D. Andrade-Lima 80-6666 (SP191543). PeRnAMBuCo: Jaqueira, Serra do Quengo, 8०42'50,4”S, $35^{\circ} 50^{\prime} 28,8^{\prime}$ 'W, ca. $713 \mathrm{~m}$ alt., interior da mata, 2-IV-2002, M.R. Pietrobom \& M.S. Lopes 5473 (SP403070); Rio Formoso, Estação Experimental de Saltinho, 11-IX-1984, O. Yano et al. 9142 (SP191764).

Distribuição no Brasil: AC, AM, AP, BA, CE, ES, PA, PB, PE, RJ, SC e SP.

Ocorre sobre tronco e folha.

Ceratolejeunea guianensis (Nees \& Mont.) Steph., Sp. Hepat. 5: 416. 1913 三 Lejeunea guianensis Nees \& Mont., Ann. Sci. Nat., Bot. sér. 2, 14: 335.1840.

Ilustração: Fulford (1945), Schuster (1956), Dauphin-López (2003) e Bastos (2004).

Material examinado: BRASIL. Pernambuco: Altinho, Fazenda Taboca, 29-VIII-1980, O. Yano \& D. Andrade-Lima 2794 (SP191323); Quipapá, Engenho Brejinho, km 31 daBR-423, perto da Cachoeira Grande, 2-IX-1980, O. Yano \& J.Z. Brito 2847 (SP191372); Escada, Engenho Massauaçu, perto do rio Pirapama, 23-VIII-1980, O. Yano \& D. Andrade-Lima 2583 A (SP191153); Rio Formoso, Córrego da Juçara, leito do córrego, 11-IX-1984, O. Yano et al. 9088 (SP191711); idem, Estação Experimental de Saltinho, leito do rio, 11-IX-1984, O. Yano et al. 9126 (SP191479); idem, 11-IX-1984, O. Yano et al. 9137 (SP191759); Cabo, Estação de Gurjaú, sobre Palmae, 14-IX-1984, O. Yano \& K.C. Pôrto 9149 (SP191771); idem, 14-IX-1984, O. Yano \& K.C. Pôrto 9155 (SP191777); idem, 14-IX-1984, O. Yano \& K.C. Pôrto 9161 (SP191783); idem, 14-IX-1984, O. Yano \& K.C. Pôrto 9174 (SP191796); idem, 14-IX-1984, O. Yano \& K.C. Pôrto 9189 (SP191811); idem, 14-IX-1984, O. Yano \& K.C. Pôrto 9163 (SP1911785); Recife, Horto Zoo-Botânico da Mata de Dois Irmãos, 6-IX-1984, O. Yano \& K.C. Pôrto 9045 (SP191669); idem, 6-IX-1984, O. Yano \& K.C. Pôrto 9051 (SP191675); idem, 6-IX-1984, O. Yano \& K.C. Pôrto 9048 (SP191672); idem, cipó, 6-IX-1984, O. Yano \& K.C. Pôrto 9050 (SP191674).

Distribuição no Brasil: AL, AM, BA, PA e PE.

Ocorre sobre tronco, tronco em decomposição e rocha.
Ceratolejeunea laetefusca (Austin) R.M. Schust., J. Elisha Mitchell Sci. Soc. 72: 306. 1956 ELejeunea laetefusca Austin, Bot. Gaz. 1: 36. 1876.

Ilustração: Schuster (1956), Gradstein \& Costa (2003), Dauphin-López (2003) e Bastos (2004).

Material examinado: BRASIL. Pernambuco: Rio Formoso, estação Experimental de Saltinho, leito do rio, 11-IX-1984, O. Yano et al. 9127 (SP191750); Cabo, Estação de Gurjaú, 14-IX-1984, O. Yano \& K.C. Pôrto 9153 (SP191775); idem, 14-IX-1984, O. Yano \& K.C. Pôrto 9156 (SP191778); idem, 14-IX-1984, O. Yano \& K.C. Pôrto 9158 (SP191780); idem, 14-IX-1984, O. Yano \& K.C. Pôrto 9166 (SP191788); idem, 14-IX-1984, O. Yano \& K.C. Pôrto 9191 (SP191813); idem, epifila sobre Melastomataceae, 14-IX-1984, O. Yano \& K.C. Pôrto 9182 (SP191804); São Lourenço da Mata, Tapacurá, 4-II-1988, O. Yano \& G. Mariz 11251 (SP222196).

Distribuição no Brasil: AC, AL, AM, BA, ES, GO, MG, PE, RJ, RR e SP.

Ocorre sobre rocha, folha e tronco.

Ceratolejeunea minuta G. Dauphin, F1. Neotrop. Monogr. 90: 66. 2003.

Ilustração: Dauphin-López (2003), Bastos (2004) e Zartman \& Ilkiu-Borges (2007).

Material examinado: BRASIL. BAHIA: Uruçuca, $6,2 \mathrm{~km} \mathrm{~N}$ of town of Serra Grande, ca. $40 \mathrm{~km} \mathrm{~N}$ of Ilhéus, along coast, $14^{\circ} 26^{\prime} \mathrm{S}, 3^{\circ} 03^{\prime} \mathrm{W}$, wet tropical forest with small stream in ravine, 17-VII-1991, D.M. Vital \& W.R. Buck 20301 p.p. (NY, SP353938).

Distribuição no Brasil: AM, BA, PA e PE.

Ocorre sobre tronco, associada a Rectolejeunea berteroana (Gottsche ex Steph.) A. Evans.

* Ceratolejeunea rubiginosa Steph., Hedwigia 34: 237. 1895.

Ilustração: Fulford (1945), Schuster (1956), Dauphin-López (2003) e Gradstein \& Costa (2003).

Material examinado: BRASIL. Pernambuco: Bonito, reserva Municipal, ca. $8 \mathrm{~km}$ da cidade, ca. $720 \mathrm{~m}$ alt., sobre Myrtaceae, 6-VIII-1998, O. Yano et al. 25467 (SP322320).

Distribuição no Brasil: AP, BA, CE, PA, RJ e SP.

Ocorre sobre tronco. 
Cheilolejeunea acutangula (Nees) Grolle, J. Hattori Bot. Lab. 45: 173. 1979 三 Jungermannia acutangula Nees in Martius, Fl. Bras. Enum. Pl. 1(1): 357.1833.

Ilustração: Gradstein et al. (2001), Gradstein \& Costa (2003) e Bastos (2004).

Material examinado: BRASIL. Pernambuco: Altinho, Fazenda Taboca, 29-VIII-1980, O. Yano \& D. Andrade-Lima 2799 (SP191327); Bituri Grande, Brejo da Madre de Deus, Mata do Caçange, 19-X-1980, L.C.F. Araújo s.n. (SP191513); Rio Formoso, Córrego da Juçara, 11-IX-1984, O. Yano et al. 9112 (SP191735).

Distribuição no Brasil: AL, AM, BA, DF, ES, GO, MG, MT, PA, PE, RJ, SC e SP.

Ocorre sobre tronco.

Cheilolejeunea adnata (Kuntze) Grolle, J. Bryol. 9: 529. 1977 E Jungermannia adnata Kuntze in Lehmann, Nov. Stirp. Pug. 6: 46. 1834.

Ilustração: Gradstein \& Costa (2003), Bastos (2004) e Zartman \& Ilkiu-Borges (2007).

Material examinado: BRASIL. BAHIA: Ilhéus, Centro de Pesquisas do Cacau, km 22 on BR-45 between Ilhéus and Itabuna, $14^{\circ} 50^{\prime} \mathrm{S}, 39^{\circ} 13^{\prime} \mathrm{W}$, Parque Zoobotânico, overgrown cacau plantation, 15-VII-1991, D.M. Vital \& W.R. Buck 20165 (NY, SP353864); idem, 15-VII-1991, D.M. Vital \& W.R. Buck 20188 (NY, SP353886); idem, ca. 6 km SW of Olivença on road to Maruim, $15^{\circ} \mathrm{S}, 39^{\circ} 04^{\prime} \mathrm{W}$, restinga, 16-VII-1991, D.M. Vital \& W.R. Buck 20247 (NY, SP353906). Pernambuco: Recife, Mata de Dois Irmãos, perto da sede do reservatório, 3-VIII-1998, O. Yano et al. 25403 (SP322258); Caruaru, Brejo dos Cavalos, Mata de Galileu, ca. 800-900 m alt., 11-VIII-1998, O. Yano et al. 25551 (SP322394); São Lourenço da Mata, perto do Engenho São Bento, Mata de Tapacurá, 6-VIII-1986, O. Yano et al. 10329 (SP207003); idem, 6-VIII-1986, O. Yano et al. 10336 (SP207010); Formoso, Córrego da Juçara, 11-IX-1984, O. Yano et al. 9078 (SP191701); Cabo, Estação de Gurjaú, 14-IX-1984, O. Yano \& K.C. Pôrto 9180 (SP191802).

Distribuição: AC, AL, AM, AP, BA, CE, ES, MT, PA, PE, PR, RR, SC e SP.

Ocorre sobre rocha e tronco.
Cheilolejeunea clausa (Nees \& Mont.) R.M. Schust., Hepat. Anthocerotae N. Amer. 4: 863. $1980 \equiv$ Lejeunea clausa Nees \& Mont. in Montagne, Ann. Sci. Nat., Bot. sér. 2, 14: 337. 1840.

Ilustração: Schuster (1980), Bastos (2004) e Yano \& Peralta (2008).

Material examinado: BRASIL. BAHIA: Ilhéus, Centro de Pesquisas do Cacau, km 22 on BR-415 between Ilhéus and Itabuna, $14^{\circ} 50^{\prime} \mathrm{S}, 39^{\circ} 13^{\prime} \mathrm{W}$, Parque Zoobotânico, cacau plantation, 15-VII-1991, D.M.Vital \& W.R. Buck 20162 (NY, SP353861); idem, 15-VII-1991, D.M.Vital \& W.R. Buck 20171 (NY, SP353870); idem, 15-VII-1991, D.M.Vital \& W.R. Buck 20197 (NY, SP353891). Pernambuco: Quipapá, Engenho Brejinho, km 31 da BR-423, perto da cachoeira, 2-IX-1980, O. Yano \& J.Z. Brito 2881 (SP191379); Recife, Horto ZooBotânico da Mata de Dois Irmãos, 6-IX-1984, O. Yano \& K.C. Pôrto 9057 (SP191681).

Distribuição no Brasil: $\mathrm{AC}, \mathrm{AL}, \mathrm{AM}, \mathrm{AP}, \mathrm{BA}, \mathrm{CE}$, ES, GO, MG, MS, MT, PA, PE, PR, RJ, RS, SC e SP.

Ocorre sobre tronco, associada a Lopholejeunea subfusca (Nees) Schiffn. e Mastigolejeunea auriculata (Wilson \& Hook.) Schiffn.

Cheilolejeunea comans (Spruce) R.M. Schust., Phytologia 45(5): 431. $1980 \equiv$ Lejeunea comans Spruce, Trans. \& Proc. Bot. Soc. Edinburgh 15: 246. 1884.

Figura 3

Ilustração adicional: Bastos (2004).

Material examinado: BRASIL. BAHIA: Uruçuca, $6,2 \mathrm{~km} \mathrm{~N}$ of town of Serra Grande, ca. $40 \mathrm{~km} \mathrm{~N}$ of Ilhéus along coast, $14^{\circ} 26^{\prime} \mathrm{S}, 39^{\circ} 03^{\prime} \mathrm{W}$, wet tropical forest with small stream in ravine, 17-VII-1991, D.M. Vital \& W.R. Buck 20311 (NY, SP353943).

Distribuição no Brasil: AM, BA, ES, PA, SC e SP.

Ocorre sobre tronco.

Cheilolejeunea conchifolia (A. Evans) W. Ye \& R.L. Zhu, J. Bryol. 32: 280. $2010 \equiv$ Archilejeunea conchifolia A. Evans, Mem. Torrey Bot. Club 8: 128. 1902.

Ilustração: Schuster (1980) e Bastos (2004).

Material examinado: BRASIL. BAHIA: São Sebastião do Passé, Lamarão do Passé, 20-I-1983, I.C. Britto 9 (SP389572). 


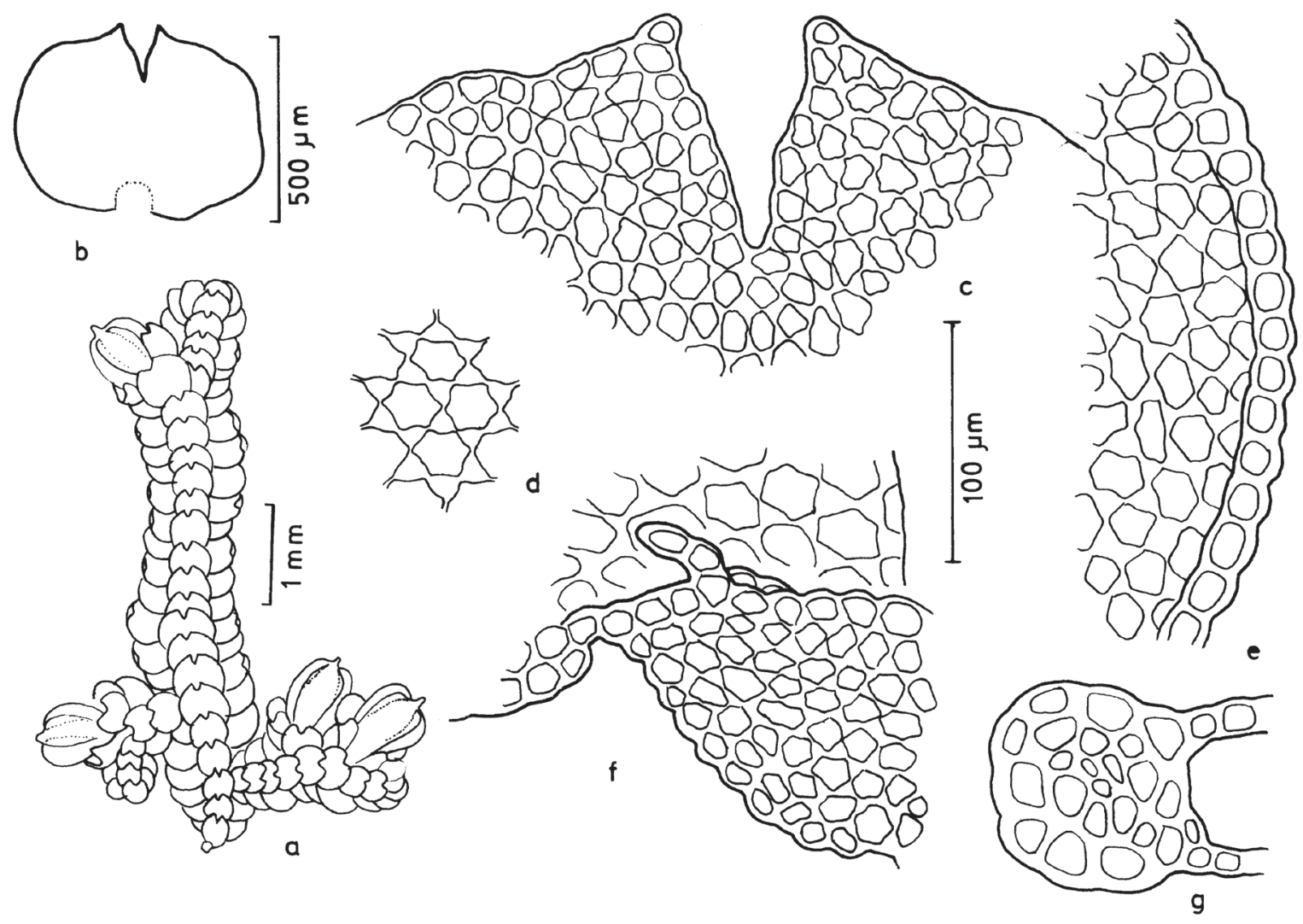

Figura 3. Cheilolejeunea comans. a. Aspecto geral do gametófito. b. Anfigastro. c. Células do anfigastro. d. Células da região mediana do lóbulo. e. Células da margem do lobo. f. Detalhe do lóbulo. g. Secção transversal do caulídio.

Figure 3. Cheilolejeunea comans. a. General aspect of the gametophyte. b. Underleaf. c. Underleaf cells. d. Leaf cells. e. Marginal cells of the leaf. f. Lobe detail. g. Cross section of stem.

Distribuição no Brasil: BA, ES, MG e SP.

Ocorre sobre tronco em decomposição.

* Cheilolejeunea discoidea (Lehm. \& Lindenb.) Kachroo \& R.M. Schust., J. Linn. Soc., Bot. 56(368): 509. 1961 E Lejeunea discoidea Lehm. \& Lindenb. in Gottsche et al., Syn. Hepat.: 383. 1845. Ilustração: Bastos (2004), Yano \& Peralta (2008) e Ilkiu-Borges et al. (2009).

Material examinado: BRASIL. BAHIA: Litoral, Ilhéus, Mangrovenvegetation an der Straße nach Olivença, 19-VII-1987, Schäfer-Verwimp \& Verwimp 8764B (hb. Schäfer-Verwimp, SP388363); Ilhéus, ca. 6 km SW of Olivença on road to Maruim, $15^{\circ} \mathrm{S}, 39^{\circ} 04^{\prime} \mathrm{W}$, restinga 16-VII-1991, D.M. Vital \& W.R. Buck 20223 (NY, SP353900). Pernambuco: Recife, Bosque da Univ. Federal Rural de Pernambuco, sobre jaqueira, 27-VIII-1980, O. Yano 2690 (SP191241); idem, Campus da Universidade Federal de Pernambuco, sobre Anacardium sp., 7-VIII-1986, O. Yano \&
M.G.V. Marinho 10347 (SP207021); São Lourenço da Mata, perto do Engenho São Bento, mata de Tapacurá, 6-VIII-1986, O. Yano et al. 10330 (SP207004); idem, 6-VIII-1986, O. Yano et al. 10332 (SP207006).

Distribuição no Brasil: BA, DF, ES, GO, MG, MS, MT, PA, SE e SP.

Ocorre sobre tronco.

Cheilolejeunea holostipa (Spruce) Grolle \& R.-L. Zhu in Grolle et al., Taxon 50: 1071. $2001 \equiv$ Lejeunea holostipa Spruce, Trans. \& Proc. Bot. Soc. Edinburgh 15: 171. 1884.

Ilustração: Grolle et al. (2001), Gradstein \& Costa (2003) e Bastos (2004).

Material examinado: BRASIL. Pernambuco: Caruaru, Fazenda Caruaru, Brejo dos Cavalos, 29-VIII-1980, O. Yano \& D. Andrade-Lima 2764 p.p. (SP191305).

Distribuição no Brasil: AM, BA, ES, MG, PA, PE, PR, RJ e SP. 
Ocorre sobre tronco, associada a Bryopteris diffusa (Sw.) Nees e Macromitrium cirrosum (Hedw.) Brid.

Cheilolejeunea oncophylla (Ångstr.) Grolle \& E. Reiner, J. Bryol. 19: 781. $1997 \equiv$ Lejeunea oncophylla Ångstr., Öfvers. Kongl. Vetensk.-Akad. Förh. 33(7): 86. 1876.

Ilustração: Bastos (2004), Zartman \& Ilkiu-Borges (2007) e Yano \& Peralta (2008).

Material examinado: BRASIL. BAHIA: Porto Seguro, Monte Pascoal bei Itamaraju, $17^{\circ} 53^{\prime} \mathrm{S}, 39^{\circ} 24^{\prime} \mathrm{W}$, Mata Atlântica am Weg zum Gipfel, 320 m alt., 5-VII-1990, Schäfer-Verwimp \& Verwimp 12900 (hb. Schäfer-Verwimp, SP398456).

Distribuição no Brasil: AP, BA, MG, PA, PR, RJ, RR, SC e SP.

Ocorre sobre tronco.

Cheilolejeunea rigidula (Nees ex Mont.) R.M. Schust., Castanea 36: 102. $1971 \equiv$ Lejeunia rigidula Nees ex Mont., Ann. Sci. Nat., Bot. sér. 2, 14: 336. 1840.

Ilustração: Schuster (1980), Gradstein \& Costa (2003) e Yano \& Peralta (2008).

Material examinado: BRASIL. Alagoas: Quebrangulo, Fazenda Pedra Talhada, 28-X-1980, D. Andrade-Lima 80-6645 (SP191530). BahiA: Itabuna, CEPLAC, sobre cacaueiro, local sombrio, 25-I-1980, O. Yano 2306 (SP133490); Litoral, Ilhéus, Mangrovenvegetation an der Straße nach Olivença, an Rhizophora mangle, 19-VII-1987, Schäfer-Verwimp \& Verwimp 8764a (hb. Schäfer-Verwimp, SP388362); Monte Pascoal zwischen Porto Seguro und Itamaraju, $17^{\circ} 53^{\prime}$ S, 39 $24^{\circ}$ 'W, Mata Atlântica am Weg zum Gipfel, 380 m alt., 21-VII-1987, Schäfer-Verwimp \& Verwimp 8796 (hb. Schäfer-Verwimp, SP388365); Ilhéus, Centro de Pesquisas do Cacau, km 22 da rod. Ilhéus-Itabuna, 19-XII-1991, A.C. Messias \& S.L. Oliveira 190 p.p. (CEPEC51616, SP280852); idem, $\mathrm{km} 22$ on BR-415 between Ilhéus and Itabuna, $14^{\circ} 50^{\prime}$ S, $39^{\circ} 13^{\prime} \mathrm{W}$, Parque Zoobotânico, cacau plantation, 15-VII-1991, D.M. Vital \& W.R. Buck 20163 (NY, SP353862). Pernambuco: Vicência, Morro do Engenho Jundiá, 13-XII-2001, M.R. Pietrobom 5251 (SP403053); Timbaúba, complexo da Serra do Mascarenhas, Usina Cruangi, Engenho Água Azul, área do poço caudaloso, $7^{\circ} 37^{\prime} 7,3^{\prime}$ 'S, $35^{\circ} 23^{\prime} 43,1^{\prime \prime} \mathrm{W}$, ca. 304-451 m alt., junto do regato, 14-XII-2001,
M.R. Pietrobom 5438 (SP403054); Recife, Mata de Dois Irmãos, 25-X-1980, D. Andrade-Lima 80-6628 (SP191518); idem, Horto Zoo-Botânico da Mata de Dois Irmãos, 6-IX-1984, O. Yano \& K.C. Pôrto 9052 (SP191676); idem, perto da sede do reservatório, 3-VIII-1998, O. Yano et al. 25405 (SP322260); idem, 3-VIII-1998, O. Yano et al. 25411 (SP322266); Caruaru, Brejo dos Cavalos, 11-VIII-1998, O. Yano et al. 25540 (SP322383); idem, 11-VIII-1998, O. Yano et al. 25546 (SP322389); idem, Fazenda Caruaru, sobre Pseudobombax sp., Brejo dos Cavalos, 29-VIII-1980, O. Yano \& D. Andrade-Lima 2748 (SP191291); Recife, Sítio Pitiguari, sobre cajueiro, 30-VIII-1980, O. Yano \& D. Andrade-Lima 2823 (SP191349); Quipapá, Engenho Brejinho, km 31 da BR-423, perto da cachoeira, 2-IX-1980, O. Yano \& J.Z. Brito 2843 (SP191368); idem, 2-IX-1980, O. Yano \& J.Z. Brito 2844 (SP191369); idem, 2-IX-1980, O. Yano \& J.Z. Brito 2845 (SP191370); idem, junto da Cachoeira Grande, 2-IX-1980, O. Yano \& J.Z. Brito 2859 (SP191382); Escada, Engenho Massauaçu, perto do rio Pirapama, 23-VIII-1980, O. Yano \& D. Andrade-Lima 2570 (SP191141); Rio Formoso, Córrego da Juçara, sobre raízes de Palmae, mata úmida, 11-IX-1984, O. Yano et al. 9110 (SP191733); idem, Estação Experimental de Saltinho, 11-IX-1984, O. Yano et al. 9136 (SP191758); Cabo, Estação de Gurjaú, mata próx. lagoa, 14-IX-1984, O. Yano \& K.C. Pôrto 9187 (SP191809); idem, 14-IX-1984, O. Yano \& K.C. Pôrto 9201 (SP191823).

Distribuição no Brasil: $\mathrm{AC}, \mathrm{AL}, \mathrm{AM}, \mathrm{AP}, \mathrm{BA}, \mathrm{CE}$, DF, ES, GO, MG, MS, MT, PA, PB, PE, PR, RJ, SC, SE e SP.

Ocorre sobre rocha e tronco, associada a Calymperes palisotii Schwägr., Ceratolejeunea confusa R.M. Schust., Frullania neesii Lindenb., F. vitalii Yuzawa \& S. Hatt., Lejeunea flava (Sw.) Nees, L. laetevirens Nees \& Mont., Lopholejeunea subfusca (Nees) Schiffn., Plagiochila patula (Sw.) Lindenb. e Schiffneriolejeunea polycarpa (Nees) Gradst.

Cheilolejeunea trifaria (Reinw., Blume \& Nees) Mizut., J. Hattori Bot. Lab. 27: 132. $1964 \equiv$ Jungermannia trifaria Reinw., Blume \& Nees, Nova Acta Phys.-Med. Acad. Caes. Leop.-Carol. Nat. Cur. 12: 226.1824.

Ilustração: Gradstein \& Costa (2003), Bastos (2004) e Yano \& Peralta (2008).

Material examinado: BRASIL. BAHIA: Ilhéus, $5 \mathrm{~km} \mathrm{~S}$ of Ilhéus on road to Olivença, $14^{\circ} 52^{\prime} \mathrm{S}, 39^{\circ} 02^{\prime} \mathrm{W}$, 
restinga, 14-VII-1991, D.M. Vital \& W.R. Buck 20076 (NY, SP353824); idem, 14-II-1991, D.M. Vital \& W.R. Buck 20087 (NY, SP353829); idem, 14-VII-1991, D.M. Vital \& W.R. Buck 20117 (NY, SP353840). Pernambuco: Recife, sobre Acrocomia intumescens, estrada para o sítio Pitiguari, 30-VIII-1980, O. Yano \& D. Andrade-Lima 2819 (SP191346); idem, Sítio Pitiguari, sobre mangueira, 30VIII-1980, O. Yano \& D. Andrade-Lima 2827 (SP191353).

Distribuição no Brasil: AC, AL, AM, AP, BA, CE, DF, ES, GO, MG, MS, MT, PA, PB, PE, PR, RJ, RR e SP.

Ocorre sobre tronco, associada a Ceratolejeunea cornuta (Lindenb.) Steph., Frullania neesii Lindenb. e Lejeunea laetevirens Nees \& Mont.

Cheilolejeunea unciloba (Lindenb.) Malombe, Acta

Bot. Hung. 51: 325. $2009 \equiv$ Lejeunea unciloba

Lindenb. in Gottsche et al., Syn. Hepat.: 311. 1845. Ilustração: Schuster (1980), Gradstein \& Costa (2003) e Bastos (2004), todos como Leucolejeunea.

Material examinado: BRASIL. Pernambuco: Recife, Mata de Dois Irmãos, perto da sede do reservatório, 3-VIII-1998, O. Yano et al. 25404 (SP322259); Brejo da Madre de Deus, Reserva Bituri Grande, ca. $950 \mathrm{~m}$ alt., 10-VIII-1998, O. Yano et al. 25513 (SP322357).

Distribuição no Brasil: AC, AM, BA, CE, ES, MG, PA, PE, RJ, RS, SC e SP.

Ocorre sobre tronco e tronco em decomposição.

* Cheilolejeunea xanthocarpa (Lehm. \& Lindenb.) Malombe, Acta. Bot. Hung. 51: 326. $2009 \equiv$ Jungermannia xanthocarpa Lehm. \& Lindenb. in Lehmann, Nov. Stirp. Pug. 5: 8. 1833.

Ilustração: Schuster (1980), Gradstein \& Costa (2003) e Bastos (2004), todos como Leucolejeunea.

Material examinado: BRASIL. Alagohs: Boca da Mata, Alto da Serra da Nacéia, epífita, 29-X-1980, D. Andrade-Lima 80-6664 p.p. (SP191541). ВАнIA: Itabuna, plantação de cacau da CEPLAC, sobre tronco de cacaueiro, 24-I-1980, D.M. Vital 8705 (SP133371); Senhor do Bonfim, Serra de Santana, 650-900 m alt., epífita em Eremanthus, 26-XII-1984, J.R. Pirani et al. CFCR 7657 (SPF36657, SP222584); Rio de Contas, estrada para Jussiape, subida para o Pico das Almas, tronco vivo, 27-X-1994, S.R. Visnadi \& D.M. Vital 2626 (SP372769). Pernambuco:
Taquaritinga do Norte, Morro Cafundó, sobre os galhos de Clusia sp. entre as pedras no Morro, 24-VIII-1980, O. Yano \& D. Andrade-Lima 2617 (SP191178); idem, sobre tronco de Inga sp. na mata da serra Cafundó, 24-VIII-1980, O. Yano \& D. Andrade-Lima 2597 (SP191164); Caruaru, Fazenda Caruaru, sobre tronco de Miconia sp. na mata úmida do Brejo dos Cavalos, 29-VIII-1980, O. Yano \& D. Andrade-Lima 2751 (SP191293); Recife, Sítio Pitiguari, sobre tronco de mangueira, 30-VIII-1980, O. Yano \& D. Andrade-Lima 2825 (SP191351); idem, sobre tronco de árvore viva, 30-VIII-1980, O. Yano \& D. Andrade-Lima 2830 (SP191356); Brejo da Madre de Deus, Reserva Bituri Grande, ca. $950 \mathrm{~m}$ alt., base do tronco de arbusto, 10-VIII-1998, O. Yano et al. 25520 (SP322363); Inajá, Serra Negra, sobre tronco de árvore viva na mata, 6-IX-1980, O. Yano \& D. Andrade-Lima 2930 (SP191439); São Lourenço da Mata, Tapacurá, sobre tronco vivo, mata úmida, 4-II-1988, O. Yano \& G. Mariz 11249 (SP222193).

Distribuição no Brasil: BA, CE, ES, GO, MG, PE, RJ, RS, SC e SP.

Ocorre sobre tronco, associada a Donnellia commutata (Müll. Hal.) W.R. Buck, Drepanolejeunea anoplantha (Spruce) Steph., Frullania caulisequa (Nees) Nees, Harpalejeunea stricta (Lindenb. \& Gottsche) Steph. e Lejeunea tapajosensis Spruce.

Cololejeunea cardiocarpa (Mont.) A. Evans, Mem. Torrey Bot. Club 8: 172. $1902 \equiv$ Lejeunea cardiocarpa Mont., Hist. Phys. Cuba, Bot., Pl. Cell. 446-447: 1838. 1842.

Ilustração: Tixier (1985), Gradstein \& Costa (2003) e Yano \& Peralta (2008).

Material examinado: BRASIL. BAHIA: Santa Bárbara, ca. $45 \mathrm{~km}$ de Feira de Santana na BR-116, sobre Caparisico, 23-X-1990, O. Yano \& J.O. Pereira 15069 (SP231185). Pernambuco: Inajá, Serra Negra, Estação Biológica do IBDF, 6-IX-1980, O. Yano \& D. Andrade-Lima 2917 (SP191429); São Lourenço da Mata, Mato do Toró, sobre Cecropia sp., 21-XII-1984, O. Yano et al. 9313 (SP191932).

Distribuição no Brasil: AL, AM, AP, BA, ES, GO, MG, MS, MT, PA, PB, PE, PR, RJ, RO, RR, RS, SC, SE e SP.

Ocorre sobre tronco e folha. 
Cololejeunea diaphana A. Evans, Bull. Torrey Bot. Club 32(4): 184. 1905 = Aphanolejeunea truncatifolia Horik., J. Sci. Hiroshima Univ. ser. 3. Div. 2, 2: 284. 1934.

Ilustração: Gradstein \& Costa (2003), Bastos (2004) e Yano \& Peralta (2008).

Material examinado: BRASIL. Pernambuco: Recife, Horto Zoo-Botânico da Mata de Dois Irmãos, epífita sobre Annonaceae, interior da mata, 6-IX-1984, O. Yano \& K.C. Pôrto 9049 (SP191673); Bonito, Reserva Municipal, ca. $8 \mathrm{~km}$ da cidade, ca. $720 \mathrm{~m}$ alt., 6-VIII-1998, O. Yano et al. 25439 (SP322294); idem, 6-VIII-1998, O. Yano et al. 25465 (SP322318).

Distribuição no Brasil: AL, AM, BA, DF, ES, GO, MG, MS, MT, PA, PE, RJ, RS, SC e SP.

Ocorre sobre tronco e folha.

Cololejeunea minutissima (Sm.) Schiffn. in Engler \& Prantl, Nat. Pflanzenfam. 1(3): 122. $1893 \equiv$ Jungermannia minutissima Sm.,Engl.Bot.1633. 1806. Ilustração Smith (1996) e Bastos (2004).

Material examinado: BRASIL. BAHIA: Ilhéus, Centro de Pesquisas do Cacau, km 22 on BR-415 between Ilhéus and Itabuna, 1450'S, 39 $13^{\circ} \mathrm{W}$, Parque Zoobotânico, cacau plantation, 15-VII-1991, D.M. Vital \& W.R. Buck 20135 (NY, SP353848). Pernambuco: Recife, Horto Zoobotânico da Mata de Dois Irmãos, mata secundária, 6-IX-1984, O. Yano \& K.C. Pôrto 9055 (SP191679); idem, Campus da Universidade Federal de Pernambuco, sobre Leguminosae, 10-IX-1984, O. Yano \& K.C. Pôrto 9069 (SP191692).

Distribuição no Brasil: AC, AM, BA, ES, MS, MT, PA, PE, PR, RJ, RR, SC e SP.

Ocorre sobre tronco.

Cololejeunea obliqua (Nees \& Mont.) Schiffn., Bot. Jahrb. Syst. 23: 586. 1897 Lejeunea obliqua Nees \& Mont., Ann. Sci. Nat., Bot. sér. 2, 19: 264. 1843. Ilustração: Ilkiu-Borges (2000), Gradstein \& Costa (2003) e Zartman \& Ilkiu-Borges (2007).

Material examinado: BRASIL. Pernambuco: São Lourenço da Mata, Engenho São Bento, Estação Ecológica de Tapacurá, Mata Toró-Cuieira, perto do riacho, 26-VIII-1980, O. Yano \& D. Andrade-Lima 2661 (SP191216).

Distribuição no Brasil: AC, AL, AM, AP, BA, PA, PE, PR, RJ, SC e SP.
Ocorre sobre folha, associada a Colura ulei Jovet-Ast e Drepanolejeunea dissitifolia A. Evans.

* Cololejunea paucifolia (Spruce) Bernecker \& Pócs in Pócs \& Bernecker, Polish Bot. J. 54(1): 10.2009 Lejeunea paucifolia Spruce, Bull. Soc. Bot. France 36(suppl. 1889): 194. 1890.

Ilustração: Reiner-Drehwald (1995), Gradstein \& Costa (2003) e Bastos (2004).

Material examinado: BRASIL. Pernambuco: Caruaru, Fazenda Caruaru, 29-VIII-1980, O. Yano \& D. Andrade-Lima 2774 (SP191311); Rio Formoso, Estação Experimental de Saltinho, próx. lagoa, 11-IX-1984, O. Yano et al. 9131 (SP191753); Bonito, Reserva Municipal, ca. $8 \mathrm{~km}$ da cidade, ca. $720 \mathrm{~m}$ alt., 6-VIII-1998, O. Yano et al. 25468 (SP322321).

Distribuição no Brasil: BA, ES, MG, RJ e SP.

Ocorre sobre tronco em decomposição e folha.

Cololejeunea subcardiocarpa Tixier, Bradea 3(6): 39. 1980.

Ilustração: Tixier (1980), Gradstein \& Costa (2003) e Bastos (2004).

Material examinado: BRASIL. Pernambuco: Bonito, reserva Municipal, ca. $8 \mathrm{~km}$ da cidade, ca. $720 \mathrm{~m}$ alt., 6-VIII-1998, O. Yano et al. 25437 p.p. (SP322292).

Distribuição no Brasil: AC, AL, AM, BA, CE, ES, GO, MG, MT, PA, PE, PR, RJ e SP.

Ocorre sobre folha, associada a Diplasiolejeunea brunnea Steph. e Leptolejeunea elliptica (Lehm. \& Lindenb.) Schiffn.

* Cololejeunea submarginata Tixier, Bradea 3(6): 40. 1980.

Ilustração: Tixier (1980), Gradstein \& Costa (2003) e Bastos (2004).

Material examinado: BRASIL. Pernambuco: Rio Formoso, Córrego Juçara, próx. córrego, 11-IX-1984, O. Yano et al. 9105 (SP191728).

Distribuição no Brasil: AL, AM, CE, GO, MT e SC. Ocorre sobre folha.

Colura ulei Jovet-Ast, Rev. Bryol. Lichénol. 22(3-4): 270. 1953.

Figura 4

Ilustração adicional: Jovet-Ast (1953).

Material examinado: BRASIL. Pernambuco: São Lourenço da Mata, Engenho São Bento, 
Estação Ecológica de Tapacurá, Mata Toró Cuieira, perto do riacho, 26-VIII-1980, O. Yano \& D. Andrade-Lima 2661 p.p. (SP191216).

Distribuição no Brasil: AM, PE, RJ e SP.

Ocorre sobre folha, associada a Cololejeunea obliqua (Nees \& Mont.) Schiffn. e Drepanolejeunea dissitifolia A. Evans.

Cyclolejeunea chitonia (Taylor) A. Evans, Bull.

Torrey Bot. Club 31: 194-196. $1904 \equiv$ Lejeunea chitonia Taylor ex Gottsche, Lindenb. \& Nees, Sp.

Hepat. Brit. Isl.: 339. 1845.

Ilustração: Evans (1904) e Gradstein \& Costa (2003).

Material examinado: BRASIL. BAHIA: Porto Seguro, Nationalpark Monte Pascoal, Mata Atlântica, Gipfelbereich, $530 \mathrm{~m}$ alt., 21-VII-1987, Schäfer-Verwimp \& Verwimp 8812 (hb. Schäfer-Verwimp, SP386179).
Distribuição no Brasil: BA, CE e PA.

Ocorre sobre folha.

* Cyclolejeunea convexistipa (Lehm. \& Lindenb.) A. Evans, Bull. Torrey Bot. Club 31(3): 198. $1904 \equiv$ Jungermannia convexistipa Lehm. \& Lindenb., Nov. Stirp. Pug. 6: 43. 1834.

Ilustração: Gradstein et al. (2001), Gradstein \& Costa (2003) e Bastos (2004).

Material examinado: BRASIL. BAHIA: Uruçuca, $6,2 \mathrm{~km} \mathrm{~N}$ of town of Serra Grande, ca. $40 \mathrm{~km} \mathrm{~N}$ of Ilhéus along coast, $14^{\circ} 26^{\prime} \mathrm{S}, 39^{\circ} 03^{\prime} \mathrm{W}$, wet tropical forest with small stream in ravine, 17-VII-1991, D.M. Vital \& W.R. Buck 20320 (NY, SP353951). Pernambuco: Jaqueira, Serra do Quengo, 842'50,4”S, 35 50'28,8' 'W, ca. $713 \mathrm{~m}$ alt., encosta, interior da mata, 21-IV-2002, M.R. Pietrobom \& M.S. Lopes 5472 (SP403069).

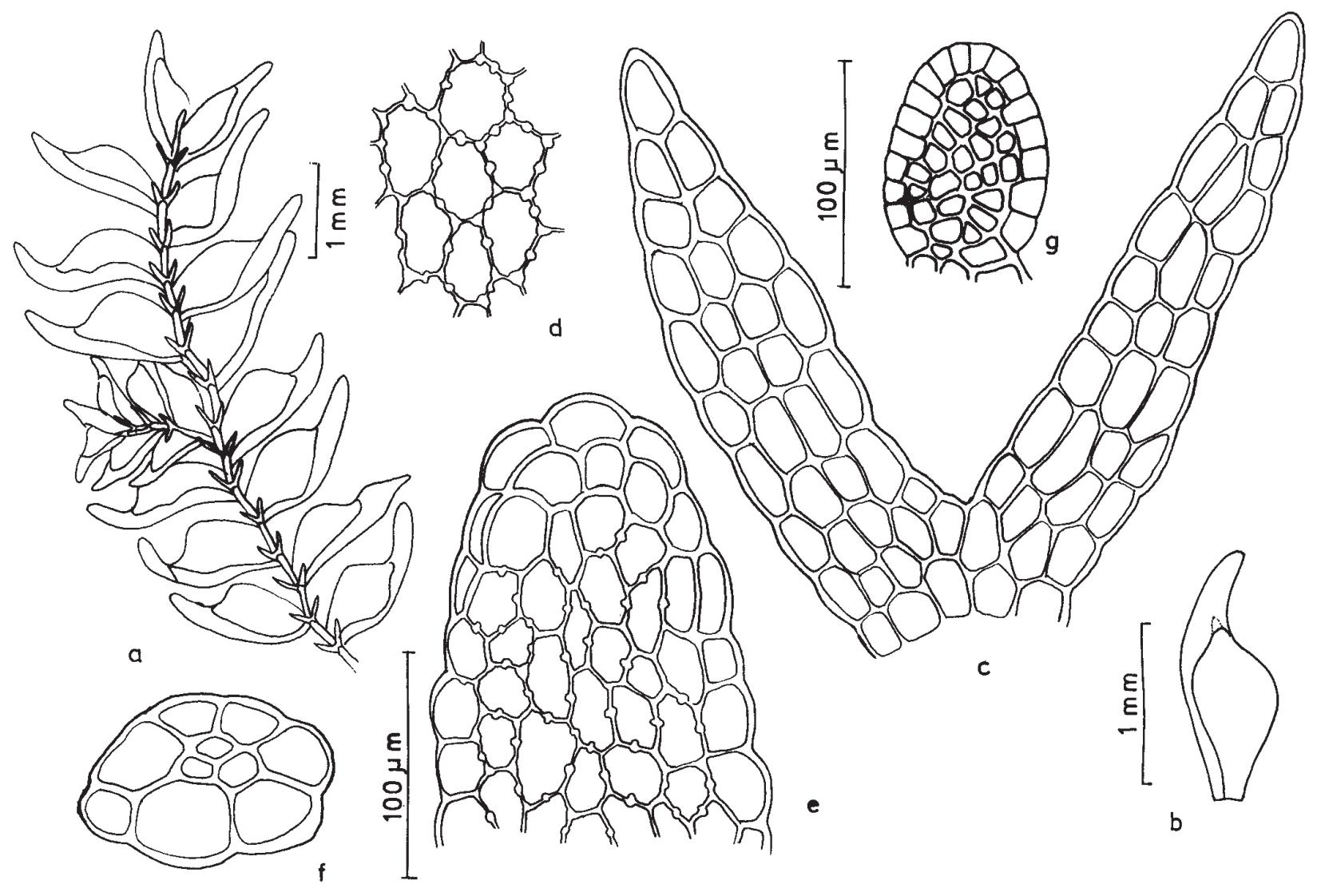

Figura 4. Colura ulei. a. Aspecto geral do gametófito. b. Filídio. c. Anfigastro. d. Células da região mediana do filídio. e. Células do ápice do lobo. f. Secção transversal do caulídio. g. Valva.

Figure 4. Colura ulei. a. General aspect of the gametophyte. b. Leaf. c. Underleaf. d. Leaf cells. e. Apical cells of the leaf. f. Cross section of stem. g. Valve. 
Distribuição no Brasil: AM, AP, BA, CE, PA e SP.

Ocorre sobre folha.

Diplasiolejeunea brunnea Steph., Sp. Hepat. 5: 922. 1916.

Ilustração: Tixier (1985), Gradstein \& Costa (2003) e Zartman \& Ilkiu-Borges (2007).

Material examinado: BRASIL. Pernambuco: Bonito, Reserva Municipal, ca. $8 \mathrm{~km}$ da cidade, ca. $720 \mathrm{~m}$ alt., 6-VIII-1998, O. Yano et al. 25437 (SP322292); idem, 6-VIII-1998, O. Yano et al. 25438 (SP322293); Rio Formoso, Córrego da Juçara, epifila de jambeiro, 11-IX-1984, O. Yano et al. 9098 (SP191721); Taquaritinga do Norte, Morro Cafundó, sobre Citrus sp., 24-VIII-1980, O. Yano \& D. Andrade-Lima 2607 (SP191170); idem, ao lado da microonda, 24-VIII-1980, O. Yano \& D. Andrade-Lima 2647 (SP191206); Caruaru, Fazenda Caruaru, Brejo dos Cavalos, 29-VIII-1980, O. Yano \& D. Andrade-Lima 2772 (SP191310); idem, Mata de Galileu, ca. 800-900 m alt., 11-VIII-1998, O. Yano et al. 25564 (SP322407); São Lourenço da Mata perto do Engenho São Bento, Mata de Tapacurá, perto do riacho na mata, 6-VIII-1986, O. Yano et al. 10337 (SP207011).

Dsitribuição no Brasil: AC, AL, AM, AP, BA, CE, ES, MT, PA, PE, RJ, RO, SC e SP.

Ocorre sobre folha e tronco, associada a Cololejeunea subcardiocarpa Tixier, Drepanolejeunea anoplantha (Spruce) Steph. e Leptolejeunea elliptica (Lehm. \& Lindenb.) Schiffn.

Diplasiolejeunea cavifolia Steph., Bot. Jahrb. Syst. 20: 318. 1895.

Ilustração: Reyes (1982), Tixier (1985, como D. brachyclada) e Gradstein \& Costa (2003).

Material examinado: BRASIL. Pernambuco: Rio Formoso, Córrego da Juçara, 11-IX-1984, O. Yano et al. 9107 (SP191730).

Distribuição no Brasil: AL, BA, CE, PE, PR, RJ, SC e SP.

Ocorre sobre folha.

* Diplasiolejeunea glaziovii Tixier, Bryophyt. Biblioth. 27: 397. 1985.

Figura 5

Ilustração adicional: Tixier (1985).
Material examinado: BRASIL. Pernambuco: Bonito, Reserva Municipal, ca. $8 \mathrm{~km}$ da cidade, ca. $720 \mathrm{~m}$ alt., 6-VIII-1998, O. Yano et al. 25435 (SP322290).

Distribuição no Brasil: citado para o Brasil, sem localidade.

Ocorre sobre folha. Esta espécie difere de D. cavifolia pois o primeiro dente é curvado, o segundo dente é mais largo no ápice e o ápice do lóbulo termina em uma célula.

Diplasiolejeunea pellucida (C.F.W. Meissn.) Schiffn. in Engler \& Prantl, Nat. Pflanzenfam. 1(3): 121. $1823 \equiv$ Jungermannia pellucida C.F.W. Meissn. in Linnaeus, Syst. Veg. ed. 16, 4(2): 325. 1827. Ilustração: Tixier (1985), Gradstein \& Costa (2003) e Zartman \& Ilkiu-Borges (2007).

Material examinado: BRASIL. BAHIA: Uruçuca, $6,2 \mathrm{~km} \mathrm{~N}$ of town of Serra Grande, ca. $40 \mathrm{~km} \mathrm{~N}$ of Ilhéus along coast, $14^{\circ} 26^{\prime} \mathrm{S}, 2^{\circ} 03^{\prime} \mathrm{W}$, wet tropical forest with small stream in ravine, 17-VII-1991, D.M. Vital \& W.R. Buck 20298 (NY, SP353935). Pernambuco: Recife, Mata de Dois Irmãos, perto da sede do reservatório, 3-VIII-1998, O. Yano et al. 25402 (SP322258).

Distribuição no Brasil: AL, AM, BA, ES, PA, PE, PR, RJ, RR, SC e SP.

Ocorre sobre tronco em decomposição.

Diplasiolejeunea rudolphiana Steph., Hedwigia 35: 79. 1896.

Ilustração: Schuster (1980), Gradstein \& Costa (2003) e Bastos (2004).

Material examinado: BRASIL. BAHIA: Porto Seguro, Monte Pascoal bei Itamaraju, $17^{\circ} 53^{\prime}$ 'S, 39²4’ W, Mata Atlântica am Weg zum Gipfel, 5-VII-1990, SchäferVerwimp \& Verwimp 12903A (hb Schäfer-Verwimp, SP398457); Ilhéus, Área do Centro de Pesquisas do Cacau, km 22 da rod. Ilhéus-Itabuna (BR-415), sobre Ingá, 16-VII-1991, D.M. Vital s.n. (SP373052). Pernambuco: Recife, mata do Horto Zoo-Botânico da Mata de Dois Irmãos, 6-IX-1984, O. Yano \& K.C. Pôrto 9039 (SP191663); idem, sobre Clitoria sp., 6-IX-1984, O. Yano \& K.C. Pôrto 9061 (SP191685); Bonito, Reserva Municipal, ca. $8 \mathrm{~km}$ da cidade, $20 \mathrm{~m}$ alt., 6-VIII-1998, O. Yano et al. 25425 (SP322280).

Distribuição no Brasil: AC, AM, BA, CE, ES, PB, PE, RJ, SC, SE e SP.

Ocorre sobre tronco. 


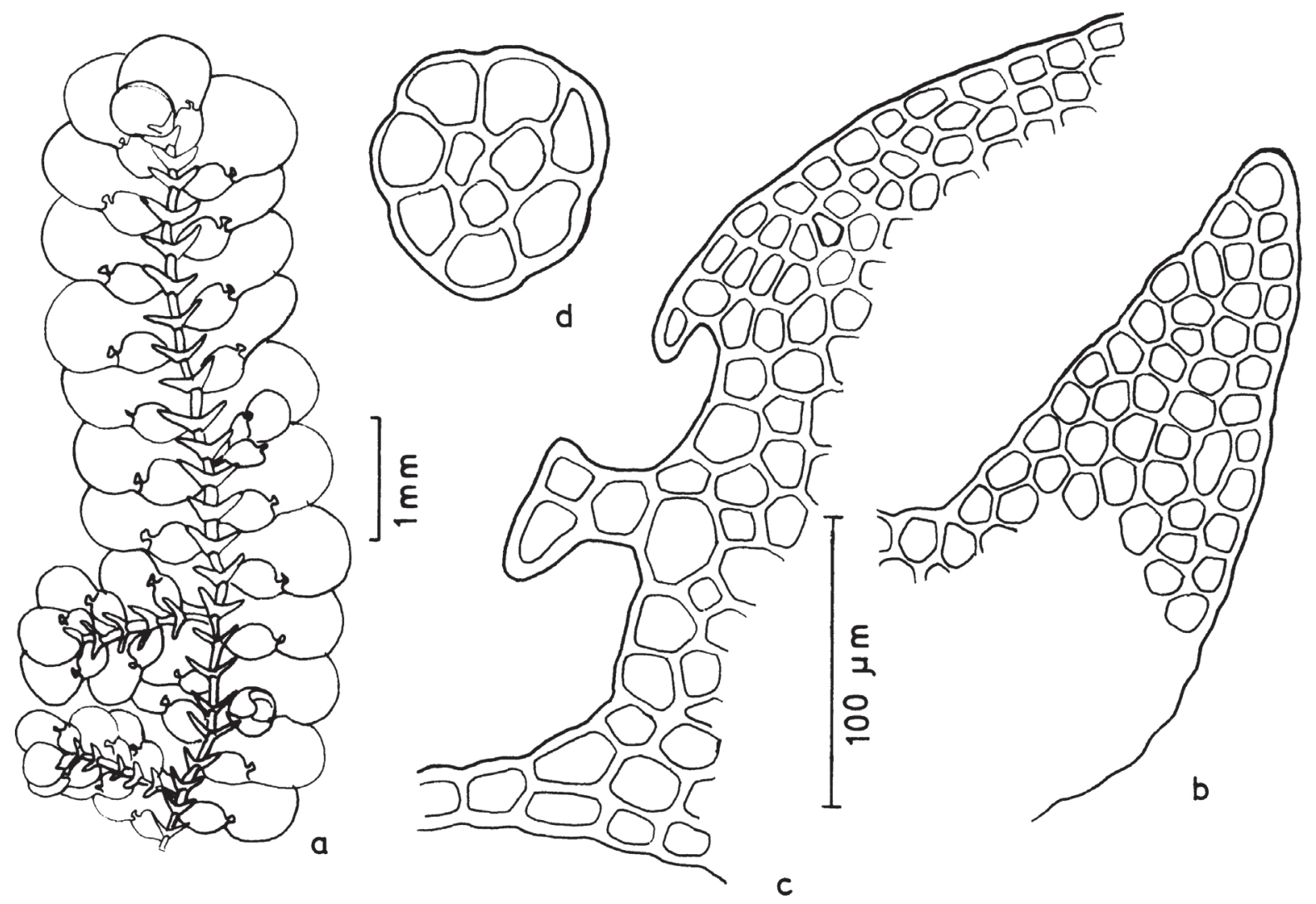

Figura 5. Diplasiolejeunea glaziovii. a. Aspecto geral do gametófito. b. Anfigastro. c. Detalhe do lóbulo. d. Secção transversal do caulídio.

Figure 5. Diplasiolejeunea glaziovii. a. General aspect of the gametophyte. b. Underleaf. c. Lobe detail. d. Cross section of stem.

* Drepanolejeunea anoplantha (Spruce) Steph., Sp.

Hepat. 5: 325. 1913 ELejeunea anoplantha Spruce, Trans. \& Proc. Bot. Soc. Edinburgh 15: 189. 1884. Ilustração: Bischler (1964), Gradstein \& Costa (2003) e Bastos (2004).

Material examinado: BRASIL. Pernambuco: Taquaritinga do Norte, ao lado da microonda, 24-VIII-1980, O. Yano \& D. Andrade-Lima 2638 (SP191196).

Distribuição no Brasil: AM, BA, CE, ES, RJ, RS e SP.

Ocorre em solo, associada a Anoplolejeunea conferta (Meissn. ex Spreng.) A. Evans, Diplasiolejeunea brunnea Steph. e Cheilolejeunea xanthocarpa (Lehm. \& Lindenb.) Malombe.

* Drepanolejeunea araucariae Steph., Hedwigia 35:

80. 1896.

Ilustração: Bischler (1964), Gradstein \& Costa (2003) e Bastos (2004).
Material examinado: BRASIL. Pernambuco: Rio Formoso, Estação Experimental de Saltinho, 11-IX-1984, O. Yano et al. 9120 (SP191743).

Distribuição no Brasil: AP, BA, MG, RJ, RS, SC e SP.

Ocorre sobre tronco em decomposição.

Drepanolejeunea bidens Steph., Hedwigia 29: 71. 1890.

Ilustração: Evans (1903a) e Bischler (1964).

Material examinado: BRASIL. Pernambuco: Recife, Mata de Dois Irmãos, perto da sede do reservatório, 3-VIII-1998, O. Yano et al. 25406 (SP322261); Bonito, Reserva Municipal, ca. $8 \mathrm{~km}$ da cidade, ca. $720 \mathrm{~m}$ alt., sobre liana, 6-VIII-1998, O. Yano et al. 25442 (SP322297).

Distribuição no Brasil: AL, AM, MG, PB, PE, RR e SP. Ocorre sobre tronco ou tronco em decomposição. 
* Drepanolejeunea dissitifolia A. Evans, Bull. Torrey Bot. Club 30: 28. 1903.

Ilustração: Evans (1903a), Bischler (1964) e Bastos (2004).

Material examinado: BRASIL. Pernambuco: São Lourenço da Mata, Engenho São Bento, Estação Ecológica de Tapacurá, Mata Toró-Cuieira, perto do riacho, 26-VIII-1980, O. Yano \& D. Andrade-Lima 2661 p.p. (SP191216).

Distribuição no Brasil: BA.

Ocorre sobre folha, associada a Cololejeunea obliqua (Nees \& Mont.) Schiffn. e Colura ulei Jovet-Ast.

* Frullanoides corticalis (Lehm. \& Lindenb.) van Slageren,Meded.Bot.Mus.Herb.Rijks Univ.Utrecht 544: 84. 1985 三Jungermannia corticalis Lehm. \& Lindenb. in Lehmann, Nov. Stirp. Pug. 4: 50.1832. Ilustração: Schuster (1980, como Brachiolejeunea corticalis), van Slageren (1985) e Yano \& Peralta (2008).

Material examinado: BRASIL. SERGIPE: Itabaiana, along atemporary river Tábora, 29-I-1974,D.M. Vital 2870 p.p. (SP88376).

Distribuição no Brasil: BA, MG, MT, RJ, RR e SP.

Ocorre sobre tronco, associada a Frullania ecklonii (Spreng.) Gottsche et al. e Microlejeunea bullata (Taylor) Steph.

Frullanoides liebmanniana (Lindenb. \& Gottsche) van Slageren, Meded. Bot. Mus. Herb. Rijks Univ. Utrecht 544: 102. $1985 \equiv$ Phragmicoma liebmanniana Lindenb. \& Gottsche in Gottsche et al., Syn. Hepat.: 744. 1847.

Ilustração: Van Slageren (1985) e Yano \& Peralta (2008).

Material examinado: BRASIL. SERgIPE: Itabaiana, rio Tábora, 29-I-1974, D.M. Vital 2869 (SP88375).

Distribuição no Brasil: AC, BA, CE, ES, GO, MG, MS, MT, PE, PR e SE.

Ocorre sobre tronco.

Frullanoides tristis (Steph.) van Slageren, Meded. Bot. Mus. Herb. Rijks Univ. Utrecht 544: 110. 1985 $\equiv$ Lejeunea tristis Steph., Hedwigia 29: 8. 1890.

Ilustração: Van Slageren (1985), Bastos (2004) e Yano \& Peralta (2008).

Material examinado: BRASIL. Pernambuco:
Taquaritinga do Norte, Morro Cafundó, sobre Lauraceae, 23-VIII-1980, O. Yano \& D. Andrade-Lima 2626 (SP191186); Triunfo, Engenho Júlio Ramos, 7-IX-1980, O. Yano \& D. AndradeLima 2989 (SP191488); Caruaru, Brejo dos Cavalos, ca. $780 \mathrm{~m}$ alt., 11-VIII-1998, O. Yano et al. 25539 (SP322382).

Distribuição no Brasil: BA, ES, GO, PE, SE e SP.

Ocorre sobre tronco, associada a Macrocoma orthotrichoides (Raddi) Wijk \& Margad., Macromitrium richardii Schwägr. e Schoenobryum concavifolium (Griff.) Gangulee.

Harpalejeunea stricta (Lindenb. \& Gottsche) Steph., Hedwigia 27: 291. 1888 三 Lejeunea stricta Lindenb.\& Gottsche in Gottsche et al., Syn. Hepat.: 756. 1847.

Ilustração: Ilkiu-Borges (2000), Gradstein \& Costa (2003) e Bastos (2004).

Material examinado: BRASIL. BAHIA: Uruçuca, $6,2 \mathrm{~km} \mathrm{~N}$ of town of Serra Grande, ca. $40 \mathrm{~km} \mathrm{~N}$ of Ilhéus along coast, $14^{\circ} 26^{\prime} \mathrm{S}, 39^{\circ} 03^{\prime} \mathrm{W}$, wet tropical forest with small stream in ravine, 17-VII-1991, D.M. Vital \& W.R. Buck 20309 (NY, SP353942). Pernambuco: Inajá, Serra Negra, 6-IX-1980, O. Yano \& D. Andrade-Lima 2932 (SP191441).

Distribuição no Brasil: AL, BA, CE, PA, PE, SC e SP.

Ocorre sobre tronco, associada a Lejeunea tapajosensis Spruce, Cheilolejeunea xanthocarpa (Lehm. \& Lindenb.) Malombe e Omphalanthus filiformes (Sw.) Nees.

Harpalejeunea uncinata Steph., Hedwigia 35: 97. 1896.

Ilustração: Evans (1903b).

Material examinado: BRASIL. Pernambuco: Inajá, Serra Negra, 6-IX-1980, O. Yano \& D. Andrade-Lima 2974 (SP191475); Bonito, Reserva Municipal, ca. $8 \mathrm{~km}$ da cidade, ca. $720 \mathrm{~m}$ alt., base do tronco, 6-VIII-1998, O. Yano et al. 25454 (SP322307); idem, 6-VIII-1998, O. Yano et al. 25464 (SP322317); Brejo da Madre de Deus, Reserva Bituri Grande, ca. $950 \mathrm{~m}$ alt., 10-VIII-1998, O. Yano et al. 25509 (SP322353).

Distribuição no Brasil: BA, PE e RJ.

Ocorre sobre tronco. 
Lejeunea adpressa Nees in Gottsche, Lindenb. \& Nees, Syn. Hepat.: 380. 1845.

Figura 6

Ilustração adicional: Schuster (1980, como Lejeunea caespitosa) e Reiner-Drehwald (2009).

Material examinado: BRASIL. Pernambuco: Taquaritinga do Norte, sobre Araceae na mata ao lado da microonda, 24-VIII-1980, O. Yano \& D. Andrade-Lima 2644 (SP191202); São Lourenço da Mata, Engenho São Bento, Estação Ecológica de Tapacurá, Mata Toró-Cuieira, 26-VIII-1980, O. Yano \& D. Andrade-Lima 2669 (SP191223); Cabo, Estação de Gurjaú, mata úmida ao redor da lagoa, 14-IX-1984, O. Yano \& K.C. Pôrto 9170 (SP191792).

Distribuição no Brasil: AC, AL, BA, CE, ES, MS, MT, PA, PE, RJ, RR, SC, SE e SP.
Ocorre sobre folha, tronco e tronco em decomposição, associada a Ceratolejeunea laetefusca (Austin) R.M. Schust.

Lejeunea calcicola R.M. Schust., J. Elisha Mitchell Sci. Soc. 75(2): 404. 1957.

Ilustração: Schuster (1957) e Bastos (2004).

Material examinado: BRASIL. BAHIA: Ilhéus, Centro de Pesquisas do Cacau, km 22 on BR-415 between Ilhéus and Itabuna, $14^{\circ} 50^{\prime} \mathrm{S}, 39^{\circ} 13^{\prime} \mathrm{W}$, Parque Zoobotânico, cacau plantation, 15-VII-1991, D.M. Vital \& W.R. Buck 20164 (NY, SP353863); Rio de Contas, estrada para Jussiape, 26-X-1994, S.R. Visnadi \& D.M. Vital 2594 (SP372883).

Distribuição no Brasil: BA, MT e SP.

Ocorre sobre tronco e muro.
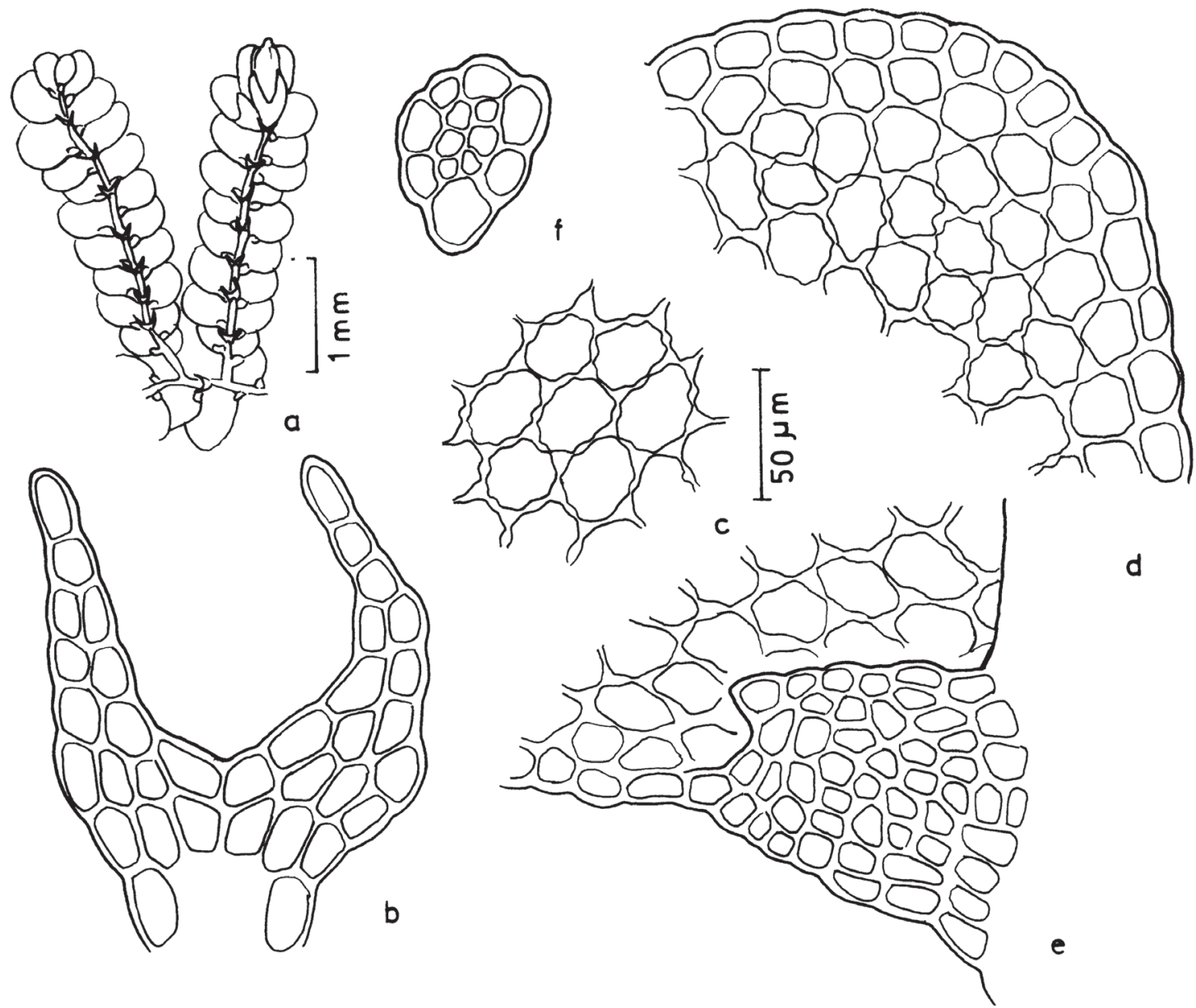

Figura 6. Lejeunea adpressa. a. Aspecto geral do gametófito. b. Anfigastro. c. Células da região mediana do lobo. d. Células da margem do lobo. e. Detalhe do lóbulo. f. Secção transversal do caulídio.

Figure 6. Lejeunea adpressa. a. General aspect of the gametophyte. b. Underleaf. c. leaf cells. d. Marginal cells of the leaf. e. Lobe detail. f. Cross section of stem. 
* Lejeunea caulicalyx (Steph.) E. Reiner \& Goda, J. Hattori Bot. Lab. 89: 13. $2000 \equiv$ Crossotolejeunea caulicalyx Steph., Sp. Hepat. 5: 237. 1913.

Ilustração: Schuster(1980), Bastos (2004), ambos como L. glaucescens e Reiner-Drehwald \& Goda (2000).

Material examinado: BRASIL. AlagoAs: São Miguel dos Campos, along the high-road BR-101, km 60, 18-I-1972, D.M. Vital 1959 (SP87713); idem, Fazenda Pau Brasil, 28-X-1980, D. Andrade-Lima 80-6653 (SP191535). Pernambuco: Recife, Mata de Dois Irmãos, área do reservatório, 3-VIII-1998, O. Yano et al. 25394 (SP322250); idem, 3-VIII-1998, O. Yano et al. 25401 (SP322257); idem, 3-VIII-1998, O. Yano et al. 25413 (SP322268); Bonito, Cachoeira do Oriente, ca. $19 \mathrm{~km}$ da cidade, ca. $500 \mathrm{~m}$ alt., 6-VIII-1998, O. Yano et al. 25491 (SP322337); idem, 6-VIII-1998, O. Yano et al. 25487 (SP322333); Caruaru, Brejo dos Cavalos, Mata de Galileu, ca. 800-900 m alt., sobre liana, 11-VIII-1998, O. Yano et al. 25554 (SP322397); São Vicente Ferrer, Complexo da Serra do Mascarenhas, Mata do Estado, 7³5'S, 35³0'W, ca. 600-650 m alt., 16-IX-1998, M.R. Pietrobom-Silva 4427 (SP352759).

Distribuição no Brasil: AC, BA, CE, DF, ES, MS, MT, PE, PR, RJ, RR, SC e SP.

Ocorre sobre rocha, tronco e tronco em decomposição, associada a Prionolejeunea scaberula (Spruce) Steph.

* Lejeunea controversa Gottsche in Gottsche \& Raben., Hepat. Eur. Exsicc.: 556. 1873.

Ilustração: Reiner-Drehwald \& Goda (2000), Bastos (2004) e Zartman \& Ilkiu-Borges (2007).

Material examinado: BRASIL. Pernambuco: Quipapá, Engenho Brejinho, km 31 da BR-423, perto da cachoeira grande, 2-IX-1980, O. Yano \& J.Z. Brito 2865 (SP191385); Rio Formoso, Córrego da Juçara, margem do córrego, 11-IX-1984, O. Yano et al. 9090 (SP191713).

Distribuição no Brasil: AC, AL, AM, BA, MS, PA e SP.

Ocorre sobre rocha.

Lejeunea deplanata Nees in Gottsche, Lindenb. \& Nees, Syn. Hepat.: 368. 1845.

Ilustração: Gradstein et al. (2001), Bastos (2004) e Yano \& Peralta (2008), todos como Lejeunea maxonii, Reiner-Drehwald (2010).
Material examinado: BRASIL. BAHIA: Santa Bárbara, ca. 45 km de Feira de Santana na BR-116, 23-X-1990, O. Yano \& J.O. Pereira 15079 (SP231189). Pernambuco: Inajá, Serra Negra, sobre Terminalia sp., transição caatinga-mata, 6-IX-1980, O. Yano \& D. Andrade-Lima 2919 (SP191431); idem, 6-IX-1980, O. Yano \& D. Andrade-Lima 2964 (SP191465); Triunfo, Engenho Júlio Ramos, 7-IX-1980, O. Yano \& D. Andrade-Lima 2983 (SP191482); Cabo, Estação de Gurjaú, 14-IX-1984, O. Yano \& K.C. Pôrto 9175 (SP191797); São Lourenço da Mata, Mata do Toró, 21-XII-1984, O. Yano et al. 9309 (SP191929); idem, 21-XII-1984, O. Yano et al. 9311 (SP191931); São Vicente Ferrer, complexo da Serra de Mascarenhas, Mata do Estado, 35³0'S-7³5'W, ca. 600-650 m alt., 5-X-1998, M.R. Pietrobom-Silva 4452 (SP352765).

Distribuição no Brasil: AM, BA, CE, ES, GO, MS, MT, PB, RJ e SP.

Ocorre sobre rocha, tronco e tronco em decomposição, associada a Frullania caulisequa (Nees) Nees.

Lejeunea elliottii Spruce, J. Linn. Soc., Bot. 30: 346. 1895.

Ilustração: Reiner-Drehwald \& Goda (2000), Bastos (2004) e Bastos \& Yano (2004).

Material examinado: BRASIL. BAHIA: Ilhéus, $5 \mathrm{~km} \mathrm{~S}$ of Ilhéus on road to Olivença, $14^{\circ} 52^{\prime} \mathrm{S}$, 3902'W, restinga, 14-VII-1991, D.M. Vital \& W.R. Buck 20085 p.p. (NY, SP353827).

Distribuição no Brasil: AL e BA.

Ocorre sobre tronco, associada a Frullania caulisequa (Nees) Nees e Microlejeunea epiphylla Bischler.

Lejeunea flava (Sw.) Nees, Naturgesch. Eur. Leberm. 3: 277.1838 E Jungermannia flava Sw., Prodr. (Swartz): 144. 1788.

Ilustração: Reiner-Drehwald (2000), Gradstein \& Costa (2003) e Yano \& Peralta (2008).

Material examinado: BRASIL. BAhia: Ilhéus, Área do Centro de Pesquisas do Cacau, km 22 da rod. Ilhéus-Itabuna (BR-415), sobre Theobroma cacao L., 15-VII-1991, D.M. Vital s.n. (SP373033). Pernambuco: Cabo, Engenho Liberdade, sobre Byrsonima sericea, margem da estrada, 23-VIII-1980, O. Yano \& D. Andrade-Lima 2556 (SP191130); idem, 
Estação de Gurjaú, sobre Myrtaceae, 14-IX-1984, O. Yano \& K.C. Pôrto 9152 (SP191774); Recife, Bosque da Univ. Federal de PE, sobre Jambosa sp., 27-VIII-1980, O. Yano 2687 (SP191239); idem, sítio Pitiguari, sobre cajueiro, 30-VIII-1980, O. Yano \& D. Andrade-Lima 2821 (SP191348); idem, sobre mangueira, 30-VIII-1980, O. Yano \& D. Andrade-Lima 2826 (SP191352); idem, 30-VIII-1980, O. Yano \& D. Andrade-Lima 2829 (SP191355); Altinho, Fazenda Taboca, 29-VIII-1980, O. Yano \& D. Andrade-Lima 2795 (SP191324); Inajá, Serra Negra, sobre Caesalpinea leucostachia, 6-IX-1980, O. Yano \& D. Andrade-Lima 2969 (SP191470); São Lourenço da Mata, Tapacurá, 4-II-1988, O. Yano \& G. Mariz 11257 (SP222201); Bonito, Cachoeira do Oriente, ca. $19 \mathrm{~km}$ da cidade, ca. $500 \mathrm{~m}$ alt., base do tronco, 6-VIII-1998, O. Yano et al. 25488 (SP322334).

Distribuição no Brasil: AC, AL, AM, BA, CE, DF, ES, GO, MG, MS, MT, PA, PB, PE, PR, RJ, RR, RS, SC, SE, SP e TO.

Ocorre sobre tronco, associada a Lejeunea laetevirens Nees \& Mont. e Microlejeunea epiphylla Bischler.

* Lejeunea grossiretis (Steph.) E. Reiner \& Goda, J. Hattori Bot. Lab. 89: 27. 2000 ECrossotolejeunea grossiretis Steph., Hedwigia 35: 75. 1896.

Ilustração: Reiner-Drehwald \& Goda (2000) e Bastos (2004).

Material examinado: BRASIL. Pernambuco: Altinho, Fazenda Taboca, 29-VIII-1980, O. Yano \& D. Andrade-Lima 2786 (SP191316).

Distribuição no Brasil: AL, BA, ES, MG, RJ e SP.

Ocorre sobre tronco em decomposição.

* Lejeunea huctumalcensis Lindenb. \& Gottsche in Gottsche et al., Syn. Hepat.: 762. 1847.

Ilustração: Dauphin-López (2003), Bastos (2004), ambos como Ceratolejeunea dussiana e Reiner-Drehwald \& Ilkiu-Borges (2007).

Material examinado: BRASIL. Pernambuco: Bonito, Reserva Municipal, ca. $8 \mathrm{~km}$ da cidade, ca. $720 \mathrm{~m}$ alt., 6-VIII-1998, O. Yano et al. 25443 (SP322298).

Distribuição no Brasil: AL, AM, BA, PA e SP.

Ocorre sobre tronco em decomposição.
Lejeunea laetevirens Nees \& Mont. in Ramón de la Sagra, Hist. Phys. Cuba, Bot., P1. Cell. 9: 469. 1842.

Ilustração: Reiner-Drehwald (2000), Bastos (2004) e Yano \& Peralta (2008).

Material examinado: BRASIL. BAHIA: Salvador, the Jardim Zoológico de Salvador, 16-I-1972, D.M. Vital 1952 (SP87711); São Sebastião do Passé, Lamarão do Passé, 13-XI-1982, I.C. Britto 14 (SP389570); Ilhéus, ca. $3 \mathrm{~km} \mathrm{~W}$ of Ilhéus on road to Itabuna, BR-415, $14^{\circ} 50^{\prime} \mathrm{S}, 39^{\circ} 04^{\prime} \mathrm{W}$, mangrove swamp of Laguncularia racemosa and Acrostichum, 16-VII-1991, D.M. Vital \& W.R. Buck 20207 (NY, SP353896). Pernambuco: Recife, Mata de Dois Irmãos, base do tronco, 3-VIII-1998, O. Yano et al. 25398 (SP322254); idem, 3-VIII-1998, O. Yano et al. 25400 (SP322256); idem, quintal do Hotel Galicia, Bairro de Boa Viagem, sobre mangueira, 2-II-1976, D.M. Vital 5450 (SP126997); idem, Praça de Parnamirim, sobre Cassia javanica, 2-III-1980, K.C. Pôrto s.n. (SP134039); idem, Bosque da Univ. Federal Rural de Pernambuco, sobre Jambosa sp., 27-VIII-1980, O. Yano 2686 (SP191238); idem, tronco de jaqueira, 26-VIII-1980, O. Yano 2693 (SP191243); idem, Horto Zoo-Botânico da Mata de Dois Irmãos, 6-IX-1984, O. Yano \& K.C. Pôrto 9044 (SP191668); idem, estação de Gurjaú, base do tronco, 14-IX-1984, O. Yano \& K.C. Pôrto 9157 (SP191779); idem, 14-IX-1984, O. Yano \& K.C. Pôrto 9184 (SP191806); São Lourenço da Mata, mata do Toró, 21-XII-1984, O. Yano et al. 9310 (SP191930); idem, 21-XII-1984, O. Yano et al. 9321 (SP191940); Cabo, Engenho Liberdade, sobre Byrsonima sericea, 23-VIII-1980, O. Yano \& D. Andrade-Lima 2557 (SP191131); Olinda, Praia do Carmo, sobre leguminosa, 26-I-1981, O. Yano 3883 (SP173916); Caruaru, Brejo dos Cavalos, ca. $780 \mathrm{~m}$ alt., 11-VIII-1998, O. Yano et al. 25541 (SP322384); Fernando de Noronha, Morro da Madeira em frente a Ilha Cabeluda, 17-XI-1989, O. Yano \& D.P. Costa 13591 (SP228508); idem, 17-XI-1989, D.P. Costa \& O. Yano 1025 (SP228596); idem, 17-XI-1989, D.P. Costa \& O. Yano 1026 (SP228597); idem, 17-XI-1989, D.P. Costa \& O. Yano 1031 (SP228602); idem, 20-XI-1989, D.P. Costa \& O. Yano 1024 (SP228595); idem, 20-XI-1989, D.P. Costa \& O. Yano 1030 (SP228601); idem, 17-XI-1989, D.P. Costa \& O. Yano 1035 (SP228606); idem, Ponta da Sapata, 20-XI-1989, O. Yano \& D.P. Costa 13628 (SP228519); idem, 20-XI-1989, 
O. Yano \& D.P. Costa 13635 (SP228526); idem, 20-XI-1989, O. Yano \& D.P. Costa 13636 (SP228527); idem, sobre Erythrina, 20-XI-1989, O. Yano \& D.P. Costa 13629 (SP228520); idem, sobre Tabebuia, 20-XI-1989, O. Yano \& D.P. Costa 13630 (SP228521); idem, 20-XI-1989, D.P. Costa \& O. Yano 1048 (SP228619); idem, sobre cajueiro, 20-XI-1989, D.P. Costa \& O. Yano 1046 (SP228617); idem, 20-XI-1989, D.P. Costa \& O. Yano 1047 (SP228618); idem, Morro do Pico, 22-XI-1989, O. Yano \& D.P. Costa 13656 (SP228540); 22-XI-1989, O. Yano \& D.P. Costa 13657 (SP228541); idem, ca. $250 \mathrm{~m}$ alt., junto da escadaria do pico, 25-XI-1989, O. Yano \& D.P. Costa 13670 (SP228545).

Distribuição no Brasil: AC, AL, AM, AP, BA, CE, DF, ES, FN, GO, MG, MS, MT, PA, PB, PE, RJ, RR, $\mathrm{SC}, \mathrm{SE}$ e SP.

Ocorre sobre rocha e tronco, associada a Cheilolejeunea rigidula (Nees \& Mont.) R.M. Schust., C. trifaria (Reinw. et al.) Mizut., Lejeunea flava (Sw.) Nees, Pycnolejeunea macroloba (Nees \& Mont.) Schiffn., Rectolejeunea berteroana (Gottsche ex Steph.) A. Evans e Taxithelium planum (Brid.) Mitt.

* Lejeunea minutiloba A. Evans, Bull. Torrey Bot. Club 44: 525. 1917.

Ilustração: Schuster (1957) e Bastos (2004).

Material examinado: BRASIL. BAHIA: Ilhéus, Centro de Pesquisas do Cacau, km 22 on BR-415 between Ilhéus and Itabuna, 1450'S, 39 $13^{\circ} \mathrm{W}$, Parque Zoobotânico, cacau plantation, 15-VII-1991, D.M. Vital \& W.R. Buck 20155 (NY, SP353854); idem, 15-VII-1991, D.M. Vital \& W.R. Buck 20160 (NY, SP353859). Pernambuco: São Lourenço da Mata, Engenho São Bento, Estação Ecológica de Tapacurá, Mata Toró-Cuieira, sobre tronco podre caído na mata úmida, 26-VIII-1980, O. Yano \& D. Andrade-Lima 2670 (SP191224); Quipapá, Engenho Brejinho, km 31 da BR-423, sobre pedras graníticas perto da cachoeira, 2-IX-1980, O. Yano \& J.Z. Brito 2889 (SP191405).

Distribuição no Brasil: BA, CE, ES, MS, PR, RJ e SP.

Ocorre sobre tronco.

* Lejeunea oligoclada Spruce, Bull. Soc. Bot. France 36(suppl.): 199. 1889.

Ilustração: Reiner-Drehwald \& Schwäfer-Verwimp (2008).
Material examinado: BRASIL. Pernambuco: Inajá, Serra Negra, sobre Terminalia sp., 6-IX-1980, O. Yano \& D. Andrade-Lima 2963 (SP191464).

Distribuição no Brasil: BA, ES, MG, RJ, SC e SP.

Ocorre sobre tronco.

Lejeunea perpapillosa Reiner-Drehwald \& Pôrto, Nova Hedwigia 85(3-4): 542. 2007.

Figura 7

Ilustração adicional: Reiner-Drehwald \& Pôrto (2007).

Material examinado: BRASIL. BAHIA: Uruçuca, $6,2 \mathrm{~km} \mathrm{~N}$ of town of Serra Grande, ca. $40 \mathrm{~km} \mathrm{~N}$ of Ilhéus along coast, $14^{\circ} 26^{\prime} \mathrm{S}, 39^{\circ} 03^{\prime} \mathrm{W}$, wet tropical forest with small stream in ravine, 17-VII-1991, D.M. Vital \& W.R. Buck 20290 (NY, SP353930).

Distribuição no Brasil: BA e PE.

Ocorre sobre tronco.
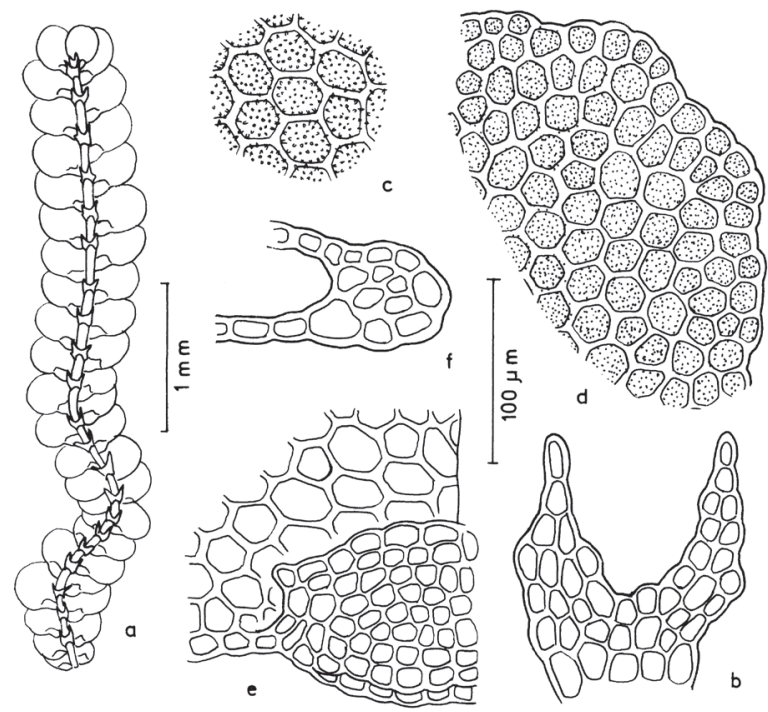

Figura 7. Lejeunea perpapillosa. a. Aspecto geral do gametófito. b. Anfigastro. c. Células da região mediana do lobo. d. Células da margem do lobo. e. Detalhe do lóbulo. f. Secção transversal do caulídio.

Figure 7. Lejeunea perpapillosa. a. General aspect of the gametophyte. b. underleaf. c. Leaf cells. d. Marginal cells of the leaf. e. Lobe detail. f. Cross section of stem. 
* Lejeunea phyllobola Nees \& Mont. in Ramón de la Sagra, Hist. Phys. Cuba, Bot., Pl. Cell. 9: 471. 1842. Ilustração: Reiner-Drehwald (2000), Bastos (2004) e Yano \& Peralta (2008).

Material examinado: BRASIL. Alagoas: São Miguel dos Campos, along the high-road BR-101, km 60, 18-I-1972, D.M. Vital 1960 (SP87714); idem, 18-I-1972, D.M. Vital 1961 (SP87715); idem, Fazenda Pau Brasil, 28-X-1980, D. Andrade-Lima 80-6651 (SP191533). BAHIA: Itabuna, plantações de cacau da CEPLAC, nos bordos do canal de drenagem, 24-I-1980, D.M. Vital 8710 (SP133373). Pernambuco: São Lourenço da Mata, Engenho São Bento, Estação Ecológica de Tapacurá, Mata Toró-Cuieira, 26-VIII-1980, O. Yano \& D. Andrade-Lima 2672 (SP191226); idem, Mata do Toró, 21-XII-1984, O. Yano et al. 9323 (SP191942); Altinho, Fazenda Taboca, 29-VIII-1980, O. Yano \& D. Andrade-Lima 2789 (SP191319); Quipapá, Engenho Brejinho, km 31 da BR-423, 2-IX-1980, O. Yano \& J.Z. Brito 2893 (SP191409); Triunfo, Engenho Júlio Ramos, 7-IX-1980, O. Yano \& D. Andrade-Lima 2991 (SP191490); Recife, Mata de Dois Irmãos, 25-X-1980, D. Andrade-Lima 80-6629 (SP191519); Formoso, Córrego da Juçara, 11-IX-1984, O. Yano et al. 9076 (SP191699); Cabo, Estação de Gurjaú, 14-IX-1984, O. Yano \& K.C. Pôrto 9183 (SP191805); mun . Inajá, Serra Negra, sobre Pisonia sp., 6-IX-1980, O. Yano \& D. Andrade-Lima 2943 p.p. (SP191450).

Distriuição no Brasil: AC, AL, AM, BA, CE, DF, ES, GO, MS, MT, PA, RJ, RS, SC e SP.

Ocorre sobre rocha, tronco e tronco em decomposição.

* Lejeunea raddiana Lindenb. in Gottsche et al., Syn. Hepat.: 342. 1845.

Ilustração: Reiner-Drehwald \& Goda (2000) e Gradstein \& Costa (2003).

Material examinado: BRASIL. AlagoAs: Marechal Deodoro auf morschem Holz am Rande eine Sekundärwaldes an der BR-101 bei km 121, 941'S, 36²' 'W, 15-VII-1987, Schäfer-Verwimp \& Verwimp 8739 (hb. Schäfer-Verwimp, SP388359).

Distribuição no Brasil: MG, PA, RJ, RS, SC e SP.

Ocorre sobre tronco.

* Lejeunea rionegrensis Spruce, Trans. \& Proc. Bot. Soc. Edinburgh 15: 579. 1885.

Figura 8
Ilustração adicional: Reiner-Drehwald \& SchäferVerwimp (2008).

Material examinado: BRASIL. Pernambuco: Inajá, Serra Negra, 6-IX-1980, O. Yano \& D.Andrade-Lima 2960 (SP191461).

Distribuição no Brasil: AM, MG, RO e SP.

Ocorre sobre tronco.

Lejeunea ruthii (A. Evans) R.M. Schust., J. Hattori Bot. Lab. 25: 23. $1962 \equiv$ Microlejeunea ruthii

A. Evans, Mem. Torrey Bot. Club 8: 161. 1902. Ilustração: Schuster (1980) e Bastos (2004).

Material examinado: BRASIL. BAhIA: Ilhéus, Morro de Pernambuco, small peninsula projecting into the ocean, $14^{\circ} 50^{\prime} \mathrm{S}, 39^{\circ} 02^{\prime} \mathrm{W}$, rocky hillsides with Cocos nucifera, 13-VII-1991, D.M. Vital \& W.R. Buck 20062 (NY, SP353810).

Distribuição no Brasil: BA e SP.

Ocorre sobre tronco.

* Lejeunea setiloba Spruce, Trans. \& Proc. Bot. Soc. Edinburgh 15: 281. 1884.

Ilustração: Reiner-Drehwald (2000).

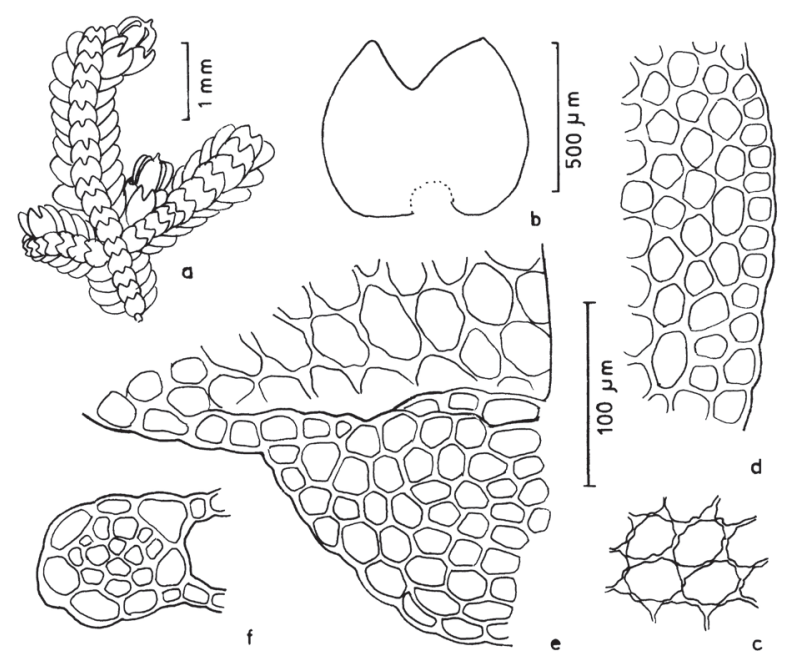

Figura 8. Lejeunea rionegrensis. a. Aspecto geral do gametófito. b. Anfigastro. c. Células da região mediana do lobo. d. Células da margem do lobo. e. Detalhe do lóbulo. f. Secção transversal do caulídio.

Figure 8. Lejeunea rionegrensis. a. General aspect of the gametophyte. b. Underleaf. c. Leaf cells. d. Marginal cells of the leaf. e. Lobe detail. f. Cross section of stem. 
Material examinado: BRASIL. BAHIA: Santa Bárbara, ca. $45 \mathrm{~km}$ de Feira de Santana na BR-116, base do tronco, 23-X-1990, O. Yano \& J.O. Pereira 15073 (SP231186); idem, 23-X-1990, O. Yano \& J.O. Pereira 15104 (SP231200). Pernambuco: Timbaúba, Complexo da Serra do Mascarenhas, Usina Cruangi, Engenho Água Azul, 7³7'6”'S, 35²3'28,9''W, ca. 304-394 m alt., 27-V-2001, M.R. Pietrobom 5230 (SP403021).

Distribuição no Brasil: AM, CE, MS e SP.

Ocorre sobre rocha e tronco.

Lejeunea tapajosensis Spruce, Trans. \& Proc. Bot. Soc. Edinburgh 15: 223. 1884.

Ilustração: Reiner-Drehwald (2000) e Bastos (2004).

Material examinado:BRASIL.BAHIA:Uruçuca, $6,2 \mathrm{kmN}$ of town of Serra Grande, ca. $40 \mathrm{~km}$ N of Ilhéus along coast, $14^{\circ} 26^{\prime} \mathrm{S}, 39^{\circ} 03^{\prime} \mathrm{W}$, wet tropical forest with small stream in ravine, 17-VII-1991, D.M. Vital \& W.R. Buck 20316 (NY, SP353947). Pernambuco: São Lourenço da Mata, Mata do Toró, 21-XII-1984, O. Yano et al. 9315 (SP191934); idem, 21-XII-1984, O. Yano et al. 9318 (SP191937); idem, 21-XII-1984, O. Yano et al. 9319 (SP191938); idem, base do tronco, 21-XII-1984, O. Yano et al. 9322 (SP191941); idem, 21-XII-1984, O. Yano et al. 9324 (SP191943); idem, 4-II-1988, O. Yano \& G. Mariz 11259 (SP222203); idem, Engenho São Bento, 6-VIII-1986, O. Yano et al. 10319 (SP206993); idem, 6-VIII1986, O. Yano et al. 10321 (SP206995); idem, Estação Ecológica de Tapacurá, Mata Toró-Cuieira, 26-VIII-1980, O. Yano \& D. Andrade-Lima 2667 (SP191221); Quipapá, Engenho Brejinho, km 31 da BR-423, 2-IX-1980, O. Yano \& J.Z. Brito 2891 (SP191407); Rio Formoso, Córrego da Juçara, sobre Melastomataceae, 11-IX-1984, O. Yano et al. 9096 (SP191719); idem, Estação Experimental de Saltinho, 11-IX-1984, O. Yano et al. 9138 (SP191760); idem, 11-IX-1984, O. Yano et al. 9140 (SP191762); Cabo, Estação de Gurjaú, 14-IX-1984, O. Yano \& K.C. Pôrto 9162 p.p. (SP191784).

Distribuição no Brasil: AC, AL, AM, BA, ES, PA, PE e SP.

Ocorre sobre rocha, folha e tronco, associada a Archilejeunea auberiana (Mont.) A. Evans, Harpalejeunea stricta (Lindenb. \& Gottsche) Steph., Isopterygium tenerifolium Mitt. e Cheilolejeunea xanthocarpa (Lehm. \& Lindenb.) Malombe.
Lejeunea trinitensis Lindenb. in Gottsche et al., Syn. Hepat:: 381. 1845.

Ilustração: Reiner-Drehwald (2000) e Gradstein \& Costa (2003) e Yano \& Peralta (2008).

Material examinado: BRASIL. BAHIA: Rio de Contas, estrada para Jussiape, tronco de Rubiaceae, 26-X-1994, S.R. Visnadi \& D.M. Vital 2590 (SP372879). SERGIPE: Itabaiana, along a temporary river Tábora, 29-I-1974, D.M. Vital 2868 (SP88374).

Distribuição no Brasil: AC, AM, BA, CE, ES, GO, MG, MS, MT, PA, PE, PR, RJ, SE e SP.

Ocorre sobre tronco, associada a Leptogium cyanescens (Rabenh.) Koerber.

Lepidolejeunea involuta (Gottsche) Grolle, J. Hattori Bot. Lab. 55: 504. 1984 E Lejeunea involuta Gottsche in Gottsche et al., Syn. Hepat.: 350. 1845. Ilustração: Piippo (1986), Gradstein \& Costa (2003), Bastos (2004) e Zartman \& Ilkiu-Borges (2007).

Material examinado: BRASIL. Pernambuco: Altinho, Fazenda Taboca, 29-VIII-1980, O. Yano \& D. Andrade-Lima 2792 (SP191321); Quipapá, Engenho Brejinho, km 31 da BR-423, 2-IX-1980, O. Yano \& J.Z. Brito 2883 (SP191399); Bonito, Reserva Municipal, ca. $8 \mathrm{~km}$ da cidade, ca. $720 \mathrm{~m}$ alt., 6-VIII-1998, O. Yano et al. 25461 (SP322314).

Distribuição no Brasil: AL, AM, AP, BA, ES, MG, PA, PE, PR, RO, RR, SC e SP.

Ocorre sobre tronco.

Leptolejeunea elliptica (Lehm. \& Lindenb.) Schiffn. inEngler\&Prantl,Nat.Pflanzenfam.1(3):126.1893 $\equiv$ Jungermannia elliptica Lehm.\&Lindenb.,Nov. Stirp. Pug. 5: 13. 1833.

Ilustração: Yano et al. (1987), Gradstein \& Costa (2003) e Yano \& Peralta (2008).

Material examinado: BRASIL. Pernambuco: São Lourenço da Mata, Engenho São Bento, Estação Ecológica de Tapacurá, Mata Toró-Cuieira, 26-VIII-1980, O. Yano \& D. Andrade-Lima 2658 (SP191213); idem, 30-IX-1980, D. Andrade-Lima 80-6627 (SP191509); idem, Tapacurá, epifila de Lecythidaceae, 4-II-1988, O. Yano \& G. Mariz 11244 (SP222188); idem, 4-II-1988, O. Yano \& G. Mariz 11245 (SP222189); idem, 4-II-1988, O. Yano \& G. Mariz 11247 (SP222191); Quipapá, Engenho Brejinho, km 31 da BR-423, 2-IX-1980, O. Yano \& 
J.Z. Brito 2838 (SP191363); Rio Formoso, Córrego Juçara, epifila de Melastomataceae, 11-IX-1984, O. Yano et al. 9100 (SP191723); idem, epifila de Palmae, 11-IX-1984, O. Yano et al. 9103 (SP191726); idem, 11-IX-1984, O. Yano et al. 9113 (SP191736); idem, 11-IX-1984, O. Yano et al. 9115 (SP191738); idem, 11-IX-1984, O. Yano et al. 9116 (SP191739); idem, 11-IX-1984, O. Yano et al. 9132 (SP191754); Cabo, estação de Gurjaú, 14-IX-1984, O. Yano \& K.C. Pôrto 9168 (SP191790); idem, epifila sobre Melastomataceae, 14-IX-1984, O. Yano \& K.C. Pôrto 9169,9199 (SP191791; SP191821); idem, epifila de arbusto, 14-IX-1984, O. Yano \& K.C. Pôrto 9200 (SP191822); idem, epifila de Palmae, 14-IX-1984, O. Yano \& K.C. Pôrto 9202 (SP191824); Brejo da Madre de Deus, Reserva Bituri Grande, ca. $950 \mathrm{~m}$ alt., 10-VIII-1998, O. Yano et al. 25526 (SP322369); Bonito, Reserva Municipal, ca. $8 \mathrm{~km}$ da cidade, ca.720 m alt., 6-VIII-1998, O. Yano et al. 25437 p.p.(SP322292).

Distribuição no Brasil: AC, AL, AM, AP, BA, CE, DF, ES, GO, MG, MT, PA, PE, PR, RJ, RR, SC, SE e SP.

Ocorre sobre folha.

Leptolejeunea exocellata (Spruce) A. Evans, Bull. Torrey Bot. Club 29: 498. $1902 \equiv$ Lejeunea exocellata Spruce, Trans. \& Proc. Bot. Soc. Edinburgh 15: 195. 1884.

Ilustração: Bischler (1969), Gradstein \& Costa (2003) e Bastos (2004).

Material examinado: BRASIL. AlagOAS: Boca da Mata, Alto da Serra de Nacéia, 29-X-1980, D. Andrade-Lima 80-6660 (SP191537). Pernambuco: Taquaritinga do Norte, sobre folha de Pseudobombax sp., 24-VIII-1980, O. Yano \& D. Andrade-Lima 2645 (SP191203); idem, 24-VIII-1980, O. Yano \& D. Andrade-Lima 2645A (SP191204); idem, 24-VIII-1980, O. Yano \& D. Andrade-Lima 2648 (SP191207); idem, sobre folha de Heliconia sp., ao lado da microonda, 24-VIII-1980, O. Yano \& D. Andrade-Lima 2646 (SP191205); Quipapá, Engenho Brejinho, km 31 da BR-423, sobre folhas de Polypodium sp., perto da Cachoeira Grande, 2-IX-1980, O. Yano \& J.Z. Brito 2841 (SP191366); idem, sobre folhas de Melastomataceae, perto da Cachoeira Grande, 2-IX-1980, O. Yano \& J.Z. Brito 2842 (SP191367); São Lourenço da Mata, Engenho São Bento, Estação Ecológica de Tapacurá, Mata Toró-Cuieira, 26-VIII-1980, O. Yano \& D. Andrade-Lima 2660 (SP191215); Rio Formoso,
Córrego da Juçara, epifila de Jambeiro, 11-IX-1984, $O$. Yano et al. 9099 (SP191722); Cabo, Estação Gurjaú, epifila sobre Melastomaceae arbustiva, 14-IX-1984, O. Yano \& K.C. Pôrto 9185 (SP191807).

Distribuição no Brasil: AC, AL, AM, BA, MS, MT, PR, RJ, SC e SP.

Ocorre sobre folha.

* Leptolejeunea obfuscata (Spruce) Steph., Sp. Hepat. 5: 373.1913 ELejeunea obfuscata Spruce, Trans. \& Proc. Bot. Soc. Edingurh 15: 579. 1855.

Ilustração: Bischler (1969), Gradstein \& Costa (2003) e Yano \& Peralta (2008).

Material examinado: BRASIL. Alagoas: Boca da Mata, Alto da Serra da Nacéia, 29-X-1980, D. Andrade-Lima 80-6659 (SP191536).

Distribuição no Brasil: AM, ES, GO e MT.

Ocorre sobre folha.

Lopholejeunea nigricans (Lindenb.) Schiffn., Consp. Hepat. Arch. Ind.: 293. $1898 \equiv$ Lejeunea nigricans Lindenb. in Gottsche et al., Syn. Hepat.: 316. 1845. Ilustração: Gradstein \& Costa (2003), Bastos (2004) e Yano \& Peralta (2008).

Material examinado: BRASIL. Pernambuco: Quipapá, Engenho Brejinho, km 31 da BR-423, perto da Cachoeira Grande, 2-IX-1980, O. Yano \& J.Z. de Brito 2856 p.p. (SP191381); idem, coberto pela água na Cachoeira Grande, 2-IX-1980, O. Yano \& J.Z. Brito 2854 (SP191379); Escada, Engenho Massauaçu, perto do rio Pirapama, 23-VIII-1980, O. Yano \& D. Andrade-Lima 2565 (SP191138); Rio Formoso, Estação Experimental de Saltinho, 11-IX-1984, O. Yano et al. 9141 (SP191763); Bonito, Cachoeira do Oriente, ca. $19 \mathrm{~km}$ da cidade, ca. $500 \mathrm{~m}$ alt., 6-VIII-1998, O. Yano et al. 25486 (SP322332).

Distribuição no Brasil: AC, AM, BA, CE, DF, ES, GO, MG, MS, MT, PA, PE, PR, RJ, SC e SP.

Ocorre sobre rocha, tronco e tronco em decomposição.

Lopholejeunea subfusca (Nees) Schiffn., Bot. Jahrh. Syst. 23: 593. 1897 Jungermannia subfusca Nees, Enum. Pl. Crypt. Jav.: 36. 1830.

Ilustração: Bastos (2004) e Yano \& Peralta (2008).

Material examinado: BRASIL. BAHIA: Ilhéus, Centro 
de Pesquisas do Cacau, km 22 on BR-415 between Ilhéus and Itabuna, $14^{\circ} 50^{\prime} \mathrm{S}, 39^{\circ} 13^{\prime} \mathrm{W}$, cacau plantation, 15-VII-1991, D.M. Vital \& W.R. Buck 20176 (NY, SP353875); idem, ca. $3 \mathrm{~km}$ W of Ilhéus on road to Itabuna, BR-415, $14^{\circ} 50^{\prime} \mathrm{S}, 39^{\circ} 04^{\prime} \mathrm{W}$, mangrove swamp of Laguncularia racemosa and Acrostichum, 16-VII-1991, D.M. Vital \& W.R. Buck 20211 (NY, SP353897); idem, km 22 da rod. Ilhéus-Itabuna, 19-XII-1991, A.C. Messias \& S.L. Oliveira 189 (CEPEC51615, SP280851). Pernambuco: Recife, Sítio Pitiguari, sobre mangueira, 30-VIII-1980, O. Yano \& D. Andrade-Lima 2828 (SP191354); idem, Horto Zoo-Botânico da Mata de Dois Irmãos, 6-IX-1984, O. Yano \& K.C. Pôrto 9043 (SP191667); Quipapá, Engenho Brejinho, km 31 da BR-423, perto da Cachoeira Grande, 2-IX-1980, O. Yano \& J.Z. Brito 2894 (SP191410); Escada, Engenho Massauaçu, perto do rio Pirapama, 23-VIII-1980, O. Yano \& D. Andrade-Lima 2576 (SP191145); Rio Formoso, Córrego da Juçara, 11-IX-1984, O. Yano et al. 9073 (SP191696); idem, Estação Experimental de Saltinho, 11-IX-1984, O. Yano et al. 9135 (SP191757); idem, 11-IX-1984, O. Yano et al. 9143 (SP191765); Cabo, Estação de Gurjau, 14-IX-1984, O. Yano \& K.C. Pôrto 9181 (SP191803); idem, base do tronco de Melastomataceae, 14-IX-1984, O. Yano \& K.C. Pôrto 9186 (SP191808); idem, base do tronco, 14-IX-1984, O. Yano \& K.C. Pôrto 9198 (SP191820).

Distribuição no Brasil: AC, AL, AM, AP, BA, CE, DF, ES, GO, MG, MS, MT, PA, PB, PE, RJ, RO, RR, $\mathrm{SC}$ e SP.

Ocorre sobre rocha, tronco e tronco em decomposição, associada a Ceratolejeunea confusa R.M. Schust., Cheilolejeunea clausa (Nees \& Mont.) R.M. Schust. e $C$. rigidula (Mont.) R.M. Schust.

Marchesinia brachiata (Sw.) Schiffn. in Engler \& Prantl, Nat. Pflanzenfam. 1(3): 128. $1893 \equiv$ Jungermannia brachiata Sw., Prodr. (Swartz): 144. 1788.

Ilustração: Gradstein (1994), Gradstein \& Costa (2003) e Bastos (2004).

Material examinado: BRASIL. Pernambuco: Taquaritinga do Norte, Morro Cafundó, 24-VII-1980, O. Yano \& D. Andrade-Lima 2603 (SP191169); Caruaru, Fazenda Caruaru, Brejo dos Cavalos, 29-VIII-1980, O. Yano \& D. Andrade-Lima 2754 (SP191295); idem, Brejo dos Cavalos, ca. $780 \mathrm{~m}$ alt., base do tronco, 11-VIII-1998, O. Yano et al. 25532
(SP322375); idem, 11-VIII-1998, O. Yano et al. 25544 (SP322387); Inajá, Serra Negra, 6-IX-1980, O. Yano \& D. Andrade-Lima 2973 (SP191474); Jaqueira, Serra do Urubu, Mata do Ageró, 8`44'9,1'S, 3550'17'W, ca. $585 \mathrm{~m}$ alt., 18-X-2001, M.R. Pietrobom \& M.S. Lopes 5235 (SP403037); Bonito, Cachoeira do Oriente, ca. $19 \mathrm{~km}$ da cidade, ca. $500 \mathrm{~m}$ alt., 6-VIII-1998, O. Yano et al. 25493 (SP322339).

Distribuição no Brasil: BA, CE, ES, MG, PE, PR, RJ, RR, SC, SE e SP.

Ocorre sobre rocha, tronco e tronco em decomposição.

* Mastigolejeunea auriculata (Wilson \& Hook.) Schiffn. in Engler \& Prantl, Nat. Pflanzenfam. 1(3): 129. 1893 Jungermannia auriculata Wilson \& Hook. in Drummond, Musci Amer. Sept. Exsicc.: 170. 1841.

Ilustração: Gradstein (1994), Gradstein \& Costa (2003) e Yano \& Peralta (2008).

Material examinado: BRASIL. AlagoAs: Marechal Deodoro, Lande eines Sekundärwaldes an der BR-101 bei km 121, 941'S, 36²'W, 5-VII-1987, Schäfer-Verwimp \& Verwimp 8735 (hb. SchäferVerwimp, SP388360). Pernambuco: São Lourenço da Mata, Engenho São Bento, Mata de Tapacurá, 6-VIII1986, O. Yano et al. 10334 (SP207008); idem, Tapacurá, 4-II-1988, O. Yano \& G. Mariz 11253 (SP222197); idem, 4-II-1988, O. Yano \& G. Mariz 11254 (SP222198); Caruaru, Brejo dos Cavalos, ca. $780 \mathrm{~m}$ alt., sobre Ingá, 11-VIII-1998, O. Yano et al. 25537 (SP322380); Nazaré da Mata, Mata de Acaparra, 19-VI-2002, M.R. Pietrobom 5516 (SP403074).

Distribuição no Brasil: AC, AM, AP, BA, CE, DF, ES, GO, MG, MS, MT, PA, PR, RJ, RO e SP.

Ocorre sobre rocha e tronco, associada a Cheilolejeunea clausa (Nees \& Mont.) R.M. Schust. e $C$. rigidula (Mont.) R.M. Schust.

Microlejeunea bullata (Taylor) Steph., Hedwigia 29: 90. 1890 三 Lejeunea bullata Taylor, London J.

Bot. 5: 398. 1846.

Ilustração: Bischler et al. (1963), Bastos (2004) e Yano \& Peralta (2008).

Material examinado: BRASIL. BAHIA: Itabuna, plantações de cacau da CEPLAC, sobre cacaueiro, 24-I-1980, D.M. Vital 8702 (SP133369). PeRnAMBUCO: Recife, Santo Antônio, an Palme in Garten des Klosters 
S. Francisca, 8-VII-1986, A. Schäfer-Verwimp 7196 (hb. Schäfer-Verwimp, SP386078); Brejo da Madre de Deus, Reserva Bituri Grande, ca. $950 \mathrm{~m}$ alt., 10-VIII-1998, O. Yano et al. 25525 (SP322368). SERGIPE: Itabaiana, along a temporary river Tábora, 29-I-1974, D.M. Vital 2871 (SP88377).

Distribuição no Brasil: AC, AM, BA, CE, DF, ES, GO, MG, MS, MT, PE, PR, RJ, RR, SC, SE e SP.

Ocorre sobre tronco, associada a Frullanoides corticalis (Lehm. \& Lindenb.) van Slageren.

Microlejeunea epiphylla Bischler in Bischler et al., Nova Hedwigia 5(1-2): 378. 1963.

Ilustração: Bischler et al. (1963), Gradstein \& Costa (2003), Bastos (2004) e Yano \& Peralta (2008).

Material examinado: BRASIL. Pernambuco: Recife, 19-VIII-1980, D. Andrade-Lima 80-6620 (SP191504); idem, Horto Zoo-Botânico da Mata de Dois Irmãos, 6-IX-1984, O. Yano \& K.C. Pôrto 9060 (SP191684); Triunfo, Engenho Júlio Ramos, 7-IX-1980, O. Yano \& D. Andrade-Lima 2984(SP191483); Caruaru, Brejo dos Cavalos, ca. $780 \mathrm{~m}$ alt., 11-VIII-1998, O. Yano et al. 25536 (SP322379).

Distribuição no Brasil: AL, AP, BA, CE, ES, GO, MG, MS, PA, PB, PE, RS, SE, SP e TO.

Ocorre sobre tronco e folha, associada a Ceratolejeunea cornuta (Lindenb.) Schiffn., Frullania caulisequa (Nees) Nees, Lejeunea elliottii Spruce e L. flava (Sw.) Nees.

Odontolejeunea lunulata (F. Webber) Schiffn. in Engler \& Prantl, Nat. Pflanzenfam. 1(3): 128. $1893 \equiv$ Jungermannia lunulata F. Webber, Hist. Musc. Hepat. Prodr.: 33. 1815.

Ilustração: Teeuwen (1989), Gradstein (1994), Gradstein \& Costa (2003) e Zartman \& Ilkiu-Borges (2007).

Material examinado: BRASIL. BAhIA: Pico das Almas, Capão de Mata, $1.400 \mathrm{~m}$ alt., sobre folhas de Myrtaceae, 21-II-1987, R.M. Harley et al. 24559 (SPF, K, SP230717). Pernambuco: Caruaru, Brejo dos Cavalos, Mata de Galileu, ca. 800-900 m alt., 11-VIII-1998, O. Yano et al. 25565 (SP322408); idem, epifila de Maranthaceae, 11-VIII-1998, O. Yano et al. 25566 (SP322409).

Distribuição no Brasil: AC, AL, AM, AP, BA, CE, ES, MG, MT, PA, PE, PR, RJ, RR, RS e SP.
Ocorre sobre folha.

Omphalanthus filiformis (Sw.) Nees in Gottsche et al., Syn. Hepat.: $304.1845 \equiv$ Jungermannia filiformis Sw., Prodr. (Swartz): 144. 1788.

Ilustração: Lemos \& Michel (2001), Gradstein \& Costa (2003) e Bastos (2004).

Material examinado: BRASIL. Pernambuco: Taquaritinga do Norte, Morro Cafundó, sobre Inga sp. na mata da serra Cafundó, 24-VIII-1980, O. Yano \& D. Andrade-Lima 2600 (SP191167); idem, sobre Lauraceae, 24-VIII-1980, O. Yano \& D. Andrade-Lima 2622 (SP191182); Caruaru, Fazenda Caruaru, Brejo dos Cavalos, 29-VIII-1980, O. Yano \& D. Andrade-Lima 2755 (SP191296); idem, Brejo dos Cavalos, 29-VIII-1980, O. Yano \& D. Andrade-Lima 2762 (SP191302); idem, 29-VIII-1980, O. Yano \& D. Andrade-Lima 2781 (SP191313); São Caetano, Serra Pelada, sobre Munguba, serra perto da microonda, 29-VIII-1980, O. Yano \& D. Andrade-Lima 2809 (SP191338); Timbaúba, complexo da Serra do Mascarenhas, Usina Cruangi, Engenho ÁguaAzul, área do poçocaudaloso, 7³7'7,3”S, $35^{\circ} 23$ '43,1'W, ca. 304-451 m alt., 15-XII-2001, M.R. Pietrobom 5461 (SP403058); Jaqueira, Serra do Quengo, 8`42'50,4”S, 3550'28,8'W, ca. $713 \mathrm{~m}$ alt., 2-IV-2002, M.R. Pietrobom \& M.S. Lopes 5469 (SP403066).

Distribuição no Brasil: AM, BA, CE, ES, MG, PE, RJ, RS, SC, SE e SP.

Ocorre sobre tronco, associada a Bryopteris diffusa (Sw.) Nees, Frullania caulisequa (Nees) Nees, Harpalejeunea stricta (Lindenb. \& Gottsche) Steph. e Taxilejeunea isocalycina (Nees) Steph.

* Prionolejeunea aemula (Gottsche) A. Evans, Bull. Torrey Bot. Club 31:219. 1904 ELejeunea aemula Gottsche in Gottsche et al., Syn. Hepat.: 338. 1845.

Ilustração: Gradstein \& Costa (2003), Bastos (2004) e Ilkiu-Borges (2005).

Material examinado: BRASIL. BAHIA: Una, Reserva Biológica do Mico-Leão, km 46 da rod. BA001 Ilhéus-Una, $15^{\circ} 09^{\prime} \mathrm{S}, 39^{\circ} 05^{\prime} \mathrm{W}, 14-\mathrm{XI}-1992$, S.L. Oliveira 268 p.p (CEPEC, SP280890). Pernambuco: Bonito, Reserva Municipal, ca. $8 \mathrm{~km}$ da cidade, ca. 720 m alt., 6-VIII-1998, O. Yano et al. 25466 (SP322319); Rio Formoso, Córrego da Juçara, sobre tronco de árvore viva, mata úmida, 11-IX-1984, O. Yano et al. 9095 (SP191718). 
Distribuição no Brasil: AM, BA, MT, PA, RJ, SC e SP.

Ocorre sobre tronco e tronco em decomposição, associada a Plagiochila fordiana Steph. e Telaranea nematodes (Gottsche ex Austin) M. Howe.

Prionolejeunea denticulata (F. Weber) Schiffn. in Engler \& Prantl, Nat. Pflanzenfam. 1(3): 127. 1893 三 Jungermannia denticulata F. Weber,

Hist. Musc. Hepat. Prodr.: 30. 1815.

Ilustração: Gradstein et al. (2001, como P. macrocardia), Bastos (2004) e Ilkiu-Borges (2005).

Material examinado: BRASIL. Pernambuco: Rio Formoso, Córrego da Juçara, 11-IX-1984, O. Yano et al. 9080 p.p. (SP191703); idem, 11-IX-1984, O. Yano et al. 9109 (SP191732); São Vicente Ferrer, complexo da Serra do Mascarenhas, Mata do Estado, $7^{\circ} 35^{\prime} \mathrm{S}, 35^{\circ} 30^{\prime} \mathrm{W}$, ca. 600-650 m alt., 16-IX-1998, M.R. Pietrobom-Silva 4422 (SP352754).

Distribuição no Brasil: AL, AM, BA, CE, PA, PE, RJ e SP.

Ocorre em solo, associada a Riccardia digitiloba (Spruce ex Steph.) Pagán.

* Prionolejeunea scaberula (Spruce) Steph., Sp. Hepat. 5: 214. 1913 ELejeunea scaberula Spruce, Trans. \& Proc. Bot. Soc. Edinburgh 15: 159. 1884.

Ilustração: Ilkiu-Borges (2005).

Material examinado: BRASIL. AlagoAs: São Miguel dos Campos, along the high-road BR-101, km 60, 18-I-1972, D.M. Vital 1957 p.p. (SP90244); idem, 18-I-1972, D.M. Vital 1958 (SP87712). Bahia: Uruçuca, $6.2 \mathrm{~km} \mathrm{~N}$ of town of Serra Grande, ca. $40 \mathrm{~km} \mathrm{~N}$ of Ilhéus along coast, $14^{\circ} 26^{\prime} \mathrm{S}, 39^{\circ} 03^{\prime} \mathrm{W}$, ca. $200 \mathrm{~m}$ alt., wet tropical forest, 17-VII-1991, D.M. Vital \& W.R. Buck 20317 p.p. (SP353948). Pernambuco: Rio Formoso, Córrego da Juçara, 11-IX-1984, O. Yano et al. 9102 (SP191725); Bonito, Reserva Municipal, ca. $8 \mathrm{~km}$ da cidade,ca. 720 malt., 6-VIII-1998, O. Yano et al. 25463 (SP322316).

Distribuição no Brasil: AM, BA e SP.

Ocorre sobre tronco, associada a Callicostella ciliata (Schimp. ex Besch.) A. Jaeger e Lejeunea caulicalyx (Steph.) E. Reiner \& Goda.

Pycnolejeunea contigua (Nees) Grolle, J. Hattori Bot. Lab. 45: 179. 1979 $\equiv$ Jungermannia contigua Nees in Martius, Fl. Bras. Enum. Pl. 1(1):360. 1833. Ilustração: He (1999), Gradstein \& Costa (2003),
Bastos (2004) e Zartman \& Ilkiu-Borges (2007).

Material examinado: BRASIL. BAHIA: Porto Seguro, 10-I-1979, M.F. Silva s.n. (SP133243); São Sebastião do Passé, Lamarão do Passé, 20-I-1983, I.C. Britto 10 (SP389573).

Distribuição no Brasil: AM, BA, CE, ES, MG, PA, PE, RR, RS, SC e SP.

Ocorre sobre tronco.

Pycnolejeunea macroloba (Nees \& Mont.) Schiffn. in Engler \& Prantl, Nat. Pflanzenfam. 1(3): 124. 1893 ELejeunea macroloba Nees \& Mont. in Montagne, Ann. Sci. Nat., Bot. sér. 2, 19: 260. 1843. Ilustração: Griffin III (1979), He (1999), Gradstein \& Costa (2003) e Bastos (2004).

Material examinado: BRASIL. BAHIA: Ilhéus, $5 \mathrm{~km} \mathrm{~S}$ of Ilhéus on road to Olivença, $14^{\circ} 52^{\prime} \mathrm{S}, 39^{\circ} 02^{\prime} \mathrm{W}$, restinga, 14-VII-1991, D.M. Vital \& W.R. Buck 20104 (NY, SP353838); idem, ca. $6 \mathrm{~km} \mathrm{SW}$ of Olivença on road to Maruim, $15^{\circ} \mathrm{S}, 39^{\circ} 04^{\prime} \mathrm{W}$, restinga, 16-VII-1991, D.M. Vital \& W.R. Buck 20224 (NY, SP353901).

Distribuição no Brasil: AL, AM, BA, CE, ES, PA, PE e SP.

Ocorre sobre tronco, associada a Lejeunea laetevirens Nees \& Mont.

Pycnolejeunea porrectilobula C. Bastos \& O. Yano, Nova Hedwigia 74(3-4): 439. 2002. Ilustração: Bastos \& Yano (2002) e Bastos (2004).

Material examinado: BRASIL. BAHIA: Ilhéus, $5 \mathrm{~km} \mathrm{~S}$ of Ilhéus on road to Olivença, $14^{\circ} 52^{\prime} \mathrm{S}, 39^{\circ} 02^{\prime} \mathrm{W}$, restinga, 14-VII-1991, D.M. Vital \& W.R. Buck 20086 (NY, SP353828); idem, ca. $6 \mathrm{~km} \mathrm{SW}$ of Olivença on road to Maruim, $15^{\circ} \mathrm{S}, 39^{\circ} 04^{\prime} \mathrm{W}$, restinga, 16-VII-1991, D.M. Vital \& W.R. Buck 20258 (NY, SP353912); idem, 16-VII-1991, D.M. Vital \& W.R. Buck 20259 (NY, SP353913).

Distribuição no Brasil: BA (Estação Veracruz).

Ocorre sobre tronco, associada a Ceratolejeunea confusa R.M. Schust.

* Rectolejeunea berteroana (Gottsche ex Steph.) A. Evans, Bull. Torrey Bot. Club 33(1): 12. 1906 三Lejeunea berteroana Gottsche ex Steph., Hedwigia 27: 282. 1888. 
Ilustração: Gradstein et al. (2001), Gradstein \& Costa (2003) e Bastos (2004).

Material examinado: BRASIL.BAHIA:Uruçuca, $6,2 \mathrm{kmN}$ of town of Serra Grande, ca. $40 \mathrm{~km} N$ of Ilhéus along coast, $14^{\circ} 26^{\prime} \mathrm{S}, 39^{\circ} 03^{\prime} \mathrm{W}$, wet tropical forest with small stream in ravine, 17-VII-1991, D.M. Vital \& W.R. Buck 20301 (NY, SP353938). Pernambuco: Cabo, Estação de Gurjaú, 14-IX-1984, O. Yano \& K.C. Pôrto 9159 (SP191781); idem, 14-IX-1984, O. Yano \& K.C. Pôrto 9177 (SP191799); idem, 14-IX-1984, O. Yano \& K.C. Pôrto 9188 (SP191810); idem, 14-IX-1984, O. Yano \& K.C. Pôrto 9195 (SP191817); São Lourenço da Mata, Tapacurá, 4-II-1988, O. Yano \& G. Mariz 11255 (SP222199).

Distribuição no Brasil: AC, AL, AM, AP, BA, ES, PA, PR, RJ, SC e SP.

Ocorre sobre tronco e folha, associada a Ceratolejeunea minuta G. Dauphin e Stictolejeunea squamata (Willd. ex Web.) Schiffn.

* Rectolejeunea emarginuliflora (Gottsche ex Schiffn.) A. Evans, Bull. Torrey Bot. Club 33(1): 14. $1906 \equiv$ Cheilolejeunea emarginuliflora Gottsche ex Schiffn., Bot. Jahrb. Syst. 23: 585. 1897.

Ilustração: Lücking (1995), Bastos (2004) e Zartman \& Ilkiu-Borges (2007).

Material examinado: BRASIL. BAHIA: Ilhéus, Centro de Pesquisas do Cacau, km 22 on BR-415 between Ilhéus and Itabuna, $14^{\circ} 50^{\prime} \mathrm{S}, 39^{\circ} 13^{\prime} \mathrm{W}$, Parque Zoobotânico, cacau plantation, 15-VII-1991, D.M. Vital \& W.R. Buck 20154 (NY, SP353853); idem, ca. $6 \mathrm{~km} \mathrm{SW}$ of Olivença on road to Maruim, $15^{\circ} \mathrm{S}, 39^{\circ} 04^{\prime} \mathrm{W}$, restinga, 16-VII-1991, D.M. Vital \& W.R. Buck 20251 (NY, SP353908). Pernambuco: Rio Formoso, Córrego da Juçara, 11-IX-1984, O. Yano et al. 9092 (SP191715).

Distribuição no Brasil: AL, AM, BA, ES, PA e SP.

Ocorre sobre tronco.

Rectolejeunea flagelliformis A. Evans, Bull. Torrey Bot. Club 33(1): 9. 1906.

Ilustração: Evans (1906) e Bastos (2004).

Material examinado: BRASIL. Pernambuco: Rio Formoso, Córrego da Juçara, 11-IX-1984, O. Yano et al. 9111 (SP191734).

Distribuição no Brasil: AL, BA, PE e SP.
Ocorre sobre tronco vivo.

Schiffneriolejeunea polycarpa (Nees) Gradst., J. Hattori Bot. Lab. 38: 355. 1974 EJungermannia polycarpa Nees in Martius, Fl. Bras. Enum. Pl. 1(1): 350. 1833.

Ilustração: Gradstein (1994), Gradstein \& Costa (2003) e Bastos (2004).

Material examinado: BRASIL. BAHIA: Itabuna, CEPLAC, 25-I-1980, O. Yano 2325 (SP133497). Pernambuco: Caruaru, Fazenda Caruaru, Brejo dos Cavalos, 29-VIII-1980, O. Yano \& D. Andrade-Lima 2745 (SP191288); idem, Brejo dos Cavalos, ca. $780 \mathrm{~m}$ alt., 11-VIII-1998, O. Yano et al. 25529 (SP322372); idem, 11-VIII-1998, O. Yano et al. 25547 (SP322390); Quipapá, Engenho Brejinho, km 31 da BR-423, perto da cachoeira, 2-IX-1980, O. Yano \& J.Z. Brito 2850 (SP191375); Inajá, Serra Negra, sobre Terminalia sp., 6-IX-1980, O. Yano \& D. Andrade-Lima 2958 p.p. (SP191459); idem, 6-IX-1980, O. Yano \& D. Andrade-Lima 2962 (SP191463); Recife, Mata de Dois Irmãos, 3-VIII-1998, O. Yano et al. 25408 (SP322263); Brejo da Madre de Deus, Reserva Bituri Grande, ca. 950m alt., 10-VIII-1998, O. Yano et al. 25510 (SP322354); idem, 10-VIII-1998, O. Yano et al. 25512 (SP322356).

Distribuição no Brasil: AC, AM, BA, CE, DF, ES, GO, MG, MS, MT, PA, PB, PE, RJ, RR, RS, SC, SE e SP.

Ocorre sobre tronco e tronco em decomposição, associada a Cheilolejeunea rigidula (Nees \& Mont.) R.M. Schust.

Stictolejeunea squamata (H.B. Willd. ex F. Weber) Schiffn. in Engler \& Prantl, Nat. Pflanzenfam. 1(3): 131. $1893 \equiv$ Jungermannia squamata H.B. Willd. ex F. Weber, Hist. Musc. Hepat. Prodr.: 33. 1815. Ilustração: Griffin III (1979), Gradstein $(1985,1994)$ e Bastos (2004).

Material examinado: BRASIL. BAHIA: Ilhéus, ca. $6 \mathrm{~km} \mathrm{SW}$ of Olivença on road to Maruim, $15^{\circ} \mathrm{S}$, 3904'W, restinga, 16-VII-1991, D.M. Vital \& W.R. Buck 20257 (NY, SP353911); Uruçuca, 6,2 km N of town of Serra Grande, ca. $40 \mathrm{~km}$ N of Ilhéus along coast, $14^{\circ} 26^{\prime} \mathrm{S}, 39^{\circ} 03^{\prime} \mathrm{W}$, wet tropical forest with small stream in ravine, 17-VII-1991, D.M. Vital \& W.R. Buck 20315 (NY, SP353946). Pernambuco: Rio Formoso, Córrego da Juçara, 11-IX-1984, O. Yano et al. 9072 (SP191695); idem, 11-IX-1984, O. Yano et al. 9114 p.p. (SP191737); São Lourenço 
da Mata, Tapacurá, perto do riacho na mata úmida, 4-II-1988, O.Yano \& G. Mariz 11268 (SP222212).

Distribuição no Brasil: AC, AL, AM, AP, BA, ES, MG, PA, PE, RJ, RS, SC e SP.

Ocorre sobre rocha, folha e tronco, associada a Rectolejeunea berteroana (Gottsche ex Steph.) A. Evans.

Symbiezidium barbiflorum (Lindenb. \& Gottsche) A. Evans, Bull. Torrey Bot. Club 34: 54. $1908 \equiv$ Lejeunea barbiflora Lindenb. \& Gottsche, Linnaea 24: 630. 1851.

Ilustração: Lücking (1995), Gradstein \& Costa (2003) e Bastos (2004).

Material examinado: BRASIL. Pernambuco: Bonito, Reserva Municipal, ca. $8 \mathrm{~km}$ da cidade, ca. $720 \mathrm{~m}$ alt., 6-VIII-1998, O. Yano et al. 25453 (SP322306); idem, 6-VIII-1998, O. Yano et al. 25462 (SP322315); Caruaru, Brejo dos Cavalos, Mata de Galileu, ca. 800-900 m alt., 11-VIII-1998, O. Yano et al. 25562 (SP322405); Rio Formoso, Estação Experimental de Saltinho, 11-IX-1984, O. Yano et al. 9139 (SP191761); idem, Córrego da Juçara, 11-IX-1984, O. Yano et al. 9108 (SP191731); São Lourenço da Mata perto do Engenho São Bento, mata de Tapacurá, 6-VIII-1986, O. Yano et al. 10328 (SP207002); idem, Tapacurá, 4-II-1998, O. Yano \& G. Mariz 11251 (SP222195).

Distribuição no Brasil: AC, AL, AM, BA, ES, PA, PE, RJ, SC e SP.

Ocorre sobre tronco.

* Symbiezidium transversale (Sw.) Trevis., Mem. Reale Ist. Lombardo Sci., ser. 3, 4: $403.1877 \equiv$ Jungermannia transversalis Sw., Nova Gen. Spec. P1. Prodr.: 144. 1788.

Ilustração: Gradstein \& van Beek (1985), Gradstein (1994) e Gradstein \& Costa (2003).

Material examinado: BRASIL. Alagoas: Boca da Mata, Alto da Serra da Nacéia, sobre Sapotaceae, 29-X1980, D. Andrade-Lima 80-6670 (SP191547). BAHIA: Ilhéus, ca. $6 \mathrm{~km} \mathrm{SW}$ of Olivença on road to Maruim, $15^{\circ} \mathrm{S}, 39^{\circ} 04^{\prime} \mathrm{W}$, restinga, 16-VII-1991, D.M. Vital \& W.R. Buck 20200 (NY, SP353893). Pernambuco: São Lourenço da Mata, perto do Engenho São Bento, mata de Tapacurá, perto do riacho, 6-VIII-1986, O. Yano et al. 10326 (SP207000).

Distribuição no Brasil: AC, AM, AP, BA, CE, ES, MG, PA, RJ, SC e SP.
Ocorre sobre tronco.

* Taxilejeunea isocalycina (Nees) Steph., Sp. Hepat. 5: 469. 1914 EJungermannia isocalycina Nees in Martius, Fl. Bras. Enum. Pl. 1(1): 356. 1833.

Figura 9

Ilustração adicional: Gradstein \& Costa (2003).

Material examinado: BRASIL. Pernambuco: Caruaru, Fazenda Caruaru, Brejo dos Cavalos, 29-VIII-1980, O. Yano \& D. Andrade-Lima 2746 (SP191289); idem, 29-VIII-1980, O. Yano \& D. Andrade-Lima 2767 (SP191308); Caruaru, Brejo dos Cavalos, Mata de Galileu, ca. 800-900 m alt., 11-VIII-1998, O. Yano et al. 25552 (SP322395); idem, sobre raízes tabulares, 11-VIII-1998, O. Yano et al. 25553 (SP322396); Bonito, Reserva Municipal, 27-III1998, K.C. Pôrto s.n. (SP324507); idem, ca. 8 km da cidade, ca. $720 \mathrm{~m}$ alt., base do tronco, 6-VIII-1998, O. Yano et al. 25459 (SP322312).

Distribuição no Brasil: ES, MG, RJ, RS e SP.

Ocorre sobre tronco e tronco em decomposição, associada a Omphalanthus filiformes (Sw.) Nees.

* Taxilejeunea pterigonia (Lehm. \& Lindenb.) Schiffn. in Engler \& Prantl, Nat. Pflanzenfam. 1(3): 125. 1893 三Jungermannia pterigonia Lehm. \& Lindenb. in Lehmann, Nov. Stirp. Pug. 6: 44.1834.

Ilustração: Reiner-Drehwald (2000) e Gradstein \& Costa (2003).

Material examinado: BRASIL. Pernambuco: Jaqueira, Serra do Urubu, Mata do Quengo, 8'42'37'S, 35 50'01'W, ca. 500-750 m alt., 31-V-2001, M.R. Pietrobom \& M.S. Lopes 5293 (SP403029).

Distribuição no Brasil: AM, BA, ES, GO, MG, RJ, $\mathrm{RS}, \mathrm{SC}$ e SP.

Ocorre sobre tronco, associada a Plagiochila macrostachya Lindenb.

Vitalianthus bischlerianus (Pôrto \& Grolle) R.M. Schust. \& Giancotti in Schuster, Nova Hedwigia 57(3-4): 448. 1998 D Drepanolejeunea bischleriana Pôrto \& Grolle, Cryptog. Bryol. Lichénol. 8(4): 301. 1987.

Ilustração: Pôrto \& Grolle(1987, como Drepanolejeunea bischleriana) e Gradstein \& Costa (2003).

Material examinado: BRASIL. BAHIA: Porto Seguro, Nationalpark Monte Pascoal, Mata Atlântica, 380 m alt., 21-VII-1987, Schäfer-Verwimp \& Verwimp 8797 


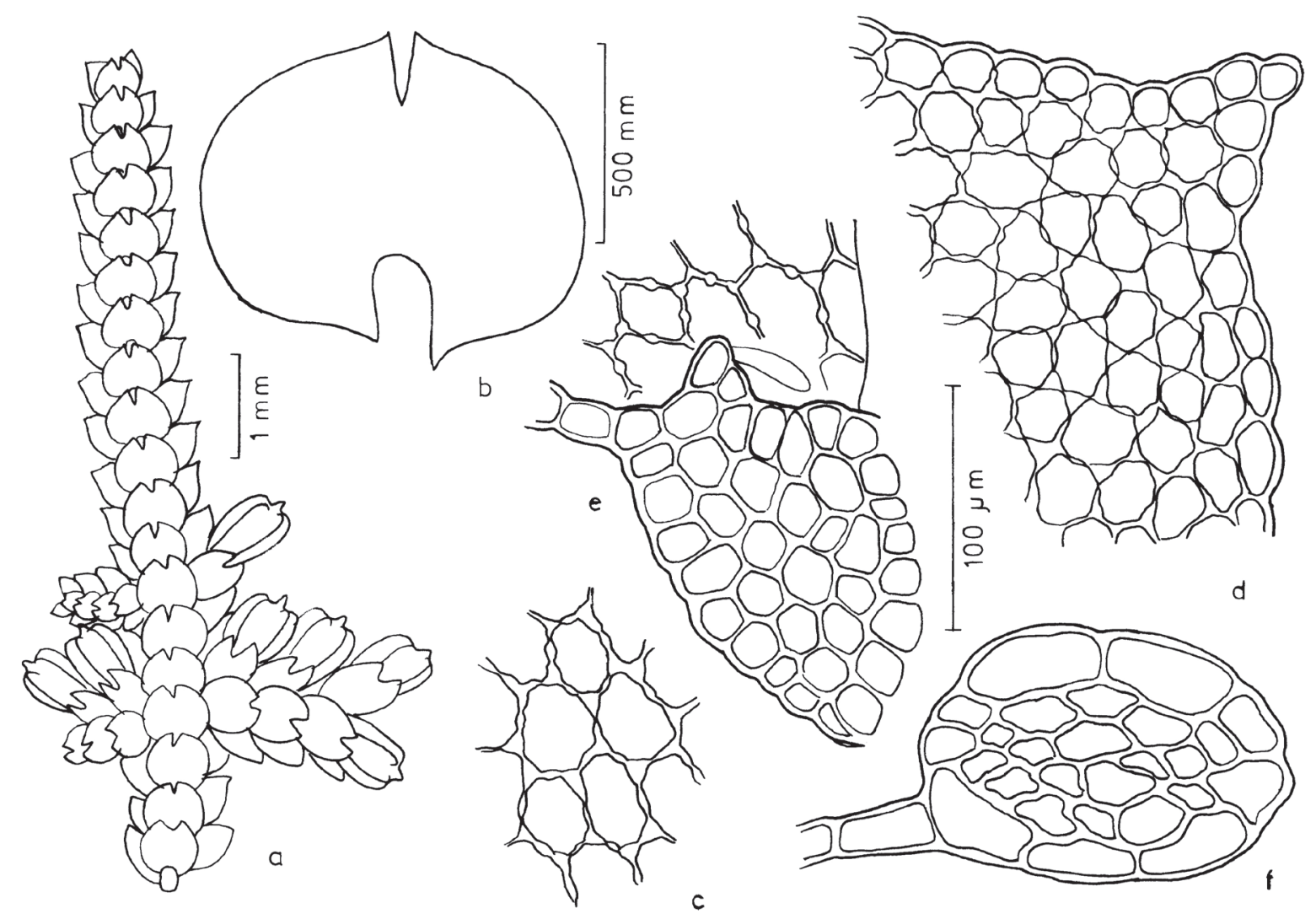

Figura 9. Taxilejeunea isocalycina. a. Aspecto geral do gametófito. b. Anfigastro. c. Células da região mediana do lobo. d. Células do ápice do lobo. Detalhe do lóbulo. f. Secção transversal do caulídio.

Figure 9. Taxilejeunea isocalycina. a. General aspect of the gametophyte. b. Underleaf. c. Leaf cells. d. Apical cells of the leaf. e. Lobe detail. f. Cros section of stem.

(hb. Schäfer-Verwimp, SP386178).

Distribuição no Brasil: BA, ES, PE, PR, RJ, SC e SP.

Ocorre sobre tronco.

Xylolejeunea crenata (Mont. \& Nees) X.-L. He \& Grolle, Ann. Bot. Fennici 38: 36. $2001 \equiv$ Lejeunea crenata Nees \& Mont. in Montagne, Ann. Sci. Nat., Bot. sér. 2, 9: 48. 1838.

Ilustração: Gradstein \& Costa (2003), Bastos (2004) e Zartman \& Ilkiu-Borges (2007).

Material examinado:BRASIL.BAHIA:Uruçuca, $6,2 \mathrm{kmN}$ of town of Serra Grande, ca. $40 \mathrm{~km}$ N of Ilhéus along coast, $14^{\circ} 26^{\prime} \mathrm{S}, 39^{\circ} 03^{\prime} \mathrm{W}$, wet tropical forest with small stream in ravine, 17-VII-1991, D.M. Vital \& W.R. Buck 20313 (NY, SP353944).

Distribuição no Brasil: AL, AM, AP, BA, MA, MG, PA, PE, RJ, RO, RR, SC e SP.
Ocorre em solo.

\section{LEPIDOZIACEAE}

Bazzania hookeri (Lindenb.) Trevis., Mem. Reale Ist. Lombardo Sci., ser. 3, 13:414. 1877 =Mastigobryum hookeri Lindenb. in Gottsche et al., Syn. Hepat.: 226. 1845.

Ilustração: Fulford (1963) e Gradstein \& Costa (2003).

Material examinado: BRASIL. BAHIA: Santa Teresinha, Serra da Jibóia, próx. torre da Embratel, ca. $500 \mathrm{~m}$ alt., vegetação de altitude, 6-IX-1994, C.W.N. Moura s.n. (SP283925); idem, 6-IX-1994, C.W.N. Moura s.n. (SP283927); idem, 6-IX-1994, C.W.N. Moura s.n. (SP283929).

Distribuição no Brasil: AM, BA, ES, MG, PE, PR, RJ, RR, RS, SC e SP.

Ocorre sobre tronco e tronco em decomposição. 
* Kurzia brasiliensis (Steph.) Grolle, Rev. Bryol. Lichénol. 32: 175. 1963 E Psiloclada brasiliensis Steph., Sp. Hepat. 3: 550. 1909.

Ilustração: Fulford (1966, como Lepidozia brasiliensis) e Yano \& Peralta (2008).

Material examinado: BRASIL. BAHIA: Palmeiras, Pai Inácio, BR-242, W of Lençóis, at km 232, 12-VI-1981, B.M. Boom \& S.A. Mori 1180 (CEPEC, SP379187); Lençóis, planalto, IX-1995, A.M. Giulietti s.n. (SP283953). Pernambuco: Jaqueira, Serra do Quengo, 8`42'50,4'S, 3550'28,8'W, ca. 713 $\mathrm{m}$ alt., 2-IV-2002, M.R. Pietrobom \& M.S. Lopes 5466 (SP403063).

Distribuição no Brasil: BA, DF, ES, GO, MG, RJ, RR, RS, SC e SP.

Ocorre sobre rocha, tronco e tronco em decomposição.

Micropterygium reimersianum Herzog, Hedwigia 81: 226. 1943.

Ilustração: Herzog (1944), Fulford (1966) e Gradstein \& Costa (2003).

Material examinado: BRASIL. BAHIA: Nationalpark Chapada Diamantina, Felshang in sickerfeuchter Rinne auf Gestein, $800 \mathrm{~m}$ alt.,11-VII-1987, Schäfer-Verwimp \& Verwimp 8709 (hb. SchäferVerwimp, SP386176).

Distribuição no Brasil: BA.

Ocorre em solo.

Micropterygium trachyphyllum Reimers, Hedwigia 73: 186. 1933(1944).

Ilustração: Reimers (1933), Fulford (1966) e Gradstein \& Costa (2003).

Material examinado: BRASIL. BAHIA: Ilhéus, ca. $6 \mathrm{~km} \mathrm{SW}$ of Olivença on road to Maruim, $15^{\circ} \mathrm{S}$, 3904'W, ca. $100 \mathrm{~m}$ alt., restinga, 16-VII-1991, D.M. Vital \& W.R. Buck 20253 (NY, SP353909); Una, Reserva Biológica do Mico-Leão, 159'S, 395'W, 14-XI-1992, S.L. Oliveira 250 (CEPEC55777, SP280888).

Distribuição no Brasil: AM, BA, DF, MT, PA e RR.

Ocorre sotre tronco em decomposição.

* Telaranea coactilis (Spruce) J.J. Engel \& G.L. Merrill, Fieldiana, Bot. n. ser., 44: 140. $2004 \equiv$
Arachniopsis coactilis Spruce, Cephalozia: 85. 1882. Ilustração: Fulford (1968, como Arachniopsis coactilis) e Engel \& Smith Merrill (2004).

Material examinado:BRASIL.BAHIA:Uruçuca, $6,2 \mathrm{kmN}$ of town of Serra Grande, ca. $40 \mathrm{~km}$ N of Ilhéus along coast, ca. $200 \mathrm{~m}, 14^{\circ} 26^{\prime} \mathrm{S}, 39^{\circ} 03^{\prime} \mathrm{W}$, wet tropical forest with small stream in ravine, 17-VII-1991, D.M. Vital \& W.R. Buck 20314 (SP353945).

Distribuição no Brasil: AM e RJ.

Ocorre sobre tronco em decomposição.

Telaranea diacantha (Mont.) J.J. Engel \& G.L. Merrill, Fieldiana, Bot. n. ser., 44: 145. $2004 \equiv$ Jungermannia diacantha Mont., Ann. Sci. Nat., Bot. sér. 4, 5: 349. 1856.

Ilustração: Fulford (1968, como Arachniopsis diacantha), Gradstein \& Costa (2003, como Arachniopsis diacantha) e Engel \& Smith Merrill (2004).

Material examinado: BRASIL. Pernambuco: Caruaru, Fazenda Caruaru, Brejo dos Cavalos, 29-VIII-1980, O.Yano \& D. Andrade-Lima 2734 (SP191278); Rio Formoso, Córrego da Juçara, 11-IX-1984, O. Yano et al. 9075 (SP191698).

Distribuição no Brasil: AL, AM, BA, DF, ES, PE, $\mathrm{RJ}, \mathrm{SC}$ e SP.

Ocorre em solo e tronco em decomposição.

* Telaranea nematodes (Gottsche ex Austin) M. Howe, Bull. Torrey Bot. Club 29: 284. $1902 \equiv$ Cephalozia nematodes Gottsche ex Austin, Bull. Torrey Bot. Club 6: 302. 1879.

Ilustração: Gradstein \& Costa (2003), Engel \& Smith Merrill (2004) e Yano \& Peralta (2008).

Material examinado: BRASIL. BAHIA: Una, Reserva Biológica do Mico-Leão, km 46 da rod. BA001 Ilhéus-Una, $15^{\circ} 09^{\prime} \mathrm{S}, 39^{\circ} 05^{\prime} \mathrm{W}, 14-\mathrm{XI}-1992$, S.L. Oliveira 268 p.p. (CEPEC55918, SP280890); Imbassaí, mata ciliar, 2-VII-2004, D.F.Peraltaetal. 2470 (SP368951). Pernambuco: Caruaru, Fazenda Caruaru, Brejo dos Cavalos, 29-VIII-1980, O. Yano \& D. Andrade-Lima 2770 (SP191309); Rio Formoso, Córrego da Juçara, 11-IX-1984, O. Yano et al. 9106 p.p. (SP191729). SERgIPE: Itabaiana, Serra de Itabaiana, 13-IX-1981, D. Andrade-Lima 81-6825 (SP174015).

Distribuição no Brasil: AC, AM, BA, CE, DF, ES, GO, 
MG, MS, MT, RJ, RR, RS, SC, SE e SP.

Ocorre em solo, tronco e tronco em decomposição, associada a Plagiochila fordiana Steph. ePrionolejeunea aemula (Gottsche) A. Evans.

* Telaranea pecten (Spruce) J.J. Engel \& G.L. Merrill, Fieldiana, Bot. n. ser., 44: 178. $2004 \equiv$ Arachniopsis pecten Spruce, Cephalozia: 85. 1882.

Ilustração: Fulford (1968, como Arachniopsis pecten) e Engel \& Smith Merrill (2004).

Material examinado: BRASIL. Pernambuco: Inajá, Serra Negra, alto da Serra, 6-IX-1980, O. Yano \& D. Andrade-Lima 2931 (SP191440).

Distribuição no Brasil: AM e SP.

Ocorre em solo.

* Zoopsidella integrifolia (Spruce) R.M. Schust., Bull. Natl. Sci. Mus., Tokyo s.n., 12(3): 666. 1969 E Cephalozia integrifolia Spruce, Cephalozia: 29. 1882.

Ilustração: Fulford (1968, como Zoopsis integrifolia) e Gradstein \& Costa (2003).

Material examinado: BRASIL. PERnAMBUCO: Jaqueira, Serra do Quengo, 8०42'50,4”S, 35 50 ' $28,8^{\circ}$ 'W, ca. $713 \mathrm{~m}$ alt., 2-IV-2002, M.R. Pietrobom \& M.S. Lopes 5465 p.p. (SP403062); Rio Formoso, Estação Experimental de Saltinho, 11-IX-1984, O. Yano et al. 9117 (SP191740); Cabo, Estação de Gurjaú, 14-IX-1984, O. Yano \& K.C. Pôrto 9178 (SP191800).

Distribuição no Brasil: AM, BA, DF, GO, MG, MT, PA, SE e SP.

Ocorre em solo e tronco em decomposição, associada a Syrrhopodon prolifer Schwägr.

\section{MARCHANTIACEAE}

* Dumortiera hirsuta (Sw.) Nees in Martius, Fl. Bras. Enum. Pl. 1(1): 307. 1833 = Marchantia hirsuta

Sw., Prodr. (Swartz): 145. 1789.

Ilustração: Hell (1969), Schuster (1992), Perold (1993) e Gradstein \& Costa (2003).

Material examinado: BRASIL. Pernambuco: Caruaru, Brejo dos Cavalos, ca. $940 \mathrm{~m}$ alt., 3-XII-2001, M.R. Pietrobom et al. 5246 (SP403043); Timbaúba, complexo da Serra do Mascarenhas, Usina Cruangi, Engenho Água Azul, área do Poço caudaloso, $7^{\circ} 37^{\prime} 7,3$ 'S, 35²3'43,1”W, ca. 304-451 m alt.,
14-XII-2001, M.R. Pietrobom 5441 (SP403057).

Distribuição no Brasil: AC, AM, DF, ES, MG, MS, MT, PA, PR, RJ, RS, SC e SP.

Ocorre em solo e rocha, associada a Lophocolea bidentata (L.) Dumort.

\section{METZGERIACEAE}

Metzgeria ciliata Raddi, Mem. Mat. Fis. Soc. Ital. Sci. Modena 19:41.1822 (1823).

Ilustração: Costa (1999, como M. decipiens, 2008) e Yano \& Peralta (2008, como M. decipiens).

Material examinado: BRASIL. Pernambuco: Caruaru, Brejo dos Cavalos, Mata de Galileu, ca. 800-900 m alt., 11-VIII-1998, O. Yano et al. 25560 (SP322403).

Distribuição no Brasil: BA, ES, GO, MG, PB, PE, $\mathrm{PR}, \mathrm{RJ}, \mathrm{RS}, \mathrm{SC}$ e SP (distribuição de $M$. decipiens, sinônimo de $M$. ciliata segundo Costa 2008).

Ocorre sobre tronco em decomposição.

Metzgeria conjugata Lindb., Acta Soc. Sci. Fenn. 10: 495. 1875.

Ilustração: Costa $(1999,2008)$ e Yano \& Peralta (2008).

Material examinado: BRASIL. Pernambuco: Inajá, Serra Negra, sobre Terminalia sp., 6-IX-1980, O. Yano \& D. Andrade-Lima 2958 (SP191459).

Distribuição no Brasil: AL, CE, ES, GO, MG, PE, PR, RJ, RS e SP.

Ocorre sobre tronco, associada a Frullania glomerata (Lehm. \& Lindenb.) Mont. e Schiffneriolejeunea polycarpa (Nees) Gradst.

Metzgeria convoluta Steph., Sp. Hepat. 1:288. 1899. Ilustração: Costa $(1999,2008)$ e Gradstein \& Costa (2003).

Material examinado: BRASIL. BAHIA: Santa Teresinha, Serra da Jibóia, próx. torre da Embratel, ca. $500 \mathrm{~m}$ alt., 6-IX-1994, C.W.N. Moura s.n. (SP283932).

Distribuição no Brasil: BA, GO, MG, PE, PR, RJ, $\mathrm{RS}, \mathrm{SC}$ e SP.

Ocorre sobre tronco.

* Metzgeria fruticola Spruce, Trans. \& Proc. Bot. Soc. Edinburgh 15: 554. 1885.

Ilustração: Kuwahara (1986) e Costa (1999, 2008). 
Material examinado: BRASIL. Pernambuco: Inajá, Serra Negra, sobre Pisonia sp., 6-IX-1980, O. Yano \& D. Andrade-Lima 2943 (SP191450).

Distribuição no Brasil: AL, PR, RJ, RS, SC e SP.

Ocorre sobre tronco, associada a Lejeunea phyllobola Nees \& Mont.

Metzgeria furcata (L.) Dumort., Recueil Observ. Jungerm.: 26. 1835 三 Jungermannia furcata L., Sp. Pl. 2: 1136. 1753.

Ilustração: Hell (1969), Costa (1999, 2008) e Yano \& Peralta (2008).

Material examinado: BRASIL. Pernambuco: Jaqueira, Serra do Quengo, 8`42'50,4”'S, 35'50'28,8'W, ca. 713 $\mathrm{m}$ alt., 2-IV-2002, M.R. Pietrobom \& M.S. Lopes 5476 (SP403071).

Distribuição no Brasil.: AC, BA, CE, ES, GO, MG, PE, PR, RJ, RS, SC e SP.

Ocorre sobre tronco.

Metzgeria leptoneura Spruce, Trans. \& Proc. Bot. Soc. Edinburgh 15: 555. 1885.

Ilustração: Costa $(1999,2008)$ e Yano \& Peralta (2008).

Material examinado: BRASIL. Pernambuco: Jaqueira, Serra do Quengo, 842'50,4'S, 35 50'28,8'W, ca. $713 \mathrm{~m}$ alt., 2-IV-2002, M.R. Pietrobom \& M.S. Lopes 5470 (SP403067); Altinho, Fazenda Taboca, 29-VIII-1980, O. Yano \& D. Andrade-Lima 2782 p.p. (SP191314).

Distribuição no Brasil: AM, BA, ES, MG, PE, PR, RJ, RS, SC e SP.

Ocorre sobre tronco, associada a Syrrhopodon incompletus Schwägr.

\section{PALLAVICINIACEAE}

Symphyogyna aspera Steph. in McCormick, Bot. Gaz. 58: 403.1914.

Ilustração: Hell (1969); Gradstein \& Costa (2003) e Yano \& Peralta (2008).

Material examinado: BRASIL. BAHIA: Uruçuca, $6,2 \mathrm{~km} \mathrm{~N}$ of town of Serra Grande, ca. $40 \mathrm{~km} \mathrm{~N}$ of Ilhéus along coast, ca. $200 \mathrm{~m}$ alt., $14^{\circ} 26^{\prime} \mathrm{S}$, $39^{\circ} 03^{\prime} \mathrm{W}$, wet tropical forest with small stream in ravine, 17-VII-1991, D.M. Vital \& W.R. Buck 20321
(NY, SP353952); Rio de Contas, estrada para Jussiape, 26-X-1994, S.R. Visnadi \& D.M. Vital 2596 (SP372885). Pernambuco: Jaqueira, Serra do Quengo, $8^{\circ} 42^{\prime}$ '50,4”'S, 3550'28,8' 'W, ca. 713 m alt., 2-IV-2002, M.R.Pietrobom \& M.S. Lopes 5471 (SP403068); São Vicente Ferrer, Complexo da Serra do Mascarenhas, mata do Estado, $7^{\circ} 35^{\prime} \mathrm{S}, 35^{\circ} 30^{\prime} \mathrm{W}$, ca. 600-650 m alt., 16-IX-1998, M.R. Pietrobom-Silva 4425 (SP352757); Quipapá, Engenho Brejinho, km 31 da BR-423, perto da cachoeira, 2-IX-1980, O. Yano \& J.Z. Brito 2892 (SP191408).

Distribuição no Brasil: AM, BA, CE, DF, ES, GO, MG, MS, MT, PA, PE, RJ, RS, SC e SP.

Ocorre em solo, rocha e tronco.

* Symphyogyna brasiliensis (Nees) Nees \& Mont. var. brasiliensis, Ann. Sci. Nat., Bot. sér. 2, 5: 67. 1836 三 Jungermannia brasiliensis Nees, Enum. Pl. Crypt. Javae 1: 11. 1830.

Ilustração: Hell (1969), Gradstein \& Costa (2003) e Yano \& Peralta (2008).

Material examinado: BRASIL, BAHIA: Serra da Água de Rega, gallery shade, ca. $26 \mathrm{~km}$ of Seabra, road to Água de Rega, near Rio Riachão, ca. $1.000 \mathrm{~m}$ alt., 23-II-1971, H.S. Irwin et al. 30853 (NY, SP133704); Santa Teresinha, Serra da Jibóia, 13-VIII-1995, E. Mello s.n. (SP283916). Pernambuco: Buíque, Vale do Catimbau, Poço do Pititi, 27-X-2000, M.R. Pietrobom \& V.S. Gomes 4629 (SP403011); Jaqueira, Serra do Quengo, 8०42'50,4”S, 35'50'28,8”W, ca. $713 \mathrm{~m}$ alt., 2-IV-2002, M.R. Pietrobom \& M.S. Lopes 5465 (SP403062); Altinho, Fazenda Taboca, base do morro, 29-VIII-1980, O. Yano \& D. Andrade-Lima 2802 (SP191330); Quipapá, Engenho Brejinho, km 31 da BR-423, perto da cachoeira, 2-IX-1980, O. Yano \& J.Z. Brito 2869 (SP191386).

Distribuição no Brasil: BA, CE, DF, ES, GO, MG, MT, PR, RJ, RO, RR, RS, SC e SP.

Ocorre em solo, rocha, tronco e tronco em decomposição, associada a Zoopsidella integrifolia (Spruce) R.M. Schust.

* Symphyogyna brongniartii Mont., Ann. Sci. Nat., Bot. sér. 2, 19: 265. 1843. Ilustração: Hell (1969) e Gradstein \& Costa (2003).

Material examinado:BRASIL. Pernambuco: Timbaúba, complexo da Serra do Mascarenhas, Usina Cruangi, Engenho Água Azul, 7³7'6”'S, 35²3’28,9”W, ca. 
304-394 m alt., 27-V-2001, M.R. Pietrobom 5231 (SP403022).

Distribuição no Brasil: AC, AM, BA, MG, RJ, SC e SP. Ocorre em rocha.

\section{PLAGIOCHILACEAE}

* Plagiochila adiantoides (Sw.) Lindenb., Sp. Hepat. fasc. 2-3: $77.1840 \equiv$ Jungermannia adiantoides Sw., Prodr. (Swartz): 142. 1788.

Ilustração: Lindenberg (1844), Gradstein \& Costa (2003) e Yano \& Peralta (2008).

Material examinado: BRASIL. BAHIA: Santa Teresinha, Serra da Jibóia, próx. torre da Embratel, $\pm 500 \mathrm{~m}$ alt., 6-IX-1994, C.W.N. Moura s.n. (SP283940); Ilhéus, Centro de Pesquisas do Cacau, km 22 da rod. IlhéusItabuna, 19-XII-1991, A.C. Messias \& S.L. Oliveira 192 (CEPEC51618, SP280853). Pernambuco: Quipapá, Engenho Brejinho, km 31 da BR-423, perto da cachoeira grande, 2-IX-1980, O. Yano \& J.Z. Brito 2899 (SP191414).

Distribuição no Brasil: BA, ES, MG, RJ e SP.

Ocorre em solo e tronco.

Plagiochila corrugata (Nees) Nees \& Mont., Ann. Sci. Nat., Bot. sér. 2, 5: 52. $1836 \equiv$ Jungermannia corrugata Nees in Martius, Fl. Bras. Enum. P1. 1(1): 378-379. 1833.

Ilustração: Lindenberg (1844), Lemos-Michel (2001), Gradstein \& Costa (2003) e Yano \& Peralta (2008).

Material examinado: BRASIL. Pernambuco: Escada, Engenho Massauaçu, perto do rio Pirapama, 23-VIII-1980, O. Yano \& D. Andrade-Lima 2562 (SP191134); Taquaritinga do Norte, Morro Cafundó, sobre Inga sp., 24-VIII-1980, O. Yano \& D. Andrade-Lima 2596 (SP191163); São Lourenço da Mata, Engenho São Bento, Estação Ecológica de Tapacurá, Mata Toró-Cuiera, 26-VIII-1980, O. Yano \& D. Andrade-Lima 2666 (SP191220); idem, perto do riacho, 26-VIII-1980, O. Yano \& D. Andrade-Lima 2682 (SP191234); Bituri Grande, Brejo da Madre de Deus, Mata do Caçange, 19-X-1980, L.C.F. Araújo s.n. (SP191517); Bonito, Reserva Municipal, ca. 8 km da cidade, ca. $720 \mathrm{~m}$ alt., 6-VIII-1998, O. Yano et al. 25433 (SP322288); Inajá, Serra Negra, 6-IX-1980, O. Yano \& D. Andrade-Lima 2955 (SP191456).

Distribuição no Brasil: AC, BA, CE, DF, ES, GO, MG,
PE, PR, RJ, RS, SC e SP.

Ocorre em rocha e tronco.

Plagiochila disticha (Lehm. \& Lindenb.) Mont., Ann. Sci. Nat., Bot. sér. 2, 14:332. $1840 \equiv$ Jungermannia disticha Lehm. \& Lindenb. in Lehmann, Nov. Stirp. Pug. 6: 64. 1834.

Ilustração: Lemos-Michel (2001), Gradstein \& Costa (2003) e Yano \& Peralta (2008).

Material examinado: BRASIL. Alagons: Boca da Mata, Alto da Serra da Nacéia, 29-X-1980, D. Andrade-Lima 80-6665 (SP191542). BAHIA: Itabuna, plantações de cacau da CEPLAC, 24-I-1980, D.M. Vital 8661 (SP133351); idem, sobre cacaueiro, 24-I-1980, D.M. Vital 8687 (SP133359); idem, 24-I-1980, D.M. Vital 8694 (SP133363); idem, sobre cacaueiro, 25-I-1980, O. Yano 2305 (SP133489); idem, 25-I-1980, O. Yano 2313 (SP133492); Santa Teresinha, Serra da Jibóia, próx. torre da Embratel, ca. 500 m alt., 6-IX-1994, C.W.N. Moura s.n. (SP283938). Pernambuco: Vicência, Engenho Jundiá, Pedra de São José, 26-V-2001, M.R. Pietrobom et al. 5194 (SP403019); Timbaúba, complexo da Serra do Mascarenhas, Usina Cruangi, Engenho Água Azul, 7³6’31,5”S, 35²2'42,9”'W, ca. 304-394 m alt., 13-XI-2000, M.R. Pietrobom et al. 4662 (SP403014); idem, 31-III-2001, M.R. Pietrobom \& A.C.P. Santiago 5066 (SP403017); Quipapá, Engenho Brejinho, km 31 da BR-423, perto da cachoeira, 2-IX-1980, O. Yano \& J.Z. Brito 2848 (SP191373); idem, perto da cachoeira, 2-IX-1980, O. Yano \& J.Z. Brito 2852 (SP191377); Inajá, Serra Negra, 5-IX-1980, O. Yano \& D. AndradeLima 2911 (SP191424); idem, 6-IX-1980, O. Yano \& D. Andrade-Lima 2959 (SP191460); idem, 6-IX-1980, O. Yano \& D. Andrade-Lima 2928 (SP191437); Brejo da Madre de Deus, Bituri Grande, mata do Cassange, 19-II-1981, D. Andrade-Lima 81-6679 (SP191556); São Lourenço da Mata, Tapacurá, 4-II-1988, O. Yano \& G. Mariz 11266 (SP222210).

Distribuição no Brasil: AC, AL, AM, AP, BA, CE, DF, ES, GO, MG, MS, MT, PA, PB, PE, RJ, RR, RS, $\mathrm{SC}$ e SP.

Ocorre em rocha e tronco, associada a Ceratolejeunea cubensis (Mont.) Schiffn., Frullania brasiliensis Raddi, F. ericoides (Nees) Mont. e Radula tectiloba Steph. 
* Plagiochila fordiana Steph., Sp. Hepat. 21: 284. 1902.

Figura 10

Ilustração adicional: Inoue (1968).

Material examinado: BRASIL. BAHIA: Una, Reserva Biológica do Mico-Leão, km 46 da rod. BA001 Ilhéus-Una, $15^{\circ} 09^{\prime} \mathrm{S}, 39^{\circ} 05^{\prime} \mathrm{W}, 14-\mathrm{XI}-1992$, S.L. Oliveira 268 (CEPEC55918, SP280890).

Distribuição: Hong Kong, Vietinam, provavelmente na Ásia Tropical e Brasil.

O ápice do filídio é bidentado, raramente tridentado, não apresenta dentes na margem e os trigônios são bem evidentes.

Ocorre sobre tronco, associada a Prionolejeunea aemula (Gotttsche) A. Evans e Telaranea nematodes (Gottsche ex Austin) M. Howe.

Plagiochila gymnocalyciana (Lehm. \& Lindenb.) Mont., d'Orbigny Voy. Amer. Mer. Bot. 7(2): 81. 1839 三 Jungermannia gymnocalyciana Lehm. \& Lindenb. in Lehmann, Nov. Stirp. Pug. 5: 28. 1833.

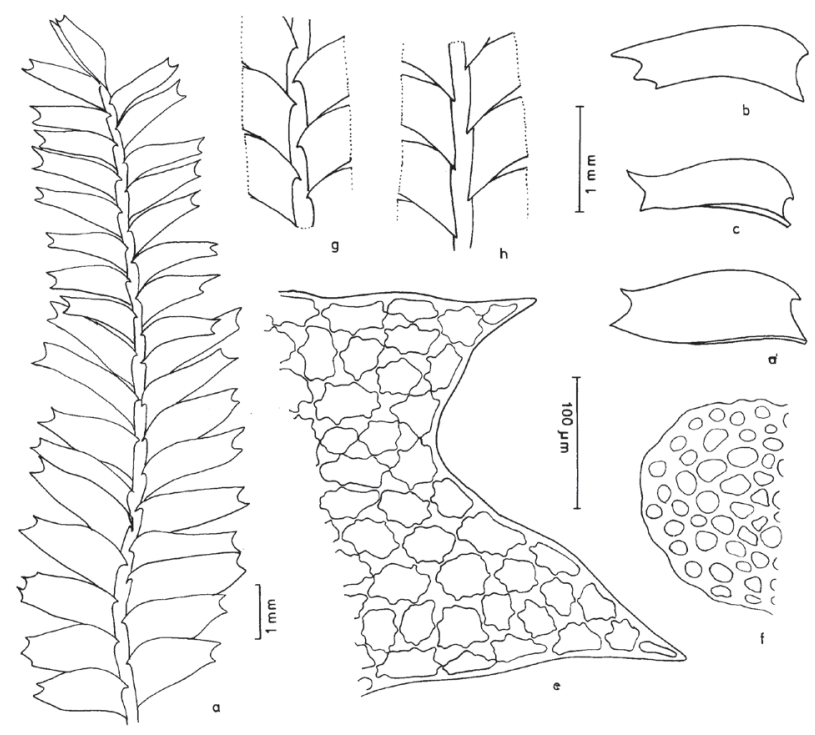

Figura 10. Plagiochila fordiana. a. Aspecto geral do gametófito. b-d. Filídios. e. Detalhe das células e ápice do filídio. f. Secção transversal do caulídio. g. Vista ventral da inserção dos filídios. h. Vista dorsal da inserção dos filídios.

Figure 10. Plagiochila fordiana. a. General aspect of the gametophyte. b-d. Leaves. e. Apical cells of the leaf. f. Cross section of stem. g. Ventral view of leaf insertion. h. Dorsal view of leaf insertion.
Ilustração:Lindenberg(1844), Gradstein \& Costa(2003). Material examinado: BRASIL. BAHIA: Una, Reserva Biológica do Mico Leão, $\mathrm{km} 46$ da rod. Ilhéus-Una, 159'S, 395'W, 14-XI-1992, S.L. Oliveira 257 (CEPEC25772, SP280889); Ilhéus, 5-6 km de Olivença, 29-VII-1993, S.L. Oliveira 335 (CEPEC55888, SP280895).

Distribuição no Brasil: AC, AL, BA, ES, MG, PA, PE, RJ, SC e SP.

Ocorre sobre tronco vivo.

* Plagiochila macrostachya Lindenb., Sp. Hepat. Fasc. 2-4: 75. 1840.

Ilustração: Lindenberg (1844), Gradstein \& Costa (2003).

Material examinado: BRASIL. Pernambuco: Timbaúba, complexo da Serra do Mascarenhas, Usina Cruangi, Engenho Água Azul, área do poço caudaloso, $7^{\circ} 37^{\prime} 7,3^{\prime}$ 'S, 35 $5^{\circ} 23^{\prime} 43,1^{\prime}$ W, ca. 304-451 m alt., 14-XII-2001, M.R. Pietrobom 5440 (SP403056); Jaqueira, Serra do Urubu, Mata do Quengo, 8०42'37'S, 3550'1'W, ca. 500-750 m alt., 31-V-2001, M.R. Pietrobom \& M.S. Lopes 5293 p.p. (SP403029).

Distribuição no Brasil: ES, GO, MG, RJ, SC e SP.

Ocorre em rocha e tronco, associada com Taxilejeunea pterigonia (Lehm. \& Lindenb.) Schiffn.

Plagiochila martiana (Nees) Lindenb., Sp. Hepat. fasc. 1:12. $1839 \equiv$ Jungermannia martiana Nees, Linnaea 6: 617. 1831.

Ilustração: Lemos-Michel (2001), Gradstein \& Costa (2003) e Yano \& Peralta (2008).

Material examinado: BRASIL. Alagoas: São Miguel dos Campos, Fazenda Pau Brasil, 28-X-1980, D. Andrade-Lima 80-6650 (SP191532); Boca da Mata, Alto da Serra da Nacéia, 29-X-1980, D. Andrade-Lima 80-6671 (SP191548). BAHIA: Ilhéus, Centro de Pesquisas do Cacau, km 22 da rod. Ilhéus-Itabuna, 19-XII-1991, A.C. Messias \& S.L. Oliveira 193 (CEPEC51619, SP280854); Itabuna, nas plantações de cacau da CEPLAC, 24-I-1980, D.M. Vital 8664 (SP133353); Ilha Grande, Baia de Camanu, 29-III-1992, C.S.N. Guimarães s.n. (ALCB18584, SP241996). Pernambuco: Vicência, Morro do Engenho Jundiá, 17-XII-2001, M.R. Pietrobom 5250 (SP403052); Recife, Mata de Dois Irmão, perto da sede do reservatório, 
3-VIII-1998, O. Yano et al. 25414 (SP322269); idem, 3-VIII-1998, O. Yano et al. 25415 (SP322270); idem, 3-VIII-1998, O. Yano et al. 25416 (SP322271); Caruaru, Brejo dos Cavalos, Mata de Galileu, ca. 800-900 m alt., 11-VIII-1998, O. Yano et al. 25555 (SP322398); idem, 11-VIII-1998, O. Yano et al. 25557 ( SP322400); São Vicente Ferrer, Complexo da Serra do Mascarenhas, mata do Estado, $35^{\circ} 30^{\prime} \mathrm{W}, 7^{\circ} 35^{\prime} \mathrm{S}$, ca. 600-650 m alt., junto do regato, 16-IX-1998, M.R. Pietrobom-Silva 4426 (SP352758); Inajá, Serra Negra, 6-IX-1980, O. Yano \& D. Andrade-Lima 2967 (SP191468); São Lourenço da Mata, Mata do Toró, 21-XII-1984, O. Yano et al. 9314 (SP191933); idem, 4-II-1988 O. Yano \& G. Mariz 11260 (SP222204); idem, 6-VIII-1986, O. Yano et al. 10333 (SP207007); idem, 6-VIII-1986, O. Yano et al. 10335 (SP207009); Escada, Engenho Massauaçu, sobre raízes de Pisonia sp., perto do rio Pirapama, 23-VIII-1980, O. Yano \& D. Andrade-Lima 2575 (SP191144); idem, perto do rio Pirapama, 23-VII-1980, O. Yano \& D. AndradeLima 2581 (SP1919150).

Distribuição no Brasil: AC, AL, BA, CE, DF, ES, GO, MG, MS, MT, PA, PE, PR, RJ, RS, SC e SP.

Ocorreemsolo, rocha, troncoetroncoem decomposição.

* Plagiochila micropteryx Gottsche, Ann. Sci. Nat., Bot. sér. 5, 1: 107. 1864.

Ilustração: Lemos-Michel (2001) e Gradstein \& Costa (2003).

Material examinado: BRASIL. Pernambuco: Taquaritinga do Norte, ao lado da microonda, 24-VIII-1980, O. Yano \& D. Andrade-Lima 2632 (SP191191); Quipapá, Engenho Brejinho, km 31 da BR-423, perto da cachoeira, 2-IX-1980, O. Yano \& J.Z. Brito 2874 (SP191390).

Distribuição no Brasil: AC, BA, CE, ES, MG, PA, RJ, RS e SP.

Ocorre sobre rocha.

Plagiochila montagnei Nees in Nees \& Mont., Ann. Sci. Nat., Bot. sér. 2, 5: 531. 1836.

Ilustração: Heinrichs \& Gradstein (2000), Gradstein \& Costa (2003) e Zartman \& Ilkiu-Borges (2007).

Material examinado: BRASIL. Pernambuco: Moreno, Morro Buscau, 23-VIII-1980, O. Yano \& D. Andrade-Lima 2588 (SP191155); Rio Formoso, Córrego da Juçara, 11-IX-1984, O. Yano et al. 9087
(SP191710); idem, Estação Experimental de Saltinho, base do tronco, próx. margem do rio, 11-IX-1984, O. Yano et al. 9129 (SP191751).

Distribuição no Brasil: AC, AL, AM, BA, CE, ES, PA, PE, RJ, RS e SP.

Ocorre sobre rocha e tronco.

* Plagiochila patentissima Lindenb., Spec. Hepat.: 64. 1840.

Ilustração: Lindenberg (1844) e Gradstein \& Costa (2003).

Material examinado: BRASIL. Pernambuco: Taquaritinga do Norte, ao lado da microonda, 24-VIII-1980, O. Yano \& D. Andrade-Lima 2635 (SP191193).

Distribuição no Brasil: BA, ES, MG, PR, RJ, RS, SC e SP.

Ocorre sobre rocha.

* Plagiochila patula (Sw.) Lindenb., Sp. Hepat. fasc. 1:21. 1839 =Jungermannia patula Sw., Flora Ind. Occid. 3: 1844. 1806.

Ilustração: Lindenberg (1844), Heinrichs et al. (1998) e Gradstein \& Costa (2003).

Material examinado: BRASIL. BAHIA: Ilhéus, Centro de Pesquisas do Cacau, km 22 on BR-415 between Ilhéus and Itabuna, $14^{\circ} 50^{\prime} \mathrm{S}, 39^{\circ} 13^{\prime} \mathrm{W}$, mata higrófila sul baiana, Parque Zoobotânico, cacau plantation, 15-VII-1991, D.M. Vital \& W.R. Buck 20159 (NY, SP353858); idem, 15-VII-1991, D.M. Vital \& W.R. Buck 20161 (NY, SP353860); idem, ca. $6 \mathrm{~km}$ SW of Olivença on road to Maruim, $15^{\circ} \mathrm{S}, 39^{\circ} 04^{\prime} \mathrm{W}$, restinga, 16-VII-1991, D.M. Vital \& W.R. Buck 20263 (NY, SP353917). Pernambuco: Bonito, Cachoeira do Oriente, ca. $19 \mathrm{~km}$ da cidade, ca. $500 \mathrm{~m}$ alt., perto da cachoeira, 6-VIII-1998, O. Yano et al. 25484 (SP322330); Caruaru, Fazenda Caruaru, Brejo dos Cavalos, 29-VIII-1980, O.Yano \& D. Andrade-Lima 2735 (SP191279); idem, 29-VIII-1980, O. Yano \& D. Andrade-Lima 2741 (SP191284); idem, 29-VIII-1980, O.Yano \& D. Andrade-Lima 2742 (SP191285); idem, sobre Araceae, Brejo dos Cavalos, 29-VIII-1980, O. Yano \& D. Andrade-Lima 2744 (SP191287).

Distribuição no Brasil: AC, BA, CE, DF, MG, RJ, $\mathrm{SC}$ e SP.

Ocorre sobre rocha, tronco e tronco em decom- 
posição, associada a Cheilolejeunea rigidula (Mont.) R.M. Schust.

Plagiochila raddiana Lindenb., Sp. Hepat. fasc. 1: 9. 1839.

Ilustração: Gradstein et al. (2001), Gradstein \& Costa (2003) e Yano \& Peralta (2008).

Material examinado: BRASIL. BAHIA: Ilhéus, Centro de Pesquisas do Cacau, km 22 da rod. Ilhéus-Itabuma, BR-415, 9-I-1992, S.L. Oliveira \& A.C. Messias 185 (CEPEC51271, SP2 80884). Pernambuco: Escada, Engenho Massauaçu, perto do rio Pirapama, 23-VIII-1980, O. Yano \& D. Andrade-Lima 2563 (SP191136); Timbaúba, complexo da Serra do Mascarenhas, usina Cruangi, Engenho Água Azul, área do Poço Caudaloso, 7³7'7,3'S, 35²3'43,1'W, ca. 304-451 malt., 15-XII-2001, M.R. Pietrobom 5463 (SP403060).

Distribuição no Brasil: AC, AM, BA, CE, ES, GO, MG, MT, PA, PE, PR, RJ, RS, SC e SP.

Ocorre sobre tronco e tronco em decomposição.

Plagiochila rutilans Lindenb., Sp. Hepat. fasc. 2-4: 47. 1841.

Ilustração: Lemos-Michel (2001), Gradstein \& Costa (2003) e Yano \& Peralta (2008).

Material examinado: BRASIL. BAHIA: Santa Teresinha, Serra da Jibóia, 12 ${ }^{\circ} 51^{\prime} 17^{\prime}$ 'S, 49²8'30”W, 15-V1999, G. Britto et al. 6 (HUEFS37967, SP326902); Itabuna, plantações de cacau da CEPLAC, 24-I-1980, D.M. Vital 8663 (SP133352). Pernambuco: Taquaritinga do Norte, mata da microonda, 24-VIII-1980, O. Yano \& D. Andrade-Lima 2640 (SP191198); Jaqueira, Serra do Urubu, Mata do Quengo, 8०42'37"S, 3550'1”W, ca. 500$750 \mathrm{~m}$ alt., 1-VI-2001, M.R. Pietrobom \& M.S. Lopes 5294 (SP403030); idem, Serra do Quengo, 8'42'50,4”'S, 35'50'28,8'W, ca. 713 m alt., 2-IV-2002, M.R. Pietrobom \& M.S. Lopes 5467 (SP403064); Caruaru, Brejo dos Cavalos, ca. $940 \mathrm{~m}$ alt., 3-XII-2001, M.R. Pietrobom et al. 5245 (SP403042); Altinho, Fazenda Taboca, 29-VIII-1980, O. Yano \& D. Andrade-Lima 2791 (SP191320); Bonito, Reserva Municipal, ca. $8 \mathrm{~km}$ da cidade, ca. 720 malt., 6-VIII-1998, O. Yano et al. 25436 (SP322291).

Distribuição no Brasil: AC, AM, AP, BA, CE, ES, MG, MT, PA, PE, RJ, RR, RS, SC e SP.

Ocorre sobre rocha e tronco, associada a Crossomitrium patrisiae (Brid.) Müll. Hal. e
Neckeropsis disticha (Hedw.) Kindb.

Plagiochila simplex (Sw.) Lindenb., Sp. Hepat. fasc. 2, 4: 54. 1840 三 Jungermannia simplex Sw., Prodr. (Swartz): 143. 1788.

Ilustração: Lindenberg (1844) e Gradstein \& Costa (2003).

Material examinado: BRASIL. Pernambuco: Jaqueira, Serra do Urubu, Mata do Quengo, 8०42'37'S, 35 50' ' "W, ca. 500-750 m alt., 1-VI-2001, M.R. Pietrobom \& M.S. Lopes 5295 (SP403031).

Distribuição no Brasil: AM, BA, ES, GO, MG, PA, PE, RJ e SP.

Ocorre em rocha.

* Plagiochila subplana Lindenb., Sp. Hepat. fasc. 2, 4: 73. 1840.

Ilustração: Lindenberg (1844) e Gradstein \& Costa (2003).

Material examinado: BRASIL. Pernambuco: Timbaúba, complexo da Serra do Mascarenhas, Usina Cruangi, Engenho Água Azul, 7³7’06”'S, 35²3'28,9'W, ca. 304-394 m alt., 27-V-2001, M.R. Pietrobom 5229 (SP403020).

Distribuição no Brasil: AC, AM, BA, MG, MT, PA, RJ, RR, SC e SP.

Ocorre em rocha.

\section{PORELLACEAE}

* Porella brasiliensis (Raddi) Schiffn., Nova Acta Acad. Caes. Leop.-Carol. German. Nat. Cur. 60: 246. $1893 \equiv$ Schultesia brasiliensis Raddi, Mem. Mat. Fis - Soc. Ital. Sci. Modena 19: 10. 1822.

Ilustração: Herzog (1923, como Madotheca ligula), Lemos-Michel (2001) e Yano \& Peralta (2008).

Material examinado: BRASIL. Pernambuco: Taquaritinga do Norte, ao lado da microonda, 24-VIII-1980, O. Yano \& D. Andrade-Lima 2631 (SP191190).

Distribuição no Brasil: DF, GO, MG, PR, RJ, RS, SC e SP.

Ocorre sobre tronco.

\section{RADULACEAE}

* Radula cubensis K. Yamada, J. Hattori Bot. Lab. 
54: 241. 1983.

Ilustração: Yamada (1983) e Gradstein \& Costa (2003).

Material examinado: BRASIL. Pernambuco: Taquaritinga do Norte, ao lado da microonda, 24-VIII-1980, O. Yano \& D. Andrade-Lima 2636 (SP191194); São Lourenço da Mata, Engenho SãoBento, Estação Ecológica de Tapacurá, Mata Toró-Cuieira, 26-VIII-1980, O. Yano \& D. Andrade-Lima 2659 (SP191214).

Distribuição no Brasil: BA, ES, SC e SP.

Ocorre em rocha e folha.

* Radula flaccida Lindenb. \& Gottsche in Gottsche et al., Syn. Hepat.: 726. 1847.

Ilustração: Gradstein et al. (2001), Gradstein \& Costa (2003) e Zartman \& Ilkiu-Borges (2007).

Material examinado: BRASIL. Pernambuco: São Lourenço da Mata, Engenho São Bento, Estação Ecológica de Tapacurá, Mata Toró-Cuieira, perto do riacho, 26-VIII-1980, O. Yano \& D. Andrade-Lima 2662 (SP191217); idem,4-II-1988, O. Yano \& G. Mariz 11248 (SP222192).

Distribuição no Brasil: AC, AL, AM, BA, ES, MG, PA, RR e SP.

Ocorre sobre folha e tronco.

Radula javanica Gottsche in Gottsche et al., Syn. Hepat.: 257. 1845.

Ilustração: Lemos-Michel (2001, como R. macrostachya), Gradstein \& Costa (2003) e Yano \& Peralta (2008).

Material examinado: BRASIL. BAHIA: Santa Teresinha, Serra da Jibóia, próx. torre da Embratel, ca. 599 m alt., 6-IX-1994, C.W.N. Moura s.n. (SP283941); Uruçuca, $6,2 \mathrm{~km} \mathrm{~N}$ of town of Serra Grande, ca. $40 \mathrm{~km} \mathrm{~N}$ of Ilhéus along coast, ca. $200 \mathrm{~m}$ alt., $14^{\circ} 26^{\prime} \mathrm{S}, 39^{\circ} 03^{\prime} \mathrm{W}$, wet tropical forest with small stream in ravine, 17-VII-1991, D.M. Vital \& W.R. Buck 20271 (NY, SP353920). Pernambuco: Jaqueira, Serra do Urubu, Mata do Ageró, 8`44'9,1'S, 3550'17'W, ca. 585 $\mathrm{m}$ alt., 18-X-2001, M.R. Pietrobom \& M.S.Lopes 5237 (SP403038); Vicência, Mata da Macambira, 13-XII-2001, M.R. Pietrobom 5249a (SP403051); São Vicente Ferrer, Complexo da Serra do Mascarenhas, Mata do Estado, $7^{\circ} 35^{\prime}$ S, 35 3030'W, ca. 600-650 m alt., 22-II-1999, M.R. Pietrobom-Silva 4534 (SP352773).
Distribuição no Brasil: AC, AM, AP, BA, ES, MG, MS, MT, PA, PE, PR, RJ, RS, SC e SP.

Ocorre em rocha e tronco.

* Radula ligula Steph., Sp. Hepat. 4: 228. 1910. Ilustração: Oliveira (1973), Yamada (1981) e Gradstein \& Costa (2003).

Material examinado: BRASIL. Pernambuco: Quipapá, Engenho Brejinho, km 31 da BR-423, perto da cachoeira, 2-IX-1980, O. Yano \& J.Z. Brito 2890 (SP191406).

Distribuição no Brasil: AL, BA, PR, RJ, RS e SC.

Ocorre sobre rocha.

Radula mexicana Lindenb. \& Gottsche in Gottsche, Kongel. Danske Vidensk. Selsk. Skr., Naturvidensk. Math. Afd..: 150. 1863.

Ilustração: Oliveira-e-Silva \& Yano (2000) e Gradstein \& Costa (2003).

Material examinado: BRASIL. Pernambuco: Escada, Engenho Massauaçu, perto do rio Pirapama, 23-VIII-1980, O. Yano \& D. Andrade-Lima 2567 (SP191139); idem, 23-VIII-1980, O. Yano \& D. Andrade-Lima 2583 (SP191152); Caruaru, Brejo dos Cavalos, Mata de Galileu, ca. 800-900 m alt., 11-VIII-1998, O. Yano et al. 25559 (SP322402).

Distribuição no Brasil: BA, ES, PE, RJ, RS e SP.

Ocorre sobre rocha e tronco.

* Radula nudicaulis Steph., Sp. Hepat. 4: 174. 1910. Ilustração: Costa (1992) e Gradstein \& Costa (2003).

Material examinado: BRASIL. Pernambuco: Timbaúba, complexo da Serra do Mascarenhas, Usina Cruangi, Engenho Água Azul, área do Poço Caudaloso, 7³7'7,3'S, 35²3'43,1'W, ca. 304-451 m alt., 14-XII-2001, M.R. Pietrobom 5439 (SP403055); São Lourenço da Mata, Tapacurá, perto do riacho, 4-II-1988, O. Yano \& G. Mariz 11262 (SP222206).

Distribuição no Brasil: ES, MG, PR, RJ e SP.

Ocorre sobre rocha.

* Radula quadrata Gottsche in Gottsche et al., Syn. Hepat.: 255. 1844.

Ilustração: Castle (1964), Reiner-Drehwald (1994) e Gradstein \& Costa (2003).

Material examinado: BRASIL. PeRnambuco: Inajá, Serra Negra, O. Yano \& D. Andrade-Lima 2929 (SP191438). 
Distribuição no Brasil: BA, GO, MG, PA, PR, RJ, RS, SC e SP.

Ocorre sobre tronco.

Radula recubans T. Taylor, London J. Bot. 5: 376. 1846.

Ilustração: Castle (1966), Yamada (1980) e Gradstein \& Costa (2003).

Material examinado: BRASIL. Pernambuco: Escada, Engenho Massauaçu, perto do rio Pirapama, 23-VIII1980, O. Yano \& D. Andrade-Lima 2582 (SP191151).

Distribuição no Brasil: AC, AL, BA, PA, PE, RJ, RS, SC e SP.

Ocorre sobre rocha.

Radula tectiloba Steph., Hedwigia 27: 298. 1888. Ilustração: Yamada (1981), Lemos-Michel (2001) e Gradstein \& Costa (2003).

Material examinado: BRASIL. BAHIA: Itabuna, plantações de cacau da CEPLAC, sobre cacaueiro, 24-I-1980, D.M. Vital 8656 (SP133350); idem, 24-I-1980, D.M. Vital 8697 (SP133365); idem, 25-I-1980, O. Yano 2321 (SP133496).

Distribuição no Brasil: BA, ES, GO, MS, PR, RJ, RS, SC e SP.

Ocorre sobre tronco.

\section{RICCIACEAE}

Riccia horrida Jovet-Ast, Cryptog. Bryol. Lichénol. 12(3): 226. 1991.

Ilustração: Jovet-Ast (1991) e Bischler-Causse et al. (2005).

Material examinado: BRASIL. BAHIA: Cruz das Almas, mata ciliar, 24-VI-2004, D.F. Peralta et al. 2468 (SP368949).

Distribuição no Brasil: BA e ES.

Ocorre em solo.

Riccia lindmanii Steph., Bih. Kongl. Svenska Vetensk.-Akad. Handl. 23(III, 2): 29. 1897.

Ilustração: Jovet-Ast (1991) e Bischler-Causse et al. (2004).

Material examinado: BRASIL. BAHIA: Cruz das Almas, mata ciliar, 24-VI-2004, D.F. Peralta et al. 2469 (SP368950).
Distribuição no Brasil: BA, MS e RS.

Ocorre em solo.

Riccia membranacea Gottsche \& Lindenb. in Gottsche et al., Syn. Hepat.: 608. 1846.

Ilustração: Vianna (1985), Yano et al. (1987), Gradstein \& Costa (2003) e Bischler-Causse et al. (2005).

Material examinado: BRASIL. BAhIA: Feira de Santana, Campus da Universidade Estadual de Feira de Santana, 29-VI-2009, D.F. Peralta \& L.T.P. Silva 8526 (SP413959). Pernambuco: Escada, Engenho Massauaçu, perto do rio Pirapama, 24-VIII-1980, O. Yano \& D. Andrade-Lima 2650 (SP191208); Cabo, Estação de Gurjaú, 14-IX-1984, O. Yano \& K.C. Pôrto 9192 (SP191814); Recife, Campus da Universidade Federal de Pernambuco, entre os prédios do Instituto de Biologia, 10-IX-1984, O. Yano \& K.C. Pôrto 9066 (SP191689); idem, atrás do Depto. de Botânica, 29-VIII-1986, M.G.V. Marinho s.n. (SP362186); idem, 5-VIII-1998, O. Yano et al. 25420 (SP322275).

Distribuição no Brasil: AC, AM, ES, MT, PA, PE, RS e SP.

Ocorre em solo, associada a Notothylas vitalii Udar \& Singh e Riccia stenophylla Spruce.

Riccia planobiconvexa Steph., Bih. Kongl. Svenska Vetensk.-Akad. Handl. 23(III, 2): 29. 1897.

Ilustração: Vianna (1985), Jovet-Ast (1991), Gradstein $\&$ Costa (2003) e Bischler-Causse et al. (2005).

Material examinado: BRASIL. BAHIA: Ilhéus, Centro de Pesquisas do Cacau, km 22 on BR-415 between Ilhéus and Itabuna, $14^{\circ} 50$ ' S, $39^{\circ} 13^{\prime} \mathrm{W}$, mata higrófila sul baiana in Parque Zoobotânico, overgrown cacau plantatiom 15-VII-1991, D.M. Vital \& W.R. Buck 20169 (NY, SP353868); Feira de Santana, Campus da Universidade Estadual de Feira de Santana, 29-VI-2009, D.F. Peralta \& L.T.P. Silva 8523 (SP413956); idem, 29-VI-2009, D.F. Peralta \& L.T.P. Silva 8525 (SP413958). Pernambuco: São Lourenço da Mata perto do Engenho São Bento, Mata de Tapacurá, 6-VIII-1986, O. Yano et al. 10316 (SP206990).

Distribuição no Brasil: AL, BA, DF, ES, MT, PE, PR, RJ, RN, RS, SC e TO.

Ocorre em solo. 
Riccia ridleyi Gepp, J. Linn. Soc., Bot. 27: 74. 1890. Ilustração: Jovet-Ast (1991) e Bischler-Causse et al. (2005).

Material examinado: BRASIL. PERNAMBUCO: Fernando de Noronha, próx. base do Pico, 31-VII-1978, D.M. Vital 8320 (SP133191); idem, entre o Alto da Bandeira, 4-VIII-1978, D.M. Vital 8347 (SP133200); idem, Morro do Pico, $\pm 315 \mathrm{~m}$ alt., junto da escadaria no pico, 25-XI-1989, O. Yano \& D.P. Costa 13673 (SP228546); idem, praia do Sancho, 27-XI-1989, O.Yano \& D.P. Costa 13675 (SP228547).

Distribuição no Brasil: PE (Ilha de Fernando de Noronha, Pico).

Ocorre em solo.

Riccia squamata Nees in Martius, Fl. Bras. Enum. P1. 1(1): 302. 1833.

Ilustração: Jovet-Ast (1991) e Bischler-Causse et al. (2005).

Material examinado: BRASIL. BAHIA: Iraquara, Fazenda Pratinga, margin of Rio Santo Antonio, ca. $16 \mathrm{~km} \mathrm{SSE}$ of Iraquara, caatinga moist soil, 14-VI-1981, B.M. Boom et al. 1202 (SP379197); Feira de Santana, 23-X-1990, O. Yano et al. 15055 (SP231175); idem, 23-X-1990, O. Yano et al. 15059 (SP231179); idem, 23-X-1990, O. Yano et al. 15060 (SP231180); idem, caatinga, 23-X-1990, O. Yano \& J.O. Pereira 15101 (SP231198); Brumado, km 121 on BA-262 between Vitória da Conquista and Brumado, $15 \mathrm{~km}$ SE of

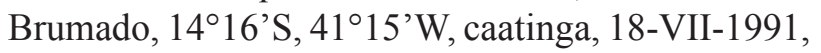
D.M. Vital \& W.R. Buck 20354 (NY, SP353967).

Distribuição no Brasil: BA, CE, MG, PB, PE e PI.

Ocorre em solo, associada a Riccia vitalii Jovet-Ast.

Riccia stenophylla Spruce, Bull. Soc. Bot. France 36 (suppl.): 195. 1889.

Ilustração: Vianna (1985), Gradstein \& Costa (2003), Bischler-Causse et al. (2005) e Yano \& Peralta (2008).

Material examinado: BRASIL. BAHIA: Itabuna, plantações de cacau da CEPLAC, canal de drenagem, 24I-1980, D.M. Vital 8708(SP133372); idem, ca. $35 \mathrm{~km} \mathrm{SW}$ de Maracás, caatinga, 26-I-1980, D.M. Vital 8716 (SP133375); Ilhéus, Centro de Pesquisas do Cacau, km 22 on BR-415, between Ilhéus and Itabuna, 14 ${ }^{\circ} 50^{\prime}$ S, 39¹3'W, cacau plantation, 15-VII-1991, D.M. Vital \& W.R. Buck 20172 (NY, SP353871); Feira de Santana, Campus da Universidade Estadual de Feira de Santana, 29-IV-2009, D.F. Peralta \& L.T.P Silva 8522 (SP413955). Pernambuco: Recife, Instituto de Pesquisas Agrônomicas, V-1967, cacimba, L.M.Carvalho s.n. (SP87333); idem, Campus da Universidade Federal de Pernambuco, 5-VIII-1998, O. Yano et al. 25423 (SP322278); idem, entre os prédios do Instituto de Biologia, 10-IX-1984, O. Yano \& K.C. Pôrto 9064 (SP191687); Caruaru, Brejo dos Cavalos, ca. $780 \mathrm{~m}$ alt., regos de drenagem, 11-VIII-1998, O. Yano et al. 25534 (SP322377).

Distribuição no Brasil: BA, CE, ES, GO, MT, PE, PR, RJ, RS, SC e SP.

Ocorre em solo, associada a Riccia membranacea Gottsche.

Riccia subdepilata Jovet-Ast, Cryptog. Bryol. Lichénol. 12(3): 228. 1991.

Ilustração: Jovet-Ast (1991) e Bischler-Causse et al. (2005).

Material examinado: BRASIL. BAHIA: Feira de Santana, Campus da Univerisdade Estadual de Feira de Santana, 29-VI-2009, D.F. Peralta \& L.T.P. Silva 8527 (SP413960). PernAmbuCo: Garanhuns, auf. schattigen Wegen in Stadt park, 840 m alt., 14-VII-1990, Schäfer-Verwimp \& Verwimp 12986 (hb. SchäferVerwimp, SP386295); São Lourenço da Mata perto do Engenho São Bento, Mata de Tapacurá, 6-VIII-1986, O. Yano et al. 10314 (SP206989); idem, 6-VIII-1986, O. Yano et al. 10318 (SP206992); Recife, Campus da Universidade, 22-VIII-1997, K.C. Pôrto s.n. (SP284152); idem, entre as gramíneas, 7-VIII-1986, O. Yano \& M.G.V. Marinho 10348 (SP207022); idem, entre os prédios do Instituto de Biologia, 10-IX-1984, O. Yano \& K.C. Pôrto 9065 (SP191688); idem, perto da Biblioteca, 16-V-1997, O. Yano \& K.C. Pôrto 24809 (SP284955); idem, 3-VIII-1994, O. Yano \& K.C. Pôrto 23060 (SP281482).

Distribuição no Brasil: BA e PE.

Ocorre em solo, associada a Micromitrium austinii Sull. e Notothylas vitalii Udar \& Singh.

Riccia vitalii Jovet-Ast, Mem. New York Bot. Gard. 45: 283.1897.

Ilustração: Jovet-Ast (1991), Bischler-Causse et al. (2005) e Yano \& Peralta (2008).

Material examinado: BRASIL. Alagoas: Delmiro Goveia, 9²4'S, 3812’W, Rio São Francisco, 
near the waterfall Paulo Afonso, 24-V-1978, D.M. Vital 8179 (SP133066); Cajueiro, 11-VI-1981, D. Andrade-Lima 81-6700 (SP191565). BAHIA: Serra Preta, on base of a rocky outcrop, 2-IV-1976, D.M. Vital 6007 (SP131846); idem, ca, 35 km Sw de Maracás, caatinga, 26-I-1980, D.M. Vital 8720 (SP133377); Brumado, km 21 on BA-262 between Vitória da Conquista and Brumado, $15 \mathrm{~km} \mathrm{SW}$ of Brumado, $14^{\circ} 16^{\prime} \mathrm{S}, 41^{\circ} 15^{\prime} \mathrm{W}$, caatinga, 18-VII-1991, D.M. Vital \& W.R. Buck 20362 (NY, SP353968); idem, 18-VII-1991, D.M. Vital \& W.R. Buck 20365 (NY, SP353969); Rio de Contas, estrada para Jussiape, 26-X-1994, S.R. Visnadi \& D.M. Vital 2585 (SP372767). Pernambuco: Pernambuco/Bahia, entre Petrolina e Juazeiro, Rio São Francisco, Ilha do Fogo, 20-I-1970, D.M. Vital 1640 (SP87500); Centro de Petrolina, ca. 22 km E, próx. Serrote do Urubú, 21-I-1970, D.M. Vital 1641 (SP87501); idem, 21-I-1970, D.M. Vital 1642 (SP87502); Salgueiro, caatinga, 25-V-1978, D.M. Vital 8191 (SP133071); Paramirim, caatinga, 25-V-1978, D.M. Vital 8194 (SP133074); Recife, em frente aos edifícios principais da Universidade Federal Rural de Pernambuco, 16-IX-1980, D. Andrade-Lima s.n. (SP134045); Caruaru, ca. $8 \mathrm{~km}$ nörd lich von city, km 56 da BR-104, ca. 650 m alt., 13-VII-1990, Schäfer-Verwimp \& Verwimp 12984 (hb. Schäfer-Verwimp, SP395695). Sergipe: São Miguel do Aleixo, 29-I-1974, D.M. Vital 2878 (SP88380).

Distribuição no Brasil: AL, AM, BA, CE, ES, GO, MA, MS, PB, PE, PI, RN, RS, SE e TO.

Ocorre em solo, associada a Riccia squamata Nees e Trichostomum brachydontium Bruch ex F. Müll.

Riccia weinionis Steph., Sp. Hepat. 1: 18. 1898. Ilustração: Jovet-Ast (1991), Bischler-Causse et al. (2005) e Yano \& Peralta (2008).

Material examinado: BRASIL. BAHIA: Jeremoabo, ca. $5 \mathrm{~km}$ south of village of Formosa on road from Tarrachil to Canudos, $9^{\circ} 37^{\prime} \mathrm{S}, 39^{\circ} 06^{\prime} \mathrm{W}$, caatinga, 18-VII-1962, G. Eiten \& L.T. Eiten 4979 (SP87861); São Estevão, left margin of the Paraguaçu river crossed by the high road BR-116, 15-I-1972, D.M. Vital 1950 (SP87710); ca. 9 km SW de Maracás, 26-I-1980, D.M. Vital 8728 (SP133379); Santa Barbara, ca. $35 \mathrm{~km}$ de Feira de Santana na BR-116, caatinga, 23-X-1990, O. Yano \& J.O. Pereira 15102 (SP231199).
Sergipe: Ribeirópolis, along a temporary river (rio de Água Salgada), 29-I-1974, D.M. Vital 2875 (SP88378).

Distribuição no Brasil: BA, CE, ES, GO, MG, MT, PB, PR, RJ, SE e SP.

Ocorre em solo.

\section{TRICHOCOLEACEAE}

Trichocolea flaccida (Spruce) J.B. Jack \& Steph., Hedwigia 31: 14. $1892 \equiv$ Leiomitra flaccida Spruce, Trans. \& Proc. Bot. Soc. Edinburgh 15: 349. 1885. Ilustração: Fulford (1962), Oliveira-e-Silva \& Yano (2000).

Material examinado: BRASIL. BAHIA: Castro Alves, Serra da Jibóia, ca. $10 \mathrm{~km}$ do Povoado de Pedra Branca, 22॰51'11"'S, 39²8'19'”, 7-V-1993, L.P. Queiroz \& T.S.N. Sena 3175 (HUEFS13419).

Distribuição no Brasil: BA, RJ, SC e SP.

Ocorre sobre tronco.

\section{Literatura citada}

Almeida Sá, P.S. \& Pôrto, K.C. 1996. Novos registros de Hepaticopsida (Bryophyta) para Pernambuco. Revista Nordestina de Biologia 11: 37-43.

Alvarenga, L.D.P., Oliveira, J.R.P.M., Silva, M.P.P., Costa, S.O. \& Pôrto, K.C. 2008. Liverworts of Alagoas State, Brazil. Acta Botanica Brasilica 22: 878-890.

Bastos, C.J.P. 2004. Lejeuneaceae (Marchantiophyta) no Estado da Bahia, Brasil. Tese de Doutorado, Universidade de São Paulo, São Paulo.

Bastos, C.J.P. \& Gradstein, S.R. 2006. Two new species of Cheilolejeunea (Spruce) Schiffn. (Lejeuneaceae) from Brazil. C. lacerata sp. nov. and C. rupestris sp. nov. Journal of Bryology 28: 133-138.

Bastos, C.J.P. \& Vilas Bôas-Bastos, S.B. 2000a. Variações morfológicas do lóbulo em Lejeunea glaucescens Gott. (Lejeuneaceae, Hepaticopsida). Acta Botanica Malacitana 25: 73-80.

Bastos, C.J.P. \& Vilas Bôas-Bastos, S.B. 2000 b. Occurrence of some Lejeuneaceae (Jungermanniophyta) in Bahia, Brazil. Tropical Bryology 20: 45-54.

Bastos, C.J.P. \& Vilas Bôas-Bastos, S.B. 2000c. Some new additions to the hepatic flora (Jungermanniophyta) for the State of Bahia, Brazil. Tropical Bryology 18: 1-11.

Bastos, C.J.P. \& Yano, O. 2002. Pycnolejeunea porrectilobula (Lejeuneaceae) a new species from Brazil. Nova Hedwigia 74: 439-443. 
Bastos, C.J.P. \& Yano, O. 2003. New records of the genus Rectolejeunea (Lejeuneaceae) for the State of Bahia. Nova Hedwigia 76: 477-485.

Bastos, C.J.P. \& Yano, O. 2004. New records of Lejeuneaceae (Marchantiophyta) for the Brazil. Acta Botanica Malacitana 29: 13-21.

Bastos, C.J.P. \& Yano, O. 2006a. Lejeuneaceae holostipas (Marchantiophyta) no Estado da Bahia, Brasil. Acta Botanica Brasilica 20: 687-700.

Bastos, C.J.P. \& Yano, O. 2006b. Briófitas de restinga das regiões metropolitana de Salvador e Litoral Norte do Estado da Bahia, Brasil. Boletim do Instituto de Botânica 18: 197-205.

Bastos, C.J.P. \& Yano, O. 2008. O gênero Ceratolejeuena Jack \& Steph. (Lejeuneaceae, Marchantiphyta) no Estado da Bahia, Brasil. Hoehnea 35: 69-74.

Bastos, C.J.P. \& Yano, O. 2009. O gênero Lejeunea Libert (Lejeuneaceae) no Estado da Bahia, Brasil. Hoehnea 36: 303-320.

Bastos, C.J.P., Albertos, B. \& Vilas Bôas-Bastos, S.B. 1998a. Bryophytes from some caatinga áreas in the State of Bahia (Brasil). Tropical Bryology 14: 69-75.

Bastos, C.J.P., Stradmann, M.T.S.\& Vilas Bôas-Bastos, S.B. 1998b. Additional contribution on to the bryophyte flora of Chapada Diamantina Park, State of Bahia, Brazil. Tropical Bryology 15: 15-20.

Bastos, C.J.P., Yano, O. \& Vilas Bôas-Bastos, S.B. 2000. Briófitas de campos rupestres da Chapada Diamantina, Estado da Bahia, Brasil. Revista Brasileira de Botânica 23: 357-368.

Bischler, H. 1962. The genus Calypogeia Raddi in Central and South America II. Subgenus Calypogeia, subgroups 1, 2, 3, 4, 5. Candollea 18: 19-93.

Bischler, H. 1964. Le genre Drepanolejeunea Steph. en Amérique Centrale et Méridionale. Revue Bryologique et Lichénologique 33: 15-179.

Bischler, H. 1969. Le genre Leptolejeunea (Spruce) Steph. en Amérique. Nova Hedwigia 17: 265-350.

Bischler, H., Bonner, C.E.B. \& Miller, H.H. 1963. Studies in Lejeuneaceae IV. The genus Microlejeunea Steph. in Central and South America. Nova Hedwigia 5:359-411.

Bischler-Causse, H., Gradstein, S.R., Jovet-Ast, S., Long, D.G. \& Allen, N.S. 2005. Marchantiidae. Flora Neotropica Monograph 97: 1-262.

Bordin, J. \& Yano, O. 2009. Novas ocorrências de antóceros e hepáticas para o Estado do Rio Grande do Sul, Brasil. Revista Brasileira de Botânica 32: 189-211.

Castle, H. 1964. A revision of the genus Radula. Part II. Subgenus Acroradula. Section 9. Densifoliae. Revue Bryologique et Lichénologique 33: 328-398.

Castle, H. 1966. A revision of the genus Radula. Part II. Subgenus Acroradula. Section 10. Ampliatae. Revue Bryologique et Lichénologique 34: 1-81.
Clarck, L. \& Svihla, R.D. 1945. Frullania atrata. The Bryologist 48: 187-189.

Costa, D.P. 1992. Hepáticas do Pico da Caledônia. Nova Friburgo, Rio de Janeiro, Brasil. Acta Botanica Brasilica 6: 3-39.

Costa, D.P. 1999. Metzgeriaceae (Metzgeriales, Hepatophyta) no Brasil. Tese de Doutorado, Universidade de São Paulo, São Paulo.

Costa, D.P. 2008. Metzgeriaceae (Hepaticae). Flora Neotropica Monograph 102: 1-169.

Costa, D.P. \& Pôrto, K.C. 2003. Estados da arte das coleções de briófitas no Brasil. In: A.L. Peixoto (org.). Coleções biológicas. Instituto de Pesquisas Jardim Botânico do Rio de Janeiro, Rio de Janeiro, pp. 75-98.

Crandall-Stotler, B. \& Stotler, R.E. 2000. Morphology and classification of the Marchantiophyta. In: A.J. Shaw \& B. Goffinet (eds.). Bryophyte Biology. Cambridge University Press, Cambridge, pp. 21-70.

Dauphin-López, G. 2003. Ceratolejeunea (Lejeuneaceae: Lejeuneoideae). Flora Neotropica Monograph 90: 1-86.

Engel, J.J. \& Smith Merrill, G.L. 2004. Astral Hepaticae 35. A taxonomic and phylogenetic study of Telaranea (Lepidoziaceae), with a monograph of the genus in temperature Australasia and commentary on extraAustralasia taxa. Fieldiana, Botany 44: 1-265.

Evans, A.W. 1903a. Hepaticae of Puerto Rico II. Drepanolejeunea. Bulletin of the Torrey Botanical Club 30: 19-41.

Evans, A.W. 1903b. Hepaticae of Puerto Rico III. Harpalejeunea, Cyrtolejeunea, Euosmolejeunea and Trachylejeunea. Bulletin of the Torrey Botanical Club 30: 544-563.

Evans, A.W. 1904. Hepaticae of Puerto Rico. IV. Odontolejeunea, Cyclolejeunea and Prionolejeunea. Bulletin of the Torrey Botanical Club 31: 183-226.

Evans, A.W. 1906. Hepaticae of Puerto Rico VI. Cheilolejeunea, Rectolejeunea, Cyrtolejeunea and Pycnolejeunea. Bulletin of the Torrey Botanical Club 33: 1-25.

Fiaschi P. \& Pirani J.R. 2009. Review of plant biogeographic studies in Brazil. Journal of Systematics and Evolution 47: 477-496.

Forzza, R.C. (org.). 2010. Catálogo das Plantas e Fungos do Brasil. vol. 1. Jardim Botânico do Rio de Janeiro, Rio de Janeiro.

Fulford, M. 1945. Studies on American Hepaticae VI. Ceratolejeunea. Brittonia 5: 368-403.

Fulford, M.H. 1963. Manual of the leafy Hepaticae of Latin America. Part I. Memoirs of The New York Botanical Garden 11: 1-172.

Fulford, M.H. 1966. Manual of the leafy Hepaticae of Latin America. Part II. Memoirs of The New York Botanical Garden 11: 173-276. 
Fulford, M.H. 1968. Manual of the leafy Hepaticae of Latin America. Part III. Memoirs of The New York Botanical Garden 11: 277-392.

Fulford, M.H. 1976. Manual of the leafy Hepaticae of Latin America. Part IV. Memoirs of The New York Botanical Garden 11: 393-535.

Germano, S.R. \& Pôrto, K.C. 1996. Floristic survey of epixilic bryophytes of an area remnant of the Atlantic forest (Timbaúba), PE, Brazil. 1. Hepaticopsida (except Lejeuneaceae) and Bryopsida. Tropical Bryology 12: 21-28.

Germano, S.R. \& Pôrto, K.C. 1998. Briófitas epíxilas de uma área remanescente de floresta atlântica (Timbaúba, PE, Brasil). 2. Lejeuneaceae. Acta Botanica Brasilica 12: 53-66.

Germano, S.R. \& Pôrto, K.C. 2004. Novos registros de briófitas para Pernambuco, Brasil. Acta Botanica Brasilica 18: 343-350.

Germano, S.R. \& Pôrto, K.C. 2005. A bryophyte checklist of the ecological Reserve of Gurjaú, Pernambuco, Brasil. Tropical Bryology 26: 1-12.

Gradstein, S.R. 1985. A revision of the genus Stictolejeunea (Spruce) Schiffn. Beiheft zur Nova Hedwigia 80: 195-220.

Gradstein, S.R. 1994. Lejeuneaceae: Ptychanteae, Brachiolejeuneae. Flora Neotropica Monograph 62: 1-216.

Gradstein, S.R. \& Costa, D.P. 2003. Hepaticae and Anthocerotae of Brazil. Memoirs of The New York Botanical Garden 87: 1-318.

Gradstein, S.R. \& van Beek, J. 1985. A revision of the genus Symbiezidium Trevis. Beiheft zur Nova Hedwigia 80: 221-248.

Gradstein, S.R., Churchill, S.P. \& Salazar-Allen, N. 2001. Guide to the bryophytes of Tropical America. Memoirs of The New York Botanical Garden 86: 1-577.

Griffin III, D. 1979. Guia preliminar para as briófitas freqüentes em Manaus e adjacências. Acta Amazonica 9(suppl. 3): 1-67.

Grolle, R. 1971. Jamesoniella und Verwandte. Feddes Repertoriu0,6m 82: 1-100.

Grolle, R., Zhu, R.-L. \& Gradstein, R. 2001. On Cyrtolejeunea A. Evans (Lejeuneaceae, Hepaticae). Taxon 50: 1067-1074.

Hässel de Menéndez, G.G. 1962. Estudio de las Anthocerotales y Marchantiales de la Argentina. Opera Lilloana 7: 1-297.

Heinrichs, J. \& Gradstein, S.R. 2000. A revision of Plagiochila sect. Crispate and sect Hypnoides (Hepaticae) in the Neotropics 1. Plagiochila disticha, P. montagnei and P. raddiana. Nova Hedwigia 70: 161-184.
Heinrichs, J., Gradstein, S.R. \& Grolle, R. 1998. A revision of the Neotropical species of Plagiochila (Dumort.) Dumort. (Hepaticae) described by Olof Swartz. The Journal of the Hattori Botanical Laboratory 85: 1-32.

He, X.-L. 1999. A taxonomic monograph of the genus Pycnolejeunea (Lejeuneaceae, Hepaticae). Acta Botanica Fennica 163: 1-77.

Hell, K.G. 1969. Briófitas talosas dos arredores da cidade de São Paulo (Brasil). Boletim da Universidade de São Paulo Faculdade de Filosofia, Ciências e Letras. Botânica 25: 1-187.

Herzog, T. 1923. Contribuições ao conhecimento da Flora Bryologica do Brasil. Archivos de Botanica do Estado de S. Paulo 1: 27-157.

Herzog, R. 1944. Micropterygium reimersianum Herz. Eine neue Art der Gattung aus Sudbrasilien. Hedwigia 81: 225-228.

Ilkiu-Borges, A.L. 2000. Lejeuneaceae (Hepaticae) da Estação Científica Ferreira Penna, Caxiuanã, município de Melgaço, Pará. Dissertação de Mestrado, Faculdade de Ciências Agrárias do Pará, Belém.

Ilkiu-Borges, A.L. 2005. A taxonomic monograph of the genus Prionolejeunea (Lejeuneaceae, Jungermanniopsida). Cuvillire Verlarg, Götting.

Ilkiu-Borges, A.L., Lisboa, R.C.L.\& Moraes, E.N.R.2009a. Avanços no conhecimento da brioflora. In: P.L.B. Lisboa (org.) Caxiuanã: Desafios para a conservação de uma Floresta Nacional da Amazônia. Belém, Museu Paraense Emílio Goeldi, pp. 313-330.

Ilkiu-Borges, A.L., Santos, R.C.P., Macedo, L.P.C. \& Pereira, M.A.V. 2009b. As briófitas. In: M.A.G. Jardim (org.). Diversidade biológica das áreas de proteção ambiental: Ilhas do Combu e Algodoal-Maiandeua, Pará, Brasil. Três C. Gráfica e Editora, Belém, pp. 227-244.

Imbassahy, C.A.A., Costa, D.P. \& Araujo, D.S.D. 2009. Briófitas do Parque Nacional da Restinga de Jurubatiba, RJ, Brasil. Acta Botanica Brasilica 23: 558-570.

Inoue, H. 1968. Contributions to the knowledge of the Plagiochilaceae of Southeastern Asia. XI. The Journal of the Hattori Botanical Laboratory 31: 297-311.

Jovet-Ast, S. 1953. Le genre Colura. Hépatique, Lejeuneaceae, Diplasiae. Revue Bryologique et Lichénologique, nov. ser. 22: 206-312.

Jovet-Ast, S. 1991. Riccia (Hépatiques, Marchantiales) d'Amérique Latine, taxons du Sous-Genre Riccia. Cryptogamie, Bryologie et Lichénologie 12: 189-370.

Kuwahara, Y. 1986. The Metzgeriaceae of the Neotropics. Bryophytorum Bibliotheca 28: 1-254.

Lemos-Michel, E. 1980. O gênero Frullania (Hepaticopsida) no Rio Grande do Sul, Brasil. Dissertação de Mestrado, Universidade Federal do Rio Grande do Sul, Porto Alegre. 
Lemos-Michel, E. 2001. Hepáticas epífitas sobre o pinheiro-brasileiro no Rio Grande do Sul. Editora da Universidade, Porto Alegre.

Lemos-Michel, E. \& Yano, O. 1998. O gênero Bryopteris (Hepatophyta) no Brasil. Acta Botanica Brasilica 12: 5-24.

Lindenberg, I.B.G. 1844. Monographia Hepaticarum generic Plagiochilae. Sunptibur Henry \& Cohen, Bonnae.

Lücking, A. 1995. Diversität und Mikrohabitats präferenzen epiphyller Moose in einen tropischen Regenwald in Costa Rica unter besonderer Berücksichtigung der Famile Lejeuneaceae. Dissertation zur Doktorgrades, Fakultat für Naturwissenchaften der Universität Ulm, Ulm.

Müller, K. 1954. Die Lebermoose. Kryptogamen-Flora 6: 1-1365.

Oliveira, H.C. \& Bastos, C.J.P. 2009. Jungermanniales (Marchantiophyta) da Chapada da Ibiapaba, Ceará, Brasil. Acta Botanica Brasilica 23: 1202-1209.

Oliveira, P.L. 1973. Espécies do gênero Radula Dumortier ocorrentes no Rio Grande do Sul, Brasil (Hepaticae). Iheringia, série Botânica 18: 48-53.

Oliveira e Silva, M.I.M.N. \& Yano, O. 2000. Anthocerotophyta e Hepatophyta de Mangaratiba e Angra dos Reis, Rio de Janeiro, Brasil. Boletim do Instituto de Botânica 13: 1-102.

Perold, S.M. 1993. Studies in the Marchantiales (Hepaticae) from southern Africa. 1. The genus Dumortiera and D. hirsuta; the genus Lunularia and L. cruciata. Bothalia 23: 49-57.

Piippo, S. 1986. A monograph of the genera Lepidolejeunea and Luteolejeunea (Lejeuneaceae, Hepaticae). Acta Botanica Fennica 132: 1-69.

Pôrto, K.C. 1990. Bryoflores d'une forêt de Plaine et d'une forêt d'altitude morjenne dans l'étad de Pernambuco (Brésil): analyse floristique. Cryptogamie, Bryologie et Lichénologie 11: 109-161.

Pôrto, K.C. \& Bezerra, M.F.A. 1996. Briófitas de Caatinga 2. Agrestina, Pernambuco, Brasil. Acta Botânica Brasilica 10: 93-102.

Pôrto, K.C. \& Grolle, R. 1987. Drepanolejeunea bischleriana sp. nov. du Brésil. Cryptogamie, Bryologie et Lichénologie 8: 301-304.

Pôrto, K.C. \& Yano, O. 1985. Novas ocorrências de briófitas em Pernambuco. Rickia 12: 9-14.

Pôrto, K.C., Germano, S.R. \& Oliveira, S.M. 2000. New records of bryophytes of Pernambuco State, Brazil. Tropical Bryology 18: 107-114.

Pôrto, K.C., Silveira, M.F. \& Sá, P.S.A. 1994. Briófitas da Caatinga 1. Estação Experimental do IPA, Caruaru, PE. Acta Botanica Brasilica 8: 77-85.

Pôrto,K.C.,Belo,M.M.A.,Fonseca,E.R.\& Silva,E.C. 1993. Brioflora da reserva Gurjaú (Cabo, PE). Biologica Brasilica 5: 27-42.
Pôrto, K.C., Gradstein, S.R., Yano, O., Germano, S.R. \& Costa, D.P. 1999. New and interesting records of Brazilian bryophytes. Tropical Bryology 17: 39-45.

Reimers, H. 1933. Revision der Lebermoosgattung Micropterygium. Hedwigia 73: 133-204.

Reiner-Drehwald, M.E. 1994. El genero Radula Dum. (Radulaceae, Hepaticae) em el Noreste de Argentina. Tropical Bryology 9: 5-22.

Reiner-Drehwald, M.E. 1995. Las Lejeuneaceae (Hepaticae) de Misiones, Argentina IV. Aphanolejeunea. Tropical Bryology 10: 29-39.

Reiner-Drehwald, M.E. 2000. Las Lejeuneaceae (Hepaticae) de Misiones, Argentina VI. Lejeunea y Taxilejeunea. Tropical Bryoplogy 19: 81-132.

Reiner-Drehwald, M.E. 2009. Lejeunea adpressa Nees (Lejeuneaceae) a widely distributed species of tropical America. Cryptogamie, Bryologie 30: 329-336.

Reiner-Drehwald, M.E. 2010. A taxonomic revision of Lejeunea deplanata (Lejeuneaceae, Marchantiophyta) from tropical America. Nova Hedwigia 91: 519-532.

Reiner-Drehwald, M.E. \& Goda, A. 2000. Revision of the genus Crossotolejeunea (Lejeuneaceae, Hepaticae). The Journal of the Hattori Botanical Laboratory 89: 1-54.

Reiner-Drehwald, M.E. \& Ilkiu-Borges, A.L. 2007. Lejeunea huctumalcensis, a widely distributed Lejeuneaceae from the Neotropics, and its relation to Ceratolejeunea. The Bryologist 110: 465-474.

Reiner-Drehwald, M.E. \& Pôrto, K.C. 2007. Lejeunea perpapillosa (Lejeuneaceae), a new species from northeastern Brazil. Nova Hedwigia 85: 541-546.

Reiner-Drehwald, M.E. \& Schäfer-Verwimp, A. 2008. Lejeunea oligoclada and L. rionegrensis (Lejeuneaceae) in tropical America: new data on morphology and geographical distribution. Nova Hedwigia 87: 175-184.

Reyes, D.M. 1982. El genero Diplasiolejeunea en Cuba. Acta Botanica Academiae Scientiarum Hungaricae 28: 145-180.

Schuster, R.M. 1956. North American Lejeuneaceae V. Schizostipae: Ceratolejeunea. The Journal of the Elisha Mitchell Scientific Society 72: 291-316.

Schuster, R.M. 1957. North American Lejeuneaceae. VI. Lejeunea subgenus Lejeunea (II: concluded). The Journal of the Mitchell Scientific Society 73: 388-443.

Schuster, R.M. 1980. The Hepaticae and Anthocerotae of North America. vol. 4. Columbia University Press, New York.

Schuster, R.M. 1992. The Hepaticae and Anthocerotae of North America east of the hundredth meridian. v. 6. Field Museum of Natural History, Chicago.

Silva, M.P.P. \& Pôrto, K.C. 2009. Effect of fragmentation on the community structure of epixylic bryophytes in Atlantic Forest remnants in the Northeast of Brazil. Biodiversity Conservation 18: 317-337. 
Smith, A.J.E. 1996. The liverworts of Britain and Ireland. Cambridge University Press, Cambridge.

Stotler, R.E. 1970. The genus Frullania subgenus Frullania in Latin America. Nova Hedwigia 18: 397-555.

Stotler, R.E. \& Crandall-Stotler, B. 2005. A revised classification of the Anthocerotophyta and a checklist of the horworts of North America, North of Mexico. The Bryologist 108: 16-26.

Teeuwen, M. 1989. A revision of the genus Odontolejeunea (Spruce) Schiffn. (Lejeuneaceae, Hepaticae). Nova Hedwigia 48: 1-32.

Tixier, P. 1980. Contribution a l'etude du genre Cololejeunea (Lejeuneaceae). IX. Espèces nouvelles du sous genre Pedinolejeunea (Ben.) Mizutani en région néotropicale. Bradea 3: 35-44.

Tixier, P. 1985. Contribution à la connaissance des Cololejeunoideae. Bryophytorum Bibliotheca 27: 1-439.

Tonini, A., Starling, M.F.V., Yano, O. \& Figueiredo, J.A. 2005. Briófitas das Ilhas do Passatempo, Parque Municipal das Mangabeiras, Belo Horizonte, MG. Bios 13: 25-34.

Udar, R. \& Singh, D.K. 1980. An interesting Notothylas from Brazil. Miscellanea Bryologica et Lichenologica 8: 173-178.

Valente, E.B. \& Pôrto, K.C. 2006a. Briófitas do afloramento rochoso na Serra da Jibóia, município de Santa Teresinha, Bahia, Brasil. Boletim do Instituto de Botânica 18: 207-211.

Valente, E.B. \& Pôrto, K.C. 2006b. Novas ocorrências de hepáticas (Marchantiophyta) para o Estado da Bahia, Brasil. Acta Botanica Brasilica 20: 195-201.

Valente, E.B. \& Pôrto, K.C. 2006c. Hepáticas (Marchantiophyta) de um fragmento de Mata Atlântica na Serra da Jibóia, município de Santa Teresinha, BA, Brasil. Acta Botanica Brasilica 29: 433-441.

Van Slageren, M.W.S.J.M. 1985. A taxonomic monograph of the genera Brachiolejeunea and Frullanoides with a SEM analysis of the sporophyte in the Ptychantoideae. Mededeeling van het Botanischi Museum en Herbarium van de Rijks Universiteit te Utrecht 544: 1-309.

Vianna, E.C. 1985. Flora ilustrada do Rio Grande do Sul 15. Marchantiales. Boletim do Instituto de Biociências, Universidade Federal do Rio Grande do Sul 38: 1-213.

Vilas Bôas-Bastos, S.B. \& Bastos, C.J.P. 1998. Briófitas de uma área de Cerrado no município de Alagoinhas, Bahia, Brasil. Tropical Bryology 15: 101-110.

Vilas Bôas-Bastos, S.B., Bastos, C.J.P. \& Ballejos, J. 2006. Novas ocorrências de hepáticas (Marchantiophyta) para o Estado da Bahia, Brasil. Boletim do Instituto de Botânica 18: 141-147.

Vital, D.M., Giancotti, C. \& Pursell, R.A. 1991. The Bryoflora of Fernando de Noronha, Brasil. Tropical Bryology 4: 23-24.
Yamada, K. 1980. Notes on the type specimens of Radula taxa from Latin America (1). The Journal of the Hattori Botanical Laboratory 48: 243-257.

Yamada, K. 1981. Notes on the type specimens of Radula taxa from Latin America (2): The Journal of the Hattori Botanical Laboratory 49: 385-398.

Yamada, K. 1983. Four new species of Radula from Cuba. The Journal of the Hattori Botanical Laboratory 54: 241-249.

Yano, O. 1984. Checklist of Brazilian liverworts and hornworts. The Journal of the Hattori Botanical Laboratory 56: 481-548.

Yano, O. 1989. An additional checklist of Brazilian bryophytes. The Journal of the Hattori Botanical Laboratory 66: 371-434.

Yano, O. 1994. Briófitas da Serra de Itabaiana, Sergipe, Brasil. Acta Botanica Brasilica 8: 45-57.

Yano, O. 1995. A new additional annotated checklist of Brazilian bryophytes. The Journal of the Hattori Botanical Laboratory 78: 137-182.

Yano, O. 2004. Novas ocorrências de briófitas para vários Estados do Brasil. Acta Amazonica 34: 559-576.

Yano, O. 2006. Novas adições ao catálogo de briófitas brasileiras. Boletim do Instituto de Botânica 17: 1-142.

Yano, O. 2008. Catálogo de antóceros e hepáticas brasileiras: Literatura original, basiônimo, localidadetipo e distribuição geográfica. Boletim do Instituto de Botânica 19: 1-110.

Yano, O. 2010. Levantamento de novas ocorrências de briófitas brasileiras. Publicação on-line do Instituto de Botânica (www.ibot.sp.gov.br/briófitas Brasileiras/ Briófitas MIOLO E CAPA.pdf).

Yano, O. \& Andrade-Lima, D. 1987. Briófitas do Nordeste Brasileiro: Estado de Pernambuco. Revista Brasileira de Botânica 10: 171-181.

Yano, O. \& Costa, D.P. 1992. Novas ocorrências de briófitas no Brasil. In: R.R. Sharif (ed.). Anais $8^{\circ}$ Congresso da Sociedade Botânica de São Paulo, Sociedade Botânica de São Paulo, São Paulo, pp. 33-45.

Yano, O. \& Mello, Z.R. 1999. Frullaniaceae dos manguezais do litoral sul de São Paulo, Brasil. Iheringia, série Botânica 52: 65-87.

Yano, O. \& Peralta, D.F. 2006a. Novas ocorrências de briófitas para os Estados de Alagoas e Sergipe, Brasil. Arquivos do Museu Nacional 64: 287-297.

Yano, O. \& Peralta, D.F. 2006b. Briófitas coletadas por Daniel Moreira Vital no Estado da Bahia, Brasil. Boletim do Instituto de Botânica 18: 33-73.

Yano, O. \& Peralta, D.F. 2008. Flora dos Estados de Goiás e Tocantins. Criptógamos: Antoceros (Anthocerotophyta) e Hepáticas (Marchantiophta). In: J.A. Rizzo (coord.). Flora dos Estados de Goiás e Tocantins, Coleção Rizzo, v. 7, pp. 1-277. 
Yano, O., Bordin, J. \& Peralta, D.F. 2009a. Briófitas dos Estados do Ceará, Maranhão, Paraíba, Piauí e Rio Grande do Norte (Brasil). Hoehnea 36: 387-415.

Yano, O., Marinho, M.G.V. \& Mariz, G. 1987. Novas ocorrências de briófitas no Nordeste Brasileiro. Rickia 14: 73-87.

Yano, O., Mello, Z.R. \& Colletes, A.G. 2003. Briófitas da Ilha Urubuqueçaba, Santos, São Paulo, Brasil. Iheringia, série Botânica 58: 195-214.

Yano, O., Visnadi, S.R. \& Peralta, D.F. 2009b. Briófitas. In: M.I.M.S. Lopes, M. Kirizawa \& M.M.R.F. Melo (orgs.). Patrimônio da Reserva Biológica do Alto da Serra de Paranapiacaba, São Paulo, Instituto de Botânica, pp. 255-267.

Yuzawa, Y. 1984. Little known species of Latin American Frullania subgen. Chonanthelia (Hepaticae). 2. The Journal of the Hattori Botanical Laboratory 57: 391-403.
Yuzawa, Y. 1988. Some little-known species of Frullania subgen. Diastaloba described from Latin America. The Journal of the Hattori Botanical Laboratory 64: 437-449.

Yuzawa, Y. 1991. A monograph of subgen. Chonanthelia of gen. Frullania (Hepaticae) of the world. The Journal of the Hattori Botanical Laboratory 70: 181-291.

Yuzawa, Y. \& Hattori, S. 1988. A new Frullania species from Brazil. The Journal of Japanese Botany 63: 30-32.

Yuzawa, Y. \& Koike, N. 1989. Studies on the type specimens of Latin American Frullania species (1). The Journal of the Hattori Botanical Laboratory 66: 343-358.

Yuzawa, Y., Mues, R. \& Hattori, S. 1987. Morphological and chemical studies on the taxonomy of the Frullania species, subgenus Chonanthelia. The Journal of the Hattori Botanical Laboratory 63: 425-436.

Zartman, C.E. \& Ilkiu-Borges, A.L. 2007. Guia para as briófitas epífitas da Amazônia Central. Editora INPA, Manaus. 